\author{
Laura Sobral Verona
}

\title{
Last Millennium volcanism impact on the South Atlantic Ocean
}





\section{Laura Sobral Verona}

\section{Last Millennium volcanism impact on the South Atlantic Ocean}

Master thesis submitted to Instituto Oceanográfico of Universidade de São Paulo in partial fulfillment of the requirements for the degree of Master of Science in Oceanography, with emphasis in Physical Oceanography.

Advisor: Prof PhD Ilana Wainer 


\title{
UNIVERSIDADE DE SÃO PAULO - USP Instituto Oceanográfico
}

\section{Last Millennium volcanism impact on the South Atlantic Ocean}

\author{
Laura Sobral Verona
}

Master thesis submitted to Instituto Oceanográfico of Universidade de São Paulo in partial fulfillment of the requirements for the degree of Master of Science of Oceanography, with emphasis in Physical Oceanography.

Date $-1-1$

Prof $\mathrm{PhD}$

Prof PhD

Prof $\mathrm{PhD}$ 


\section{Acknowledgments}

A seção de agradecimentos é a seção mais difícil de ser escrita de todo o trabalho, pois é difícil expressar a importância de cada pessoa. Primeiramente agradeço especialmente a minha orientadora Ilana Wainer, sou grata a cada input de energia e empolgação, sempre me mostrando o melhor lado do meu trabalho e me dando motivação para os próximos passos. Gostaria de agradecer ao CNPq, órgão de fomento que financiou o meu mestrado. Obrigada também ao IOUSP, a todos os professores envolvidos na minha formação. Além disso, agradeço ao NCAR pela disponibilização dos dados utilizados no estudo.

A todos os membros do $\mathrm{OC}_{2}$ por me receberem de portas abertas. Pelas conversas sobre ciência e sobre não-ciência, mercearias e risadas. Agradeço especialmente as $\mathrm{OC}_{2}$ girls, Fê e Ma, pelo suporte emocional integral. Além disso, Mineiro e Gabriel sou grata por contribuírem imensamente na reta final da dissertação. O primeiro ano do mestrado é uma árdua jornada onde somos testados a todo momento. Paulinha, Marina, Hotel, Martim, Vadim, Fabrício e Barba, obrigada pelo apoio, descontrações e momentos de muita concentração durante esta jornada. Obrigada, malandras, Lara, Gi e Macaca por me acolherem de portas e braços abertos quando cai de paraquedas em SP. Falando em amizade, Ca obrigada por manter a minha esperança sempre alta. Não poderia deixar de agradecer a vocês que sempre foram parte da minha família, que me cuidaram de longe durante o primeiro ano, não aguentaram a saudade e acabaram vindo para SP. Obrigada Ju e Xuxa, pela amizade de verdade, manter minha sanidade e especialmente por me acolherem na casa de vocês nos últimos momentos do segundo tempo.

Mãe e pai, agradecimento especial por serem a base de tudo que sou hoje e apoiar as minhas decisões, mesmo quando elas foram muito difíceis. Obrigada por me segurarem quando eu mais precisei. Vocês são meus maiores mestres e exemplos. E Thiago, obrigada por fazer funcionar a ponte aérea FLO-SP. Te agradeço por ser meu amigo, parceiro e apesar da distância estar presente. Obrigada por dizer sempre que eu conseguiria alcançar todos os meus objetivos e me incentivar a ser o meu melhor. Todos vocês tiveram participação especial no meu amadurecimento profissional e pessoal. 


\section{Contents}

List of Figures $\quad$ vi

List of Acronyms xiv

ABSTRACT xvi

RESUMO xvii

1 INTRODUCTION 1

1.1 Volcanism and Climate Variability . . . . . . . . . . . . . . . . 2

1.1.1 Volcanism impact on the atmosphere . . . . . . . . . . . 5

1.1.2 Volcanism impact on the ocean . . . . . . . . . . . . . 7

1.1.3 Modern eruption: Mt. Pinatubo . . . . . . . . . . . . . . . . . . . 10

1.2 The South Atlantic Ocean . . . . . . . . . . . . . . . . . . 12

1.3 Motivation and Scientific Hypothesis . . . . . . . . . . . . . . . 16

1.4 Objectives . . . . . . . . . . . . . . . . . . . 17

2 MATERIAL AND METHODS 18

2.1 Data . . . . . . . . . . . . . . . . . . . . 18

2.1.1 Community Earth System Model - Last Millennium

Ensemble . . . . . . . . . . . . . . . . . . . 18

2.1 .2 Auxiliary Data . . . . . . . . . . . . . . . . . 21

2.2 Analysis . . . . . . . . . . . . . . . . . . . . 22

2.2.1 Last Millennium eruptions analysis . . . . . . . . . . . . . 22 
2.2.2 Modern Eruption Analysis: Mt. Pinatubo . . . . . . . . . . . . . . 24

3 RESULTS AND DISCUSSION 25

3.1 General aspects of the Last Millennium . . . . . . . . . . . . . . . 25

3.1.1 Mean Surface Climatology . . . . . . . . . . . . . . . . . 25

3.1 .2 Vertical Sections . . . . . . . . . . . . . . 30

3.1 .3 Time Series . . . . . . . . . . . . . . . 33

3.2 Last Millennium eruptions . . . . . . . . . . . . . . . . . . . . . 36

3.2 .1 Surface Analysis . . . . . . . . . . . . . . . . 36

3.2 .2 Vertical Analysis . . . . . . . . . . . . . . . . . 49

3.2.3 Water Masses Analysis . . . . . . . . . . . . . . . . . . 58

3.2.4 Regional Analysis: Weddell Sea . . . . . . . . . . . . . . . . 59

3.3 Modern Eruption: Mt. Pinatubo . . . . . . . . . . . . . . . . . 68

$\begin{array}{lll}4 & \text { CONCLUSIONS } & 76\end{array}$

$\begin{array}{ll}\text { References } & 94\end{array}$ 


\section{List of Figures}

1.1 Schematic overview of the climate effects after a large eruption | Impact is exemplified on stratosphere, troposphere, ocean, marine biogeochemistry and vegetation (fromTimmreck, 2012). . . . . . . . . 2

1.2 Volcanic radiative forcing | Total volcanic aerosol (green line), shortwave (red line) and long-wave (blue line) radiative forcing $\left[\mathrm{W} \mathrm{m}^{-2}\right]$ at the top of the atmosphere from 1950 to 2000 (from Stenchikov, 2016). . . . . 4

1.3 Mt. Pinatubo | (a) 1991 Mt. Pinatubo eruption (https://www.wired. com/2016/). (b) Geographical location of Mt. Pinatubo in the Philippines. 10

1.4 Wind-driven surface schematics for the South Atlantic Ocean and its southern sector | The Community Earth System Model (CESM)Last Millennium Ensemble (LME) mean climatological (850-2005) wind stress curl $\left[\mathrm{N} \mathrm{m}^{-3}\right]$ is shown in background colors. Black arrows represent the main circulation based on Talley et al. (2011) and Pontes et al. (2016). The abbreviations are used for ACC: Antarctic Circumpolar Current, WG: Weddell Gyre, ACoC: Antarctic Coastal Current, SAC: South Atlantic Current, BC: Brazil Current, MC: Malvinas Current, NBC: North Brazil Current, SEC: South Equatorial Current and BeC: Benguela Current. . .

2.1 Runs from CESM-LME | Lengths of the control (black lines) and forced runs from the CESM-LME, which are 10 full forcings, 5 volcanic onty, 4 solar only, 3 green house sases (GHG), 3 land use only, 3 orbital only and 2 ozone-aerosol only (from Otto-Bliesner et al., 2016) . . . . . . . . . . . 
2.2 Volcanic mass evolution | Period between 850 and 2005 used in the CESM-LME. Three of the greatest explosions from the Last Millennium (LM) are marked: Samalas (1258), Kuwae (1452) and 1815 Tambora. Volcanic mass is in $\mathrm{Tg}$ (from Otto-Bliesner et al., 2016). . . . . . . . . . .

3.1 Sea surface climatological means | LM (850-1850) (a) SST $\left[{ }^{\circ} \mathrm{C}\right]$ and (c) SSS climatological means. Difference between the LM and PD (19802005) climatological means for (b) SST $\left[{ }^{\circ} \mathrm{C}\right]$ and (d) SSS. Significance levels are determined according to a t-test, and values that are insignificant at $90 \%$ are marked with crosses. . . . . . . . . . . . . . . 26

3.2 Wind stress climatological mean | Wind stress $\left[\mathrm{N} \mathrm{m}^{-2}\right]$ (a) LM (8501850) climatological mean and (b) difference between the LM and PD (1980-2005) climatological means. The wind stress magnitude is represented in the background and the vectors represent the direction. . . . . . .

3.3 Seasonal climatological means | LM climatological mean for the SST $\left[{ }^{\circ} \mathrm{C}\right]$ field in the (a) austral summer (DJF) and (b) austral winter (JJA). The same for the SSS field (c) austral summer (DJF) and (d) austral winter (JJA). Black continuous line represent the $-1.4^{\circ} \mathrm{C}$ isotherm. . . . .

3.4 Wind stress seasonal climatological mean | LM climatological mean for the austral summer (DJF) in left-hand column (a) TAUX, (c) TAUY and (e) total wind stress $\left[\mathrm{N} \mathrm{m}^{-2}\right]$, magnitude in the background and the vectors represent the direction. Right-hand column show the austral winter (JJA), respectively (b) TAUX, (d) TAUY and (f) total wind stress. . . .

3.5 South Atlantic climatological zonal sections | (a) potential temperature $\left[{ }^{\circ} \mathrm{C}\right]$, the black line represent the $0^{\circ} \mathrm{C}$ isotherm and (b) salinity, both for the austral summer (DJF) . . . . . . . . . . . . . . . . 30 
3.6 WOCE SR4 transect | (a) Bathymetry map for the Weddell Sea and South Atlantic Ocean showing the location of WOCE SR4 transect in black. (b) Figure reproduced from Robertson et al. (2002) of the typical potential temperature section along WOCE SR4 transect. From east to west, the warm core of WDW in the inflow and outflow regions are denoted as core. (c) Climatological LM mean of the potential temperature $\left[{ }^{\circ} \mathrm{C}\right]$ for the WOCE SR4 section during the austral summer (DJF). The inflow and outflow regions are marked, respectively $71.5 \mathrm{~S}, 11 \mathrm{~W}$ and $63.5 \mathrm{~S}, 53 \mathrm{~W} . .$.

3.7 WOCE SR4 transect | LM climatological mean for (a) salinity and (b) meridional velocity $\left[\mathrm{cm} \mathrm{s}^{-1}\right]$ for the austral summer (DJF). The inflow and outflow regions are marked, respectively $71.5 \mathrm{~S}, 11 \mathrm{~W}$ and $63.5 \mathrm{~S}, 53 \mathrm{~W} . .$.

3.8 $\mathbf{S S T}\left[{ }^{\circ} \mathbf{C}\right]$ anomaly time series $\mid$ Annual ensemble average and spread for 850-2005 period. The dotted line is the \pm 1 standard deviation representing the internal variability. The black triangles represent the selected volcanic eruptions. Colors represent different periods that are described in the legend. 33

3.9 SSS anomaly time series | Annual ensemble average and spread for 850-2005 period. The dotted line is the \pm 1 standard deviation representing the internal variability. The black triangles represent the selected volcanic eruptions. Colors represent different periods that are described in the legend. 34

3.10 Wind stress components time series | (a) TAUX anomaly $\left[\mathrm{N} \mathrm{m}^{-2}\right]$ and (b) TAUY anomaly $\left[\mathrm{N} \mathrm{m}^{-2}\right]$ time series of annual ensemble average and spread for $850-2005$ period. The dotted line is the \pm 1 standard deviation representing the internal variability. The black triangles represent the selected volcanic eruptions. Colors represent different periods that are described in the legend. . . . . . . . . . . . . . . . .

3.11 South Atlantic zonal average | (a) SST anomaly $\left[{ }^{\circ} \mathrm{C}\right]$ and (b) SSS. Each line represents a composite year that is described in the legend. The black vertical line is the \pm 1 standard deviation representing the internal variability. . . . . . . . . . . . . . . . . . 
3.12 South Atlantic zonal average | (a) TAUX anomaly $\left[\mathrm{N} \mathrm{m}^{-2}\right]$ and (b) TAUY $\left[\mathrm{N} \mathrm{m}^{-2}\right]$. Each line represents a composite year that is described in the legend. The black vertical line is the \pm 1 standard deviation representing the internal variability. . . . . . . . . . . . . . .

3.13 Zonal wind stress composites | TAUX $\left[\mathrm{N} \mathrm{m}^{-2}\right]$ response to selected eruptions for (a) $\mathrm{Yr}+1$, (b) $\mathrm{Yr}+2$,(c) $\mathrm{Yr}+3$ and (d) $\mathrm{Yr}+4$. Shown only for the austral summer (DJF). Significance levels are determined according to the WRS test, and values that are insignificant at $90 \%$ are marked with crosses. . . . . . . . . . . . . . . . . . .

3.14 Meridional wind stress composites | TAUY $\left[\mathrm{N} \mathrm{m}^{-2}\right]$ response to selected eruptions for (a) $\mathrm{Yr}+1$, (b) $\mathrm{Yr}+2$,(c) $\mathrm{Yr}+3$ and (d) $\mathrm{Yr}+4$. Shown only for the austral summer (DJF). Significance levels are determined according to the WRS test, and values that are insignificant at $90 \%$ are marked with crosses. . . . . . . . . . . . . . . .

3.15 SST composites $\mid \mathrm{SST}\left[{ }^{\circ} \mathrm{C}\right]$ response to selected eruptions for (a) $\mathrm{Yr}+1$, (b) $\mathrm{Yr}+2$, (c) $\mathrm{Yr}+3$, (d) $\mathrm{Yr}+4$ and (e) $\mathrm{Yr}+5$. Shown only for the austral summer (DJF). Significance levels are determined according to the WRS test, and values that are insignificant at $90 \%$ are marked with crosses. . .

3.16 SSS composites $\mid$ SSS response to selected eruptions for (a) $\mathrm{Yr}+1$, (b) $\mathrm{Yr}+2$, (c) $\mathrm{Yr}+3$, (d) $\mathrm{Yr}+4$ and (e) $\mathrm{Yr}+5$. Shown only for the austral summer (DJF). Significance levels are determined according to the WRS test, and values that are insignificant at $90 \%$ are marked with crosses. . .

3.17 Tambora (1815) eruption | Response for $\mathrm{Yr}+1$ (first line) and $\mathrm{Yr}+2$ (second line) for $[(\mathbf{a}),(\mathbf{d})] \operatorname{SST}\left[{ }^{\circ} \mathrm{C}\right],[(\mathbf{b}),(\mathbf{e})] \operatorname{SSS}$ and $[(\mathbf{c}),(\mathbf{f})]$ wind stress $\left[\mathrm{N} \mathrm{m}^{-2}\right]$ in which the magnitude is in the background and vectors represent

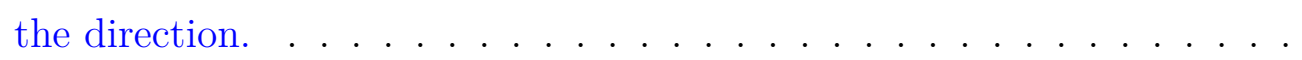


3.181341 eruption | 1341 eruption response for $\mathrm{Yr}+1$ (first line) and $\mathrm{Yr}$ +2 (second line) for $[(\mathbf{a}),(\mathbf{d})] \operatorname{SST}\left[{ }^{\circ} \mathrm{C}\right],[(\mathbf{b}),(\mathbf{e})] \operatorname{SSS}$ and $[(\mathbf{c}),(\mathbf{f})]$ wind stress $\left[\mathrm{N} \mathrm{m}^{-2}\right]$ in which the magnitude is in the background and vectors represent the direction. . . . . . . . . . . . . . . . . . . 48

3.19 Greenwich Meridian (0W) section | Composite potential temperature $\left[{ }^{\circ} \mathrm{C}\right]$ response to the selected eruptions. From $\mathrm{Yr}+1$ to $\mathrm{Yr}+6$ after the eruption, respectively [(a)-(f)]. Black lines represent isopycnals. . . . . .

3.20 Antarctic Peninsula (54W) section | Composite potential temperature $\left[{ }^{\circ} \mathrm{C}\right]$ response to the selected eruptions. From $\mathrm{Yr}+1$ to $\mathrm{Yr}+6$ after the eruption, respectively [(a)-(f)]. Black lines represent isopycnals. . . . . .

3.21 Greenwich Meridian (0W) section | Composite salinity response to the selected eruptions. From $\mathrm{Yr}+1$ to $\mathrm{Yr}+6$ after the eruption, respectively [(a)-(f)]. Black lines represent isopycnals. . . . . . . . . . . . . . .

3.22 Antarctic Peninsula $(\mathbf{5 4 W})$ section | Composite salinity response to the selected eruptions. From $\mathrm{Yr}+1$ to $\mathrm{Yr}+6$ after the eruption, respectively $[(\mathbf{a})-(\mathbf{f})]$. Black lines represent isopycnals. . . . . . . . . . . . .

3.23 Location of the averaged areas in the Hovmöller | Bathymetry map for the Southern Ocean Atlantic sector showing the location of selected regions for the Hovmöller. Antarctic Peninsula region (60-48W,61-67S) and the oceanic region $(0-10 \mathrm{E}, 30-34 \mathrm{~S}) \ldots \ldots \ldots$

3.24 Vertical Hovmöller | Potential temperature $\left[{ }^{\circ} \mathrm{C}\right]$ on the left-hand column and salinity on the right-hand column. $[(\mathbf{a}),(\mathbf{b})]$ for the Antarctic Peninsula region $(60-48 \mathrm{~W}, 61-67 \mathrm{~S})$ and $[(\mathbf{c}),(\mathbf{d})]$ the oceanic region $(0-10 \mathrm{~W}, 30-34 \mathrm{~S})$. The dotted vertical line marks the eruption year.

3.25 TS diagram for the Weddell Sea | (a) Averaged Weddell Sea TS diagram from surface to $2000 \mathrm{~m}$. (b) Zoom for the first $\sim 100 \mathrm{~m}$. Climotological mean for the LM is represented as the thick black line and different colors represent each composite year that is described in the legend. 
3.26 Regional Weddell Sea composites | Composite response to the selected eruptions only showing DJF $\mathrm{Yr}+1$ for (a) SST $\left[{ }^{\circ} \mathrm{C}\right]$ and (b) SSS anomalies. Vectors show the wind stress anomaly. It is only shown regions that are significant at $90 \%$ according to the WRS test. . . . . . . . . .

3.27 Wind stress response at $\mathbf{Y r}+\mathbf{1} \mid$ The right-hand column is the LM climatological mean, the central column the $\mathrm{Yr}+1$ anomaly and the left-hand column the sum of both for $[(\mathbf{a}),(\mathbf{b}),(\mathbf{c})]$ TAUY $\left[\mathrm{N} \mathrm{m}^{-2}\right]$ and $[(\mathbf{d}),(\mathbf{e}),(\mathbf{f})]$ TAUX $\left[\mathrm{N} \mathrm{m}^{-2}\right]$. The continuous line represent the zero contour for LM climatological mean and the dotted line the zero contour resultant from the year after the eruption perturbation. . . . . . . . . . .

3.28 Zonal wind stress $\left[\mathrm{N} \mathrm{m}^{-2}\right]$ zonal average for the South Atlantic Ocean | The black line is the LM climatological mean for DJF, the ensemble spread is represented by the dotted line, in magenta is the year after the eruption $(\mathrm{Yr}+1)$ and in green 8 years after the eruption $(\mathrm{Yr}+8)$. The vertical lines represent the associated maximum zonal wind stress position for the climatology (black line) and $\mathrm{Yr}+1$ (magenta line). . . . . . . . .

3.29 Superposed Epoch Analysis | (a) Bathymetry map for the Southern Ocean Atlantic sector showing the location of selected regions for SEA. (b) Antarctic Peninsula region averaged between 60-48W and 61-67S and (c) oceanic region averaged between 12-26E and 53-59S. In [(a), (b)] the vertical continuous line marks the year of the eruption ( $\mathrm{Yr} 0$ ) and the dotted line the first year after the eruption $(\mathrm{Yr}+1) \ldots \ldots \ldots$ 
3.30 Surface ocean velocities | (a) Surface ocean velocity DJF climatological mean for the LM, the background is the magnitude $\left[\mathrm{cm} \mathrm{s}^{-1}\right]$, the white vector represent the direction, the black arrows represent the Weddell Gyre circulation and the grey arrows the southern extension of the ACC. [(b), (c)] Velocity components, VVEL $\left[\mathrm{cm} \mathrm{s}^{-1}\right]$ and UVEL $\left[\mathrm{cm} \mathrm{s}^{-1}\right]$ respectively, DJF climatological mean field for the LM. [(d), (e)] Associated anomaly in the VVEL $\left[\mathrm{cm} \mathrm{s}^{-1}\right]$ and UVEL $\left[\mathrm{cm} \mathrm{s}^{-1}\right]$ fields, respectively due to volcanism during the year after the eruption $(\mathrm{Yr}+1) \ldots \ldots \ldots$

3.31 WOCE SR4 transect | Composite response to the selected eruptions during the first year after the eruption $(\mathrm{yr}+1)$ for $(\mathbf{a})$ potential temperature anomaly $\left[{ }^{\circ} \mathrm{C}\right]$ and (b) VVEL anomaly $\left[\mathrm{cm} \mathrm{s}^{-1}\right]$. The inflow and outflow regions are marked, respectively $71.5 \mathrm{~S}, 11 \mathrm{~W}$ and $63.5 \mathrm{~S}, 53 \mathrm{~W}$.

3.32 Schematics from the suggested mechanism in the Weddell Sea near the Antarctic Peninsula | The surface and vertical section in the SR4 transect represent the temperature anomaly for the year after the eruption $(\mathrm{Yr}+1)$. The wind circulation is represented (yellow and blue arrows), the inflow and outflow of the Weddell Gyre in green and blue, respectively. . . . . . . . . . . . . . . . . .

$3.33 \mathrm{SST}\left[{ }^{\circ} \mathbf{C}\right]$ response to Mt. Pinatubo eruption | Left-hand column for CESM-LME [(a), (d), (g), (j)], central column for ERSSTv5 [(b), (e), (h), (k)] and right-hand column for SODA [(c), (f), (i), (l)]. Each line represent different years from 1991 (Yr 0, the eruption year) to 1994 (Yr

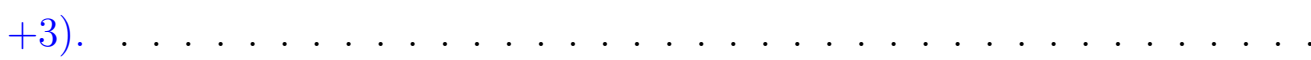

$3.34 \mathrm{SST}\left[{ }^{\circ} \mathrm{C}\right]$ differences relative to the year before the Mt. Pinatubo eruption (1991) | Left-hand column for CESM-LME [(a), (d), (g), (j)], central column for ERSSTv5 [(b), (e), (h), (k)] and right-hand column for SODA [(c), (f), (i), (l)]. Each line represent different years from 1991 (Yr 0, the eruption year) to $1994(\mathrm{Yr}+3) \ldots \ldots \ldots \ldots$ 
$3.35 \mathrm{SST}\left[{ }^{\circ} \mathrm{C}\right]$ anomaly time series | (a) Antarctic Peninsula region and (b) oceanic region, the same regions as Figure 3.29. The different data sets are represented in colors as described in the legend. The continuous vertical line mark the eruption year (Yr 0, 1991) and the dotted vertical line the second year after the eruption $(\mathrm{Yr}+2,1993) \ldots \ldots . \ldots 73$

\subsection{Zonal wind stress $\left[\mathrm{N} \mathrm{m}^{-2}\right]$ zonal average for the South Atlantic} Ocean $\mid$ (a) CESM-LME and (b) SODA. The dotted line is the climatological DJF mean for the period of 1980-2005. The vertical lines represent the associated maximum zonal wind stress position for the climatology (black line) and $\mathrm{Yr}+1$ (magenta line)

3.37 Meridional wind estress response at $\mathbf{y r}+\mathbf{1} \mid$ The right-hand column is 1980-2005 TAUY [ $\left.\mathrm{N} \mathrm{m}^{-2}\right]$ climatological mean, in the central column the $\mathrm{Yr}+1$ (1992) anomaly and the left-hand column the sum of both for $[(\mathbf{a}),(\mathbf{b}),(\mathbf{c})]$ CESM-LME and $[(\mathbf{d}),(\mathbf{e}),(\mathbf{f})]$ SODA. The continuous line represent the zero contour of the climatological mean and the dotted line the zero contour resultant from the year after Mt. Pinatubo eruption

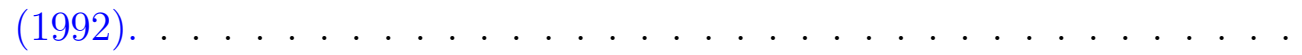




\section{List of Acronyms}

AABW Antarctic Bottom Water

AAIW Antarctic Intermediate Water

ACC Antarctic Circumpolar Curent

AMOC Atlantic Meridional Overturning Circulation

AASW Antarctic Surface Water

CAM5 Community Atmosphere Model version 5

CDW Circumpolar Deep Water

CESM Community Earth System Model

CMIP5 Coupled Model Intercomparison Project Phase 5

ENSO El Niño-Southern Oscillation

ERSSTv5 Extended Reconstructed Sea Surface Temperature Version 5

GHG green house sases

LIA Little Ice Age

LM Last Millennium

LME Last Millennium Ensemble

NADW North Atlantic Deep Water 
NCAR National Center for Atmospheric Research

OHC ocean heat content

PD Present Day

SAM Southern Annular Mode

SAMW Subantarctic Modal Water

SEA superposed epoch analysis

SODA Simple Ocean Data Assimilation

SSS sea surface salinity

SST sea surface temperature

TAUX zonal wind stress

TAUY meridional wind stress

UVEL zonal velocity

VVEL meridional velocity

WDW Warm Deep Water

WRS Wilcoxon Rank-Sum 


\section{ABSTRACT}

Volcanism is the cause of great non-anthropogenic perturbations on the Earth climate through energy imbalance changes. There is still much to be uncovered relative to its impacts on the Southern Hemisphere, even more with respect to the Southern Ocean. The South Atlantic and its Southern Ocean sector response to volcanism are examined using simulation results from the Last Millennium Ensemble Experiment of the Community Earth System Model (CESM-LME), for the period 850-2005. Composite results point to significant changes in sea surface temperature and salinity in the first austral summer following the eruption. North of $60 \mathrm{~S}$, there is ocean cooling, as expected because of the higher albedo related to the volcanic forcing. In contrast, near the Antarctic Peninsula in the Weddell Sea, a local warming of $\sim 0.8^{\circ} \mathrm{C}$ is observed (significant at the $90 \%$ level). Salinity shows positive anomaly $(\sim 0.1)$ at the northern region off Antarctic Peninsula from the first year after the eruption to the fourth subsequent year. Oceanic surface anomalies weaken after the fifth subsequent year, however it is still present in deeper layers $(\sim 500 \mathrm{~m})$. At the same time, wind stress changes are evident, results show a poleward shift $\left(\sim 2^{\circ}\right)$, strengthening $(\sim 10 \%)$ of the prevailing westerlies and the reversal in direction of the meridional wind stress component in the northern Antarctic Peninsula. As consequence, there is intensification of the Antarctic Circumpolar Current southern extension. Together with the stronger westerlies, the mixing in the northern Antarctic Peninsula is enhanced, bringing up warmer subsurface waters, therefore explaining the anomalous surface warming after the eruption. The 1991 Mt. Pinatubo eruption response is also investigated. CESM-LME, observations and reanalysis have shown similar behavior, however for the second subsequent year, thus suggesting the occurrence of the same mechanism identified after Last Millennium eruptions.

Key-words: Weddell Sea, Mt. Pinatubo, CESM-LME, sea surface temperature, Antarctic Peninsula 


\section{RESUMO}

Vulcanismo é uma das maiores causas naturais de mudanças no clima. Poucos estudos tiveram foco no seu impacto no hemisfério sul, principalmente no Oceano Austral. Desta forma, o impacto de erupções vulcânicas é investigado no Oceano Atlântico Sul incluindo o seu setor austral, em resultados do modelo CESM-LME (Community Earth System Model Last Millennium Ensemble) entre 850 e 2005. Os resultados utilizando composições mostram mudanças significativas na temperatura e salinidade da superfície do oceano no primeiro verão austral depois da erupção. Ao norte de 60S, há uma anomalia negativa de $\sim-0.8^{\circ} \mathrm{C}$ na temperatura em superfície, devido ao maior albedo após a erupção. No entanto, próximo à Península Antártica no Mar de Weddell, é visto uma anomalia positiva de $\sim 0.8^{\circ} \mathrm{C}$ (significativa a $90 \%$ ). A salinidade apresenta mudanças importantes entre o primeiro e o quarto ano após a erupção, com anomalia positiva $(\sim 0.1)$ ao norte da Península Antártica. A resposta ao vulcanismo em superfície desaparece no quinto ano sequente, mas permanecem anomalias em profundidade $(\sim 500 \mathrm{~m})$. O campo de vento também se altera no mesmo ano, os ventos de oeste migram para sul $\left(\sim 2^{\circ}\right)$ e se intensificam $(\sim 10 \%)$, além da componente meridional inverter seu sentido ao norte da Península Antártica. Como consequência, é observada intensificação da borda sul da Corrente Circumpolar Antártica. Junto com isto, há aumento da mistura próximo à Península Antártica, desta forma, águas subsuperficiais mais quentes afloram, explicando a anomalia quente após a erupção. Finalmente, é verificada a ocorrência de resposta similar após a erupção do Monte Pinatubo (1991). Resultados do CESM-LME tiveram comportamento aproximado quando comparados com dados observacionais e reanálise. O aquecimento próximo à Península Antártica é evidenciado no segundo ano após a erupção, sugerindo a ocorrência do mesmo mecanismo do último milênio.

Palavras-chave: Mar de Weddell, Monte Pinatubo, CESM-LME, temperatura da superfície do mar, Península Antártica 



\section{INTRODUCTION}

Evidences of climate change such as increased surface atmospheric temperature, green house gases (GHG) concentration, changes in precipitation pattern and increased sea surface temperature (SST) have already been extensively documented (IPCC, 2013; McGregor et al., 2015). About 90\% of the Earth energy imbalance is stored in the global ocean as ocean heat content (OHC) (Levitus et al., 2005, 2012; Trenberth et al., 2014; Cheng et al., 2017). Recent OHC estimation by Cheng et al. (2017) showed that all ocean basins experienced significant warming since 1998.

One of the most important natural (non-anthrophogenic) forcing in the Earth's climate system is the volcanic one (Robock, 2000; Stenchikov et al., 2009; Stenchikov, 2016). Earth's climate is regulated primarily by its energy imbalance, which is the equilibrium between incoming and outgoing radiation, energy redistribution and exchange among the system components (Cole-Dai, 2010), such as atmosphere, ocean, land, cryosphere and biosphere. In this sense, volcanic eruptions are important because they cause changes in the climate by altering Earth's energy steady state, due to changes in the energy budget, such as modifications on the planetary albedo ${ }^{1}$ (Cole-Dai, 2010).

Quantifying how much of the climate system is impacted by natural forcing is a key aspect for understanding the Earth's climate, in order to evaluate the relative impacts of human pollution and land surface modification (Gao et al., 2008) and to anticipate future climate projections (Mignot et al., 2011; Stevenson et al., 2016). Furthermore, evaluation of climate model outputs that include volcanic forcing helps to improve Earth System Climate Models that are needed to study anthropogenic effects (Robock, 2000).

\footnotetext{
${ }^{1}$ The fraction of incident solar radiation that is reflected back to space (Talley et al., 2011)
} 


\subsection{Volcanism and Climate Variability}

Volcanic eruptions are important elements of natural climate variability and climate change in different scales (Robock, 2000; Stenchikov et al., 2009; Cole-Dai, 2010) as seen in Figure 1.1 in a schematic overview. Typically the atmosphere is composed by a mix of permanent gases that are nitrogen and oxygen, in greater volume, and minor constituents as carbon dioxide, water vapour and ozone which play a crucial role (Andrews, 2010). Large volcanic eruptions inject various gases and particles into the atmosphere, which modifies its composition (Timmreck, 2012). Volcanic ash is injected in the atmosphere and because of its great size and density it drops out in a couple of weeks (Robock, 2000; Timmreck, 2012; Langmann, 2014). Thus, acting only in short-term and regional to continental scale changes in the Earth's radiative imbalance and mainly in weather characteristics (Stenchikov, 2016). For detailed role of volcanic ash on the climate the reader is referred to Langmann (2014).

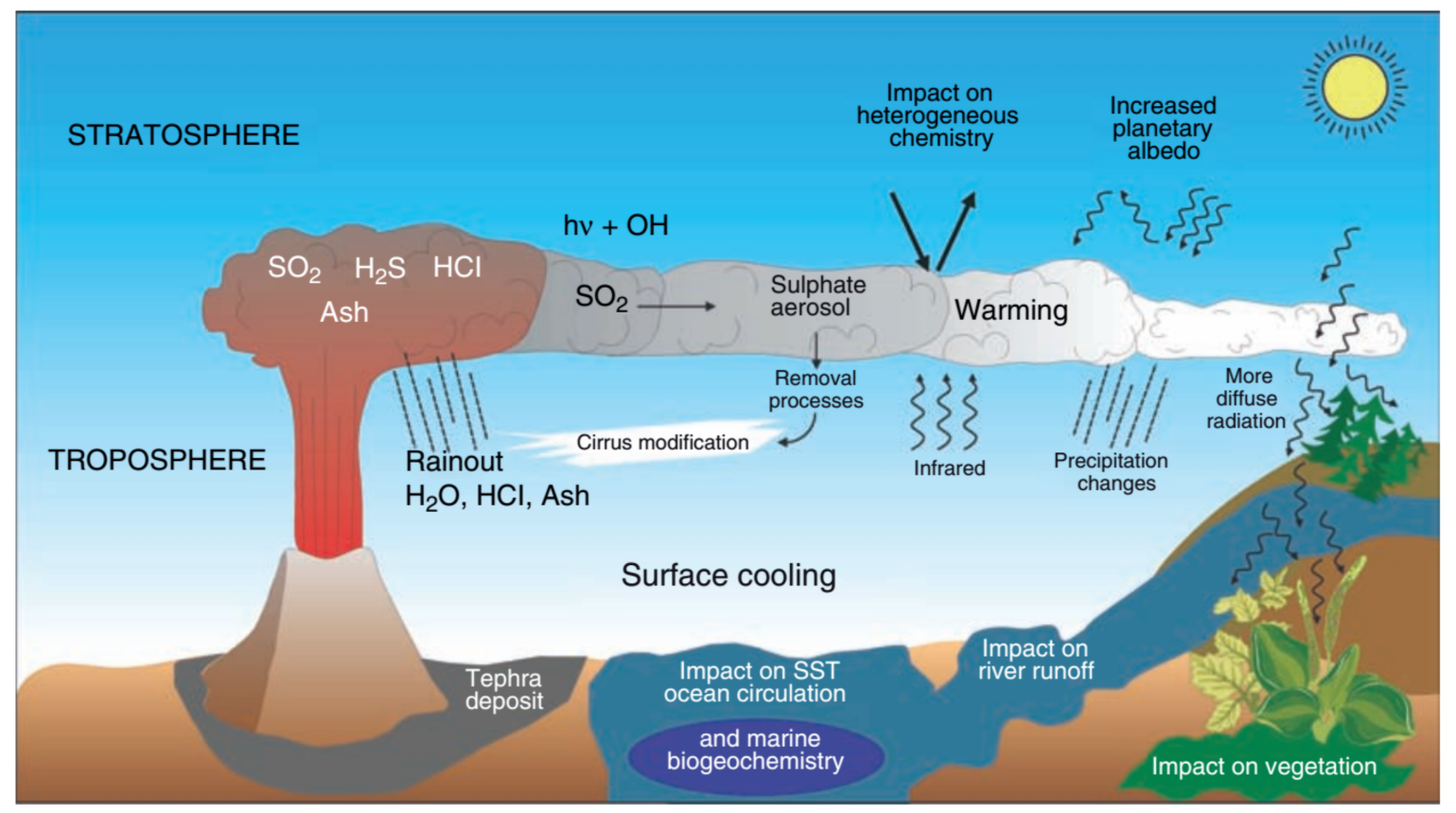

Figure 1.1: Schematic overview of the climate effects after a large eruption | Impact is exemplified on stratosphere, troposphere, ocean, marine biogeochemistry and vegetation (fromTimmreck, 2012).

In addition, there is emission of two important GHG - water vapor and carbon dioxide, which are negligible in comparison to their atmospheric concentration (Robock, 2000). 
Effects on atmospheric carbon concentration due to volcanism are small, as well as its feedbacks (Meronen et al., 2012). According to Gerlach (2011) the anthropogenic $\mathrm{CO}_{2}$ emission dominate over all kind of volcanic emissions (e.g., degassing, submarine volcanoes and explosions), authors even suggest that the present day annual anthropogenic emissions may exceed the output of at least one super eruption. The same occurs for $\mathrm{N}_{2}$ emissions (Stenchikov, 2016). In addition, there is an input of halogen compounds, such as $\mathrm{HCl}$ and $\mathrm{Br}$ substances, which could react with the ozone layer increasing ozone depletion (Timmreck, 2012; Stenchikov, 2016).

In global scale climate effect, emission of sulfur-containing gases is the most relevant. Strong enough eruptions are capable of insert gases such as sulfur dioxide $\left(\mathrm{SO}_{2}\right)$ and hydrogen sulfide $\left(\mathrm{H}_{2} \mathrm{~S}\right)$ into the stratosphere (Robock, 2000; Cole-Dai, 2010; Timmreck, 2012). As depicted in Figure 1.1, these gases are oxidized, reacting with $\mathrm{OH}$ and $\mathrm{H}_{2} \mathrm{O}$, to sulfuric acid vapor $\left(\mathrm{H}_{2} \mathrm{SO}_{4} g\right)$ on timescale of weeks (Robock, 2000). Then, it is converted to sulfate aerosols that produce the dominant radiative effect from volcanism, which is the focus of the present study (Timmreck, 2012). After injected into the stratosphere sulfate aerosols are able to be advected around the globe very rapidly, driven by atmospheric circulation (Robock, 2000).

The sulfate aerosol cloud has an e-folding decay time of $\sim 1$ year, during this period it impacts on both short-wave and long-wave radiation (Robock, 2000). According to Stenchikov (2016), the total forcing related to volcanic eruptions results from a compensation mechanism between the long-wave and short-wave radiation. At the same time that there is an increase in short-wave reflection (between 3 to $5 \mathrm{~W} \mathrm{~m}^{-2}$ ), there is aerosol absorption of long-wave radiation, so the total cooling of the system is between 2 to 3 $\mathrm{W} \mathrm{m}^{-2}$. As exemplified in Figure 1.2 of volcanic aerosol total, short-wave and long-wave radiative forcing at the top of the atmosphere during some of the great modern eruptions, such as Agung (1963), El Chichón (1982) and Mt. Pinatubo (1991). 


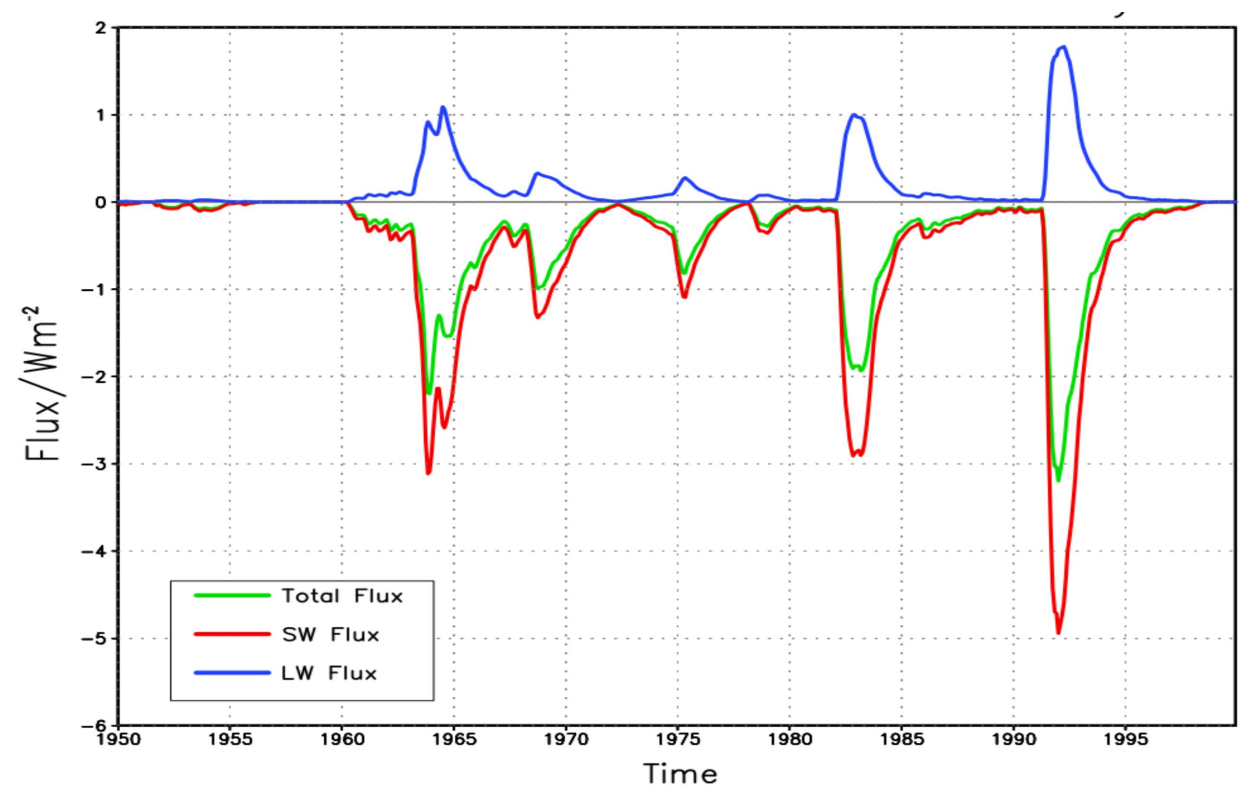

Figure 1.2: Volcanic radiative forcing | Total volcanic aerosol (green line), short-wave (red line) and long-wave (blue line) radiative forcing $\left[\mathrm{W} \mathrm{m}^{-2}\right]$ at the top of the atmosphere from 1950 to 2000 (from Stenchikov, 2016).

The information about magnitude and approximate location of past eruptions is obtained from paleovolcanic ice-core records, mainly sulfate aerosol deposits in Arctic and Antarctica (Cole-Dai, 2010; Timmreck, 2012; Stevenson et al., 2016). This information helps create reconstructions of eruption strength such as Gao et al. (2008) and Crowley et al. (2008). However, Sigl et al. (2014) points out that reconstructions may overestimate or underestimate volcanic aerosol before 1500 , which leads to simulations of stronger cooling from what is found in temperature reconstructions. Also, there are other ways to have evidence of past volcanic eruptions climate responses, for example from tree-rings and other proxy archives (Sigl et al., 2015; Stevenson et al., 2016). Different from ice-core records, the tree-rings measurements are an indirect way of obtaining volcanism evidence, since what is imprinted in the tree-rings is the temperature change and not the direct amount of sulfate aerosol in the atmosphere (Cole-Dai, 2010).

A common index used to compare the eruption magnitude is the Volcanic Explosivity Index (VEI), which is used as a measurement of the climatological impact of volcanoes (Robock, 2000). The greatest volcanic eruptions in history have a VEI of 8, but the scale is open-ended (Newhall and Self, 1982).

Because of the sulfate aerosols ability to spread in both hemispheres, tropical eruptions 
are the most important relative to global climate (Schneider et al., 2009). High latitude volcanoes primarily affect the hemisphere in which they are located (Timmreck, 2012; Meronen et al., 2012). The season of eruption is also an important factor, since the distribution of the sulfate aerosol cloud is mainly controlled by large-scale circulation of the atmosphere (Timmreck, 2012). As described in Meronen et al. (2012) winter eruptions cause smaller climate effects than summer and early autumn eruptions. Stevenson et al. (2017) suggest that the eruption season could help explain the differences between proxy data and models.

The effect of volcanism on the atmosphere can last for about five to seven years and even more in the oceans (Stenchikov, 2016). Examples of the impact of volcanism on the atmosphere and ocean are shown in Sections 1.1.1 and 1.1.2, respectively.

\subsubsection{Volcanism impact on the atmosphere}

The sulfate aerosol acts like a shield from incoming solar radiation on the top of the troposphere. By scattering short-waves atmosphere albedo is increased (Cole-Dai, 2010), thereby causing primarily surface cooling (Robock, 2000; Timmreck, 2012; Stenchikov, 2016). Aerosols also absorb long-wave and near-infrared radiation (Stenchikov, 2016), producing strong stratospheric warming (Figure 1.1). In the lower latitudes Robock and Mao (1992) observed cooling due to reduced solar flux, the maximum surface atmospheric temperature anomaly is of $-0.172 \mathrm{~K}$ during July (Meronen et al., 2012). At the same time, there is winter warming over northern hemisphere continents, which is connected with changes in the atmosphere dynamics processes (Robock and Mao, 1992; Robock, 2000; Robock et al., 2007; Graf et al., 2007). Surface atmosphere temperature changes over the oceans are smaller than over the continents, related with the larger heat capacity of water (Meronen et al., 2012).

While the northern hemisphere atmospheric variability related to volcanic activity is well known, eruptions consequences on the southern hemisphere still in debate (Timmreck, 2012). For example, studies diverge about the effect for the Southern Annular Mode 
$(\mathrm{SAM})^{2}$ (e.g., Roscoe and Haigh, 2007; Robock et al., 2007; McGraw et al., 2016). Results from Roscoe and Haigh (2007) showed a negative correlation between volcanic aerosol and SAM. Schneider et al. (2009) observed the westerlies shift equatorward in a highlatitude eruption scenario in the CCSM3. Results from Karpechko et al. (2010) also showed westerlies intensification after eruptions, which is in agreement with positive SAM. On the other hand, Robock et al. (2007) does not observe any significant change in the SAM intensity. Using Large Ensemble experiment from CESM and Coupled Model Intercomparison Project Phase 5 (CMIP5), McGraw et al. (2016) also show results that the southern hemisphere response to eruptions is a robust positive SAM, however with large internal variability ${ }^{3}$. The authors discuss that El Niño-Southern Oscillation (ENSO) influences the SAM response to volcanism, in which the SAM anomaly is larger during negative ENSO conditions.

There is a relation between volcanic eruptions and ENSO events (Lehner et al., 2016; Pausata et al., 2016). Timmreck (2012) with climate models and Li et al. (2013) with proxy evidence proposed that volcanism could force the climate system a favorable state to ENSO occurrence in the year after an eruption. As well, Pausata et al. (2015) showed with climate model that high-latitude eruptions in the northern hemisphere could induce ENSO occurrence in the 8-9 months. Stevenson et al. (2016) also observed using an ensemble approach that northern eruptions tends toward El Niño, while southern eruptions tends toward La Niña. Maher et al. (2015) observed with 610 ensemble set from CMIP5, the same increased likelihood of an El Niño-like response after an eruption and also suggest that there is an increased chance of La Niña occurrence in the third austral summer (defined as the December, January and February average, DJF) after the eruption.

Also the hydrological cycle is globally affected by great volcanic activity (Barnes et al., 2016; Fasullo et al., 2017). Significant reduction in global mean precipitation following volcanic eruptions is shown in Trenberth and Dai (2007), Schneider et al. (2009) and Meronen et al. (2012). However, the response is not always linear because of cloud

\footnotetext{
${ }^{2}$ The primary mode of extratropical variability in the southern hemisphere.

${ }^{3}$ The variability related to each of the ensemble members, normally measured as a standard deviation from the average of selected members of the ensemble, or the ensemble average
} 
microphysics, great variability and different atmosphere time scales (Timmreck, 2012). In addition, Joseph and Zeng (2011) found evidence that the precipitation response over the land is faster than over the oceans, related to their difference heat capacities. Stevenson et al. (2016) discuss that volcanic eruptions influence the monsoon system as well.

\subsubsection{Volcanism impact on the ocean}

Ocean properties and its dynamics are affected by volcanic eruptions as well, however its response could reach even longer time scales than the atmospheric disturbance.

\section{Ocean temperature}

As with the atmosphere temperature, surface ocean cools after volcanic events (e.g., Church et al., 2005; Ding et al., 2014; McGregor et al., 2015; Stenchikov, 2016). According to Church et al. (2005) the automatic reduction in the net solar flux after an eruption is the first trigger for SST changes. Evan et al. (2009) show that about $67 \%$ of the low frequency SST variability is driven by aerosol effects on the incoming radiation, in which $55 \%$ is from volcanic activity for the period of 1082-2007.

Results from Church et al. (2005) discuss a decrease in the SST of $-0.4^{\circ} \mathrm{C}$ in the model output and $-0.3^{\circ} \mathrm{C}$ in observations. Evan et al. (2009) studying the Tropical North Atlantic Ocean with models observe a cooling that ranges from -0.1 to $-2^{\circ} \mathrm{C}$. During the period 850-1850 (LM), Mignot et al. (2011) observe an abrupt surface ocean cooling of $1^{\circ} \mathrm{C}$. Stenchikov (2016) show a negative anomaly in the SST of $0.4-1 \mathrm{~K}$. For eruptions between 1871 and 2005, Ding et al. (2014) observe a globally averaged post eruption cooling of 0.1 to $0.3^{\circ} \mathrm{C}$. In the same period, results using ORAs4 reanalysis show global cooling episodes related to El Chichón (1982) eruption (Balmaseda et al., 2013). In addition, there is evidence of cooling in the polar North Atlantic SST in proxy data and model simulations detected in Sicre et al. (2011). Authors observe decadal cooling of 1 to $2^{\circ} \mathrm{C}$, which agree with episodes of volcanic eruption during the LM.

Using CMIP5 results Ding et al. (2014) observe that the SST cold anomaly due to 
volcanic eruptions is the lowest 1-2 years following eruptions. This fact is consistent with Pausata et al. (2015) model experiments that show a cooling that develops in the 1-3 years after the eruption in the Pacific Ocean. Moreover, volcanic activity could be responsible for the beginning of the anomalous cold period known as Little Ice Age (LIA), between 1400-1700 (Crowley et al., 2008; Sicre et al., 2011). This agrees with Miller et al. (2012), where they discuss that the repeated explosive volcanism at the time would be able to create a anomalous cooling, which could be maintained by sea-ice-ocean feedback.

The cooling due to volcanic explosions could even impact the recent ocean warming. Results from 7 ensemble simulations between 1861-2000 show that the atmosphere aerosol input from volcanic eruptions is able to reduce in $\sim 2 / 3$ the magnitude of the recent ocean warming due to GHG (Delworth et al., 2005). This agrees with Gleckler et al. (2006) that shows the importance of models that included volcanic forcing in understanding and correctly estimating global climate. The author discuss the dramatic effect on simulated changes in $\mathrm{OHC}$ and sea level over the $20^{\text {th }}$ century.

Church et al. (2005) observe $3 \times 10^{22} \mathrm{~J}$ decrease in OHC, while Stenchikov (2016) observe a maximum of $5 \times 10^{22} \mathrm{~J}$. Church et al. (2005) point that the maximum cooling occurs between $50 \mathrm{~S}$ and $60 \mathrm{~N}$, during the first and second summers for both hemispheres. Probably due to shallow mixed layers at this time of year, which responds more rapidly to heat flux changes (Church et al., 2005).Delworth et al. (2005) suggests that the subsurface recovery time scales is greater than surface anomalies, because of the absence of air-sea fluxes. Stenchikov (2016) discuss that the time necessary to ocean recover to its unperturbed state could reach centennial scales. This agrees with Pausata et al. (2015) results in SST on Nino3.4 region. However, Church et al. (2005) results show smaller recovery time scales. Authors suggest that on the thermocline the signal from volcanism would remain for decades, fact that also agrees with Ding et al. (2014).

Stenchikov et al. (2009) propose that if the surface anomalous temperature could last at least a decade, the portion of this anomaly that is transmitted to the $\mathrm{OHC}$, would last up to 50 years. On the other side, Gregory (2010) discuss that the OHC drop after an eruption and the long-term recovery time may not be real, but a result from an artifact 
of experimental design related to Ocean General Circulation Models spin up scheme. The size of the eruption is an important consideration when analyzing its consequences (Gleckler et al., 2006; Sigl et al., 2015; Stenchikov, 2016). In addition, the background condition, meaning the ocean condition before the volcanic event, is also important in evaluating the climate response, as shown in Zanchettin et al. (2013).

Due to changes in the $\mathrm{OHC}$, consequently there are alterations in the mean sea level through steric height (Gregory et al., 2006; Stenchikov, 2016). Simulations indicate a drop of 6 to $25 \mathrm{~mm}$ in the mean sea level after a volcanic event, that takes a decade to recover (Church et al., 2005; Cazenave, 2005; Fasullo and Nerem, 2016). In addition, volcanic induced perturbations propagate into the ocean deeper layers. Stenchikov (2016) identified a cooling in the deep Southern Ocean. The signal in the deep ocean, between 0-1000m, may persist for several decades (Ding et al., 2014).

Sea-Ice

A complex consequence of volcanic eruptions is the sea-ice feedback. Based on a series of CMIP5 ensembles Ding et al. (2014) observe sea ice extent and mass increase by about 5\%. Stenchikov et al. (2009) observe in the Arctic maximum sea ice extent anomaly of 0.6 to $0.8 \times 10^{6} \mathrm{~km}^{2}$. Even though sea-ice modifications being hard to estimate in observations and models, Stenchikov (2016) point that the sea-ice extension responds more to ocean temperature and circulation, than to the direct change of the radiative forcing. Fact that agrees with Zhong et al. (2011) that discuss the high sensitivity of the sea-ice response. Zanchettin et al. (2014), using climate simulation ensembles, point to Arctic and Antarctic asymmetry after an eruption. Authors have divided the response in two phases, firstly the sea-ice in both poles expand followed by contraction only in Antarctica sea-ice. 


\subsubsection{Modern eruption: Mt. Pinatubo}

The Mt. Pinatubo is the best observed eruption so far (Timmreck, 2012), being the largest volcanic explosion from the $20^{\text {th }}$ century (Robock, 2002) and since of the beginning of the satellite era (Barnes et al., 2016). It erupted in June 1991 in the Philippines, Luzon Island at $15.1 \mathrm{~N}$ and $120.4 \mathrm{E}$ shown in Figure 1.3. Its explosion liberated $20 \mathrm{Tg}$ of $\mathrm{SO}_{2}$ into the stratosphere (Robock and Mao, 1992) and a estimated release of 0.05 Gigatons of $\mathrm{CO}_{2}$ in the atmosphere (Gerlach, 2011).
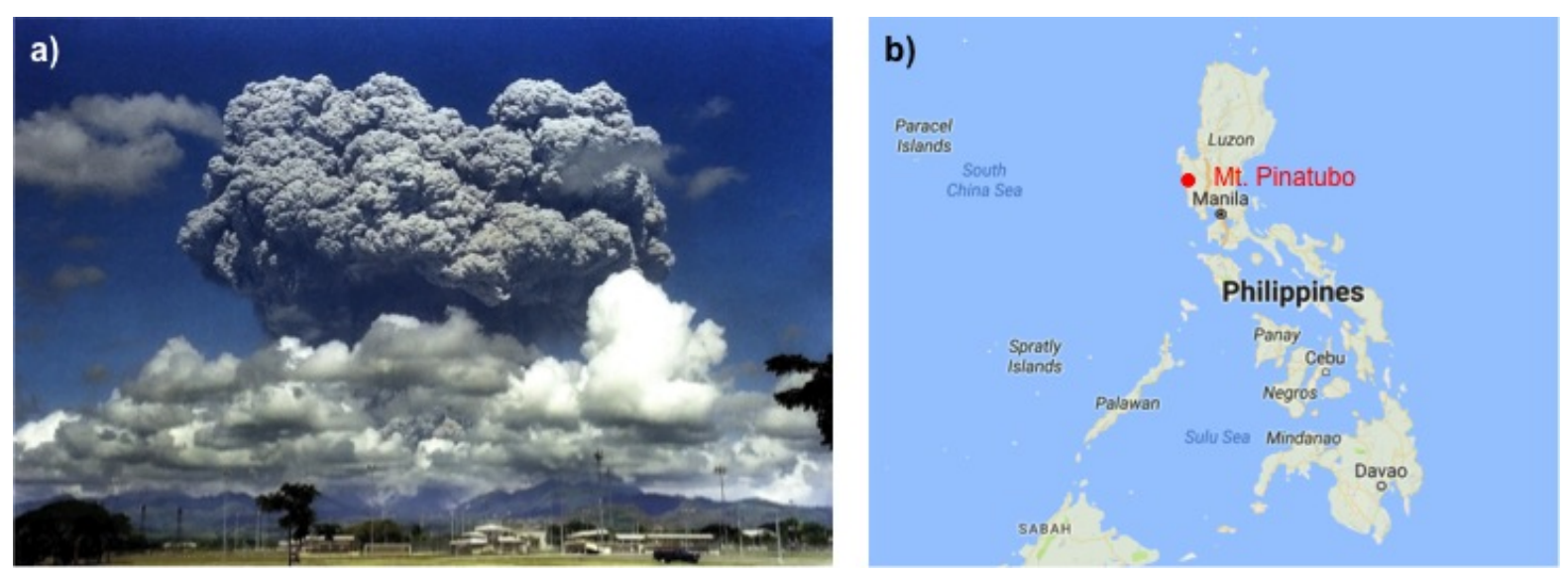

Figure 1.3: Mt. Pinatubo | (a) 1991 Mt. Pinatubo eruption (https://www.wired. com/2016/). (b) Geographical location of Mt. Pinatubo in the Philippines.

Mt. Pinatubo eruption has been widely studied (e.g., Hansen et al., 1992; Stenchikov et al., 1998; Robock et al., 2007; Otterå, 2008; Bender et al., 2010; Meehl et al., 2015; Barnes et al., 2016; Predybaylo et al., 2017). The amount of aerosol injection is equivalent to a radiative cooling of $0.2-0.3^{\circ} \mathrm{C}$ (Gao et al., 2008). As major effect in the northern hemisphere documented in Robock (2002) the surface atmosphere was cooled by about $2^{\circ} \mathrm{C}$ during the boreal summer of the next year and in the boreal winter of 1992-1993 it was warmer by $3^{\circ} \mathrm{C}$.

Another fact pointed in Robock (2002) is the possibility of delayed global warming in several years because of the cooling effect related to Mt. Pinatubo explosion. Further, aerosol from volcanic eruptions are described as one possible driver of hiatus periods during warming scenario (Maher et al., 2014; Santer et al., 2015; Smith et al., 2016). At the same time, Maher et al. (2014) also discuss the importance of the background condition in the eruption, because even Mt. Pinatubo being one of the largest eruptions since 1860, 
it was not enough to increase the likelihood of hiatus period, as observed in the Krakatoa eruption in 1883. Also, due to non-stationary background of large anthropogenically forced changes in ocean heat content, the anomalies induced by Mt. Pinatubo eruption are much smaller than Krakatoa (1883) temperature anomalies (Gleckler et al., 2006).

A Mt. Pinatubo sized eruption simulation creates a -0.4K SST anomaly, a decrease in the mean sea level of $9 \mathrm{~mm}$, a decrease in the $\mathrm{OHC}$ of $5 \times 10^{22} \mathrm{~J}$ and Atlantic Meridional Overturning Circulation (AMOC) ${ }^{4}$ strengthening of $~ 1.8$ Sv (Stenchikov et al., 2009; Stenchikov, 2016). The same surface cooling after Mt. Pinatubo eruption is observed in simulations by Church et al. (2005), however observations have shown smaller cooling of $0.3^{\circ} \mathrm{C}$ and a decrease in $\mathrm{OHC}$ of $3 \times 10^{22} \mathrm{~J}$. At the same time, in CMIP5 results Ding et al. (2014) find negative SST anomaly of only $0.1^{\circ} \mathrm{C}$. Also documented as consequences of the Mt. Pinatubo eruption are the decrease in stratospheric ozone, increase in the stratospheric temperature (Timmreck, 2012 and references therein) and changes in the hydrological cycle (Trenberth and Dai, 2007) .

It should be noted that Mt. Pinatubo eruption followed other two eruptions Agung in 1963 and El Chichón in 1982. Bender et al. (2010) discuss that Mt. Pinatubo eruption may have overlapping of anomalies due to eruptions proximity, even though that the radiative perturbation has already decayed. In the same year of Mt. Pinatubo explosion an ENSO event was observed, Robock et al. (2007) suggests that the 1991-1992 El Niño event could even suppress the volcanic signal in the observational data. Bender et al. (2010) discuss that this could help explain differences between observational and model simulations in the volcanic signals. Although Mt. Pinatubo has been the great eruption of the $20^{\text {th }}$ century, during August 1991, Cerro Hudson (Chile) erupted as well (Cole-Dai et al., 1999). This eruption was smaller than the Mt. Pinatubo, however its location is in the southern hemisphere (Cole-Dai et al., 1997). Therefore, there may be influence of this eruption on the South Atlantic Ocean, however this volcano is not present in the reconstruction (Gao et al., 2008) that forced CESM-LME (Otto-Bliesner et al., 2016).

\footnotetext{
${ }^{4}$ Atlantic limb of the global Meridional Overturning Circulation that includes thermohaline induced fluxes as well as wind-driven circulation (Talley, 2013).
} 


\subsection{The South Atlantic Ocean}

Here the main characteristics of the South Atlantic region including its Southern Ocean sector are described, which is the focus of this work.

\section{Surface Winds}

Over the South Atlantic the wind circulation is mainly composed by a strong westerly wind belt, on average between 40S and 60S (Talley et al., 2011). Westerlies are stronger during the austral winter, however the variability is smaller than the subtropical zone wind in the northern hemisphere (Tomczak and Godfrey, 2001). Further south, around Antarctica the wind regime is dominated by the polar easterlies, which are the most intense in the Atlantic Ocean (Tomczak and Godfrey, 2001). Over the Weddell Sea, the wind circulation is controlled by a low pressure center (Deacon, 1979). The representation of surface wind circulation for the LM is shown on Figure 3.2. For further details about the wind circulation in the South Atlantic Ocean the reader is referred to Cavalcanti et al. (2009).

\section{Wind-driven Circulation}

The dominant wind regime is responsible for the surface circulation in the South Atlantic Ocean and its southern sector, represented in Figure 1.4. The northern limit of the study region is $30 \mathrm{~S}$ and extends to the Antarctic coastline. The Atlantic sector is considered from $70 \mathrm{~W}$ to $30 \mathrm{E}$. It includes part of the southern hemisphere anticyclonic subtropical gyre in the South Atlantic Ocean, the Antarctic Circumpolar Curent (ACC), as well the subpolar gyre in the Weddell Sea.

The South Atlantic anticyclonic subtropical gyre is composed by the South Equatorial Current (SEC) as its northern extension (Tomczak and Godfrey, 2001), a broad westward flow that splits at the western boundary into the Brazil Current (BC) and North Brazil Current (NBC). The Brazil Current is the western boundary current, that flows southward to the Brazil-Malvinas Confluence, around 36-38S; where it meets the Malvinas Current 
(MC), the north-eastward extension of the ACC into the Atlantic (Talley et al., 2011). The South Atlantic Current (SAC) closes the gyre in its southern extension, it flows eastward to the Benguela Current $(\mathrm{BeC})$ and recirculates within the subtropical gyre.

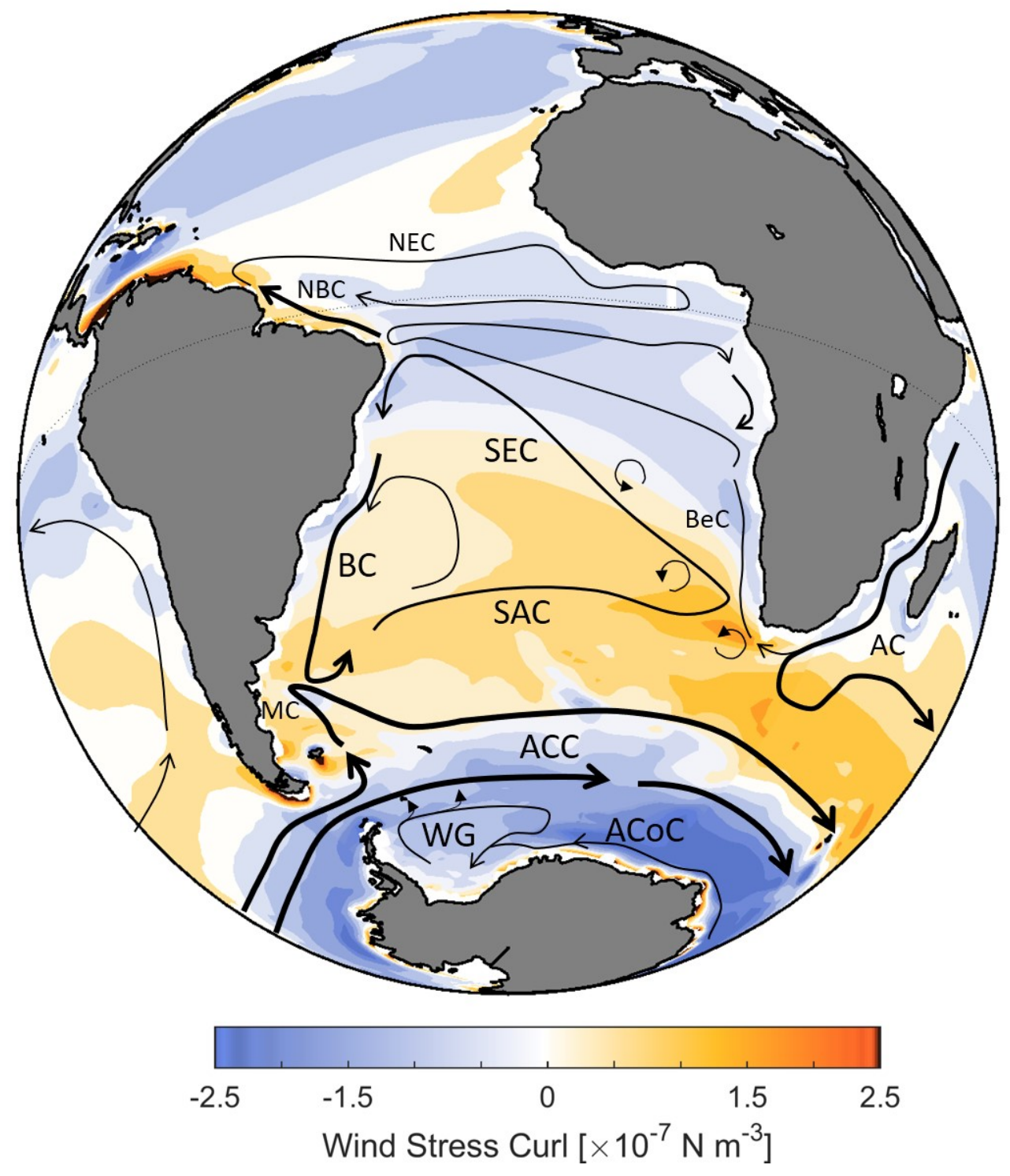

Figure 1.4: Wind-driven surface schematics for the South Atlantic Ocean and its southern sector | The CESM-LME mean climatological (850-2005) wind stress curl $\left[\mathrm{N} \mathrm{m}^{-3}\right]$ is shown in background colors. Black arrows represent the main circulation based on Talley et al. (2011) and Pontes et al. (2016). The abbreviations are used for ACC: Antarctic Circumpolar Current, WG: Weddell Gyre, ACoC: Antarctic Coastal Current, SAC: South Atlantic Current, BC: Brazil Current, MC: Malvinas Current, NBC: North Brazil Current, SEC: South Equatorial Current and BeC: Benguela Current.

The Southern Ocean region is dominated by the eastward flow of the ACC, its north boundary is the Subtropical Front. The ACC is mostly driven by the wind circulation; however it is not a broad eastward flow, but a composition of three main jets associated 
with oceanic fronts (Talley et al., 2011), which are from north to south, the Subantarctic Front, Polar Front and the South Antarctic Circumpolar Current Front. The main ACC characteristic is its circumpolar circulation, which makes it an important and only connection between the other oceans in the globe. The Antarctic Divergence is located at the ACC southern boundary, it exists because of the wind circulation transition between the westerlies to easterlies (Carter et al., 2008). This region is related to upwelling of intermediate and deep waters (e.g., North Atlantic Deep Water (NADW)).

South of the ACC is the Weddell subpolar gyre, which is separated from the ACC flow by the Weddell Gyre Front, around 60S (Heywood et al., 2004). The Weddell Gyre extends from approximately 60W to 20E (Cavalieri and Parkinson, 2008). Near the continent the Weddell Gyre is formed partially by the Antarctic Coastal Current (ACoC)(Talley et al., 2011). According to Núñez-Riboni and Fahrbach (2009), this current flows westward over the shelf acting as a dynamic barrier to the Warm Deep Water (WDW) and it is associated with shelf break fronts, as the Antarctic Shelf Front (Talley et al., 2011). For more details about the Weddell Sea, the reader is referred to Hellmer et al. (2016).

\section{Water Masses}

Most of the ocean floor, about 58\% (Johnson, 2008), is covered by the Antarctic Bottom Water (AABW), which is part of the deep branch of the AMOC. Its production is dependent on many complex ocean-atmosphere-cryosphere interaction processes in the Southern Ocean (e.g., Kerr et al., 2017), one of the most important is the shelf break convection $^{5}$.

The AABW formation depends on different source water types, which originates local types of bottom water that later are exported to the global circulation. Jullion et al. (2014) discuss that the role of the Weddell Sea in producing and exporting AABW is yet not completely understood and stems in part from the inflow from the Indian sector. Meredith (2013) points that the Weddell Sea is one of the most important site for the

\footnotetext{
${ }^{5}$ Mixture of surface waters, near the freezing point, with intermediate waters, which are warmer and saltier; therefore, sinking by convection near the Antarctic shelf break (Nicholls et al., 2009 and references therein).
} 
AABW formation, contributing roughly $40 \%$. Therefore, the local water masses from the Weddell Sea play a role on the AABW formation, such as the WDW, which is a local variety of the Circumpolar Deep Water (CDW) entering the Weddell Gyre at its eastern boundary. It is characterized by temperature and salinity within the ranges $0<\theta<1^{\circ} \mathrm{C}$ and $34.60<\mathrm{S}<34.75$ and flows in the Weddell Gyre deep layer (Ryan et al., 2016). The CDW is the most important water present in the ACC circulation, from 200 to almost 4000m depth (Tomczak and Godfrey, 2001). Normally, it is divided in two types: Upper CDW, that is low in oxygen and high in nutrients, and the high salinity Lower CDW (e.g., Kerr, 2010).

At the surface there is the Antarctic Surface Water (AASW), that responds to ice-melt and freezing related to seasonality (Talley et al., 2011), from the surface to about 200m depth. In the Weddell Sea region there is also the Continental Shelf Water, divided in different waters present in the shelf region (e.g., Winter Water, High Salinity Shelf Water and the Ice Shelf Water).

Finally, in the intermediate to deep layers of the oceanic region there is a northward flow of the Subantarctic Modal Water (SAMW) and Antarctic Intermediate Water (AAIW) (Talley et al., 2011). The SAMW is identified by its low oxygen index, placed below the Subantarctic Surface Water, that is a thick mixed layer formed during winter (Talley et al., 2011). Also located north of the Subantarctic Front, AAIW is characterized by a low salinity layer present from 500 to $1500 \mathrm{~m}$ depth (Talley et al., 2011). 


\subsection{Motivation and Scientific Hypothesis}

Volcanism is widely known to have an important role in climate change and in controlling the Earth energy imbalance (Stenchikov et al., 2009; Cole-Dai, 2010). Understanding how different components of the climate system respond to natural forcings is a key aspect to access how the whole Earth system would respond to future climate change. One important component of the Earth system is the Southern Ocean, in which there is a lack of knowledge about the impact of the volcanic forcing.

The impact of great volcanic eruptions in the southern hemisphere is not well known yet, even more in the South Atlantic and its Southern Ocean sector. Investigation of the atmospheric and ocean response to volcanism has been addressed in modeling studies, particularly for the large LM eruptions as well as for the 1991 Mt. Pinatubo eruption, but not for this region. The LM is one of the periods with more proxy data records (Otto-Bliesner et al., 2016), which make it possible to evaluate results from coupled climate system models that give a complete and longer perspective on climate variability (Schneider et al., 2009). Moreover, quantification of volcanic induced changes in the oceans from LM super eruptions (i.e., Mt. Samalas eruption during 1258 in Indonesia) might help to better understand the current climate trends (Stenchikov et al., 2009). As a comparison to the LM eruptions $1991 \mathrm{Mt}$. Pinatubo event is analyzed, because it is a recent and significant eruption proven to have global impact (Bender et al., 2010), for which observations and reanalysis products are available.

Therefore, the hypothesis of this study is that great volcanic eruptions will have an impact on the South Atlantic and its Southern Ocean sector circulation during the LM. Thus, if there is a signal from great volcanic eruptions detected in the coupledclimate model numerical simulations, would it be possible to identify the same signal from observations considering the much smaller eruption of 1991 Mt. Pinatubo? 


\subsection{Objectives}

Investigate the impact of Last Millennium volcanic events on the South Atlantic and its Southern Ocean sector.

\section{Specific objectives to verify the hypothesis outlined above:}

i Quantify changes due to volcanic eruptions in air-sea properties on the South Atlantic and its Southern Ocean sector through the Last Millennium using results from the Last Millennium Ensemble experiment from the Community Earth System Model developed at the National Center for Atmospheric Research (CESM-LME/NCAR).

ii Investigate if the observed impact of Last Millennium eruptions on the South Atlantic Ocean is also detected from observations related to the 1991 Mt. Pinatubo eruption. 


\section{MATERIAL AND METHODS}

\subsection{Data}

Volcanically induced changes in the South Atlantic and its southern sector are examined using simulation results from the National Center for Atmospheric Research (NCAR) Last Millennium Ensemble Experiment (LME) of the Community Earth System Model (CESM), hereafter referred to as CESM-LME (Otto-Bliesner et al., 2016). The simulation results are subdivided in two periods for this study: (i) 850-1850, the same period used in Mignot et al. (2011) and Stevenson et al. (2016), with focus on the natural external forcings. Then, (ii) 1980-2005, in contrast with the first subperiod, contains the anthropogenic imprint. Detection and attribution of climate change in this kind of study is possible, because the CESM-LME long runs without any anthropogenic influence (Otto-Bliesner et al., 2016).

For the results validation the Extended Reconstructed Sea Surface Temperature Version 5 (ERSSTv5) from the National Oceanic and Atmospheric Administration (NOAA), details described in Huang et al. (2017), and the Simple Ocean Data Assimilation (SODA) reanalysis version 3.4.1 (Carton and Giese, 2008) are used as auxiliary data. The auxiliary data is used in comparison with the CESM-LME post industrial period, specifically with the modern eruption of Mt. Pinatubo from June 1991. More details concerning each data set mentioned above and the analysis used are provided in the following sections.

\subsubsection{Community Earth System Model - Last Millennium Ensemble}

The LME simulations use the CESM version 1.1 with the Community Atmosphere Model version 5 (CAM5), see Hurrell et al. (2013) and Kay et al. (2015). The spatial 
resolution of the atmosphere and land components is $\sim 2^{\circ}$. The ocean and sea-ice components use $\sim 1^{\circ}$ spatial resolution and 60 layers as ocean vertical resolution, from the surface $(15 \mathrm{~m})$ to $145 \mathrm{~m}$ the vertical resolution is $10 \mathrm{~m}$. The vertical resolution starts to increase in greater depths, from approximately $880 \mathrm{~m}$ the vertical resolution is of $100 \mathrm{~m}$, increasing to a maximum of $244 \mathrm{~m}$ in greater depths around $3000 \mathrm{~m}$.

The model has been spun up from an 1850 control simulation of 650 year and for an 850 control simulation as well, therefore all simulations were started from year 850 of the control simulation (Otto-Bliesner et al., 2016). CESM-LME is composed by 10 full forcing runs, in which all forcings evolve from 850 to 2005. Also, 6 ensembles of single forcing runs considering the evolution of each forcing individually with all other fixed at values from the year 850 (Otto-Bliesner et al., 2016). The single forcing members are 4 solar only, 5 volcanic only, 3 land use only, 3 GHG only, 3 orbital only and 2 ozone-aerosol only (Figure 2.1). The forcings and implementation are the same as used in Landrum et al. (2013).

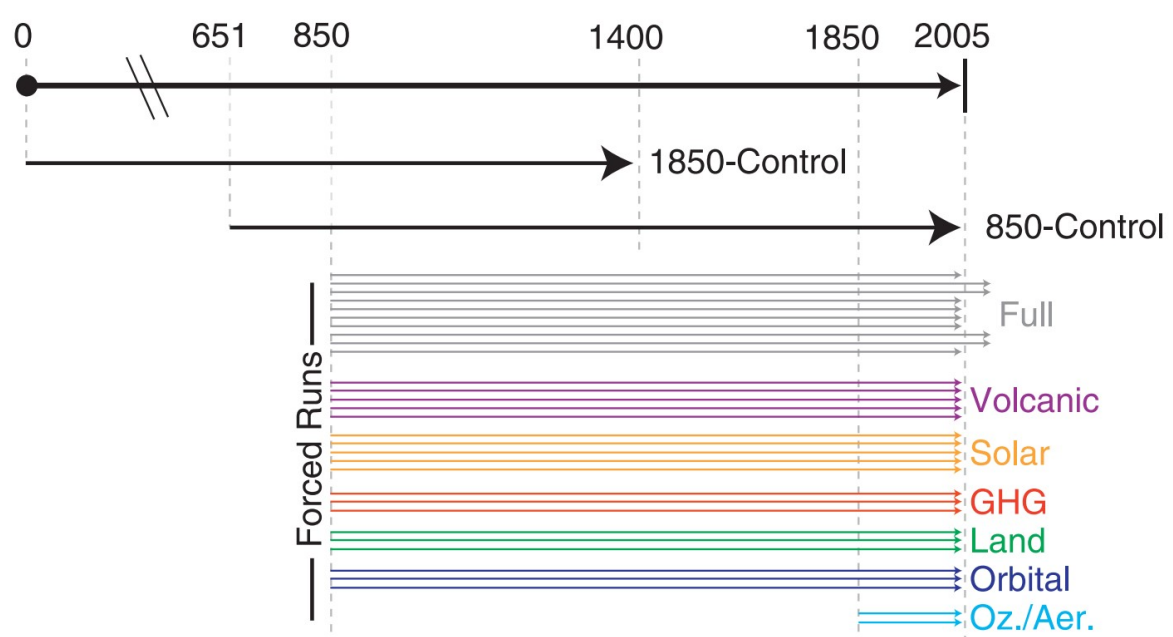

Figure 2.1: Runs from CESM-LME | Lengths of the control (black lines) and forced runs from the CESM-LME, which are 10 full forcings, 5 volcanic onty, 4 solar only, 3 GHG, 3 land use only, 3 orbital only and 2 ozone-aerosol only (from Otto-Bliesner et al., 2016).

As described in Otto-Bliesner et al. (2016), the only difference between ensemble members is a small perturbation of order $10^{-4}{ }^{\circ} \mathrm{C}$ in the air temperature initial conditions. The ensemble approach allows improved estimate of the uncertainty from internal variability and modeling process (Randall et al., 2007). 
The forcings considered for the period from 850 to 1850 were GHG (e.g., $\mathrm{CO}_{2}, \mathrm{CH}_{4}$ and $\mathrm{N}_{2} \mathrm{O}$ ) based on Schmidt et al. (2011); orbital changes from Berger (1978); changes in the total solar irradiance prescribed using Vieira et al. (2011); land use derived from a merge between Pongratz et al. (2008) and Hurtt et al. (2011); finally, the volcanic eruptions from the reconstruction version 1 from Gao et al. (2008). What changed for the period from 1850 to 2005 was the inclusion of ozone and aerosol forcings (e.g., GHG) evolving through time (Otto-Bliesner et al., 2016).

The volcanic eruptions are one of the most important forcings from the LM (Colose et al., 2016), thus it is the focus of the present study. For the volcanic eruptions reconstruction Gao et al. (2008) use a total of 53 ice cores, 32 from the Arctic and 22 from Antarctica, composing a comprehensive stratospheric volcanic sulfate mass loading for the past 1500 years. This can be converted to optical perturbation index and/or to radiative forcing series. Aerosol concentration varies as function of time, responding to seasonal variations in stratospheric circulation, latitude and altitude. Eruptions without recorded seasonality have been assumed to occur in April, which introduce a 10\% uncertainty, mostly in high-latitude sulfate deposition (Gao et al., 2008).

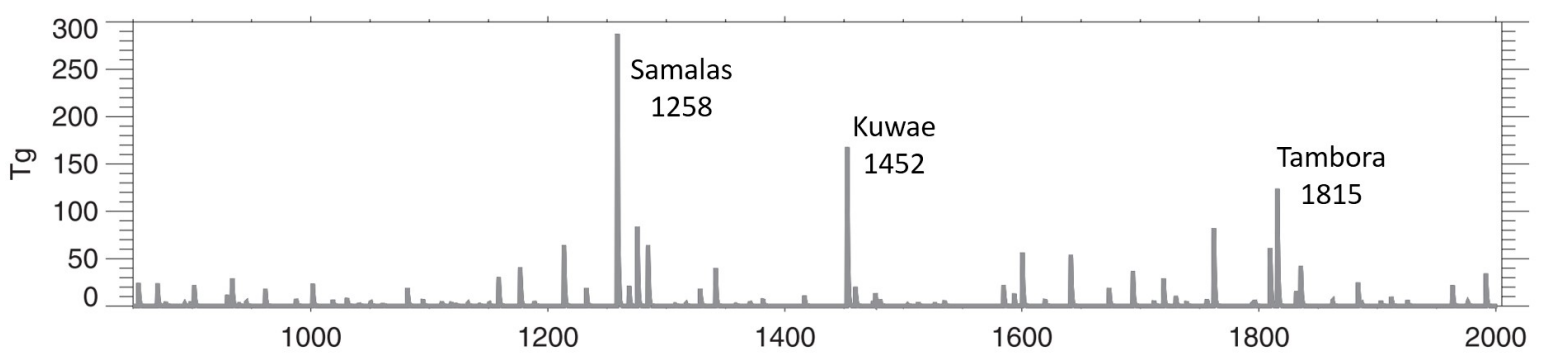

Figure 2.2: Volcanic mass evolution | Period between 850 and 2005 used in the CESMLME. Three of the greatest explosions from the LM are marked: Samalas (1258), Kuwae (1452) and 1815 Tambora. Volcanic mass is in Tg (from Otto-Bliesner et al., 2016).

Two LM periods were marked by great and frequent volcanic activity: the last half of the thirteenth century and the first half of the nineteenth century (Otto-Bliesner et al., 2016). Gao et al. (2008) state that the cumulative amount of volcanic sulfate flux was 2 to 10 times larger during the thirteenth century than any other century within the LM. In terms of estimated total global stratospheric volcanic sulfate aerosol injection, as seen in Figure 2.2, the largest eruptions were the Salamas in Indonesia during 1258 (257.9 
$\mathrm{Tg})$, followed by Kuwae of Vanuatu in $1452(137.5 \mathrm{Tg})$ and in 1815 Tambora located in Indonesia estimated at 109.7 Tg (Gao et al., 2008; Otto-Bliesner et al., 2016).

\subsubsection{Auxiliary Data}

\section{ERSSTv5}

As an auxiliary data for CESM-LME validation, monthly means of SST from the NOAA ERSSTv5 data set are used (Huang et al., 2017). This data set is derived from the International Comprehensive Ocean-Atmosphere Data Set (ICOADs) and spatial completeness enhanced with statistical methods. The product has a spatial resolution of $2^{\circ}$ and cover January 1854 up to 2015 . The data set is available on <https://data. nodc.noaa.gov/cgi-bin/iso?id=gov.noaa.ncdc:C00927>. For the present study the period between 1980 and 2005 is used, with focus on the 1991 Mt. Pinatubo eruption.

\section{SODA 3.4.1}

The SODA version 3.4.1 is an estimate of the evolving state of the ocean (Carton and Giese, 2008). SODA uses an ocean general circulation model (GFDL MOM5/SIS) to assimilate available in situ temperature and salinity profiles, also data from satellite. The product is a gridded data set of monthly values from 1980 to 2015 , at $0.5^{\circ}$ horizontal resolution and 40 vertical levels (Carton and Giese, 2008).

According to Carton et al. (2018), the version 3.4.1 of SODA includes an active sea ice component and is forced by European Centre for Medium-Range Weather Forecasts (ECMWF) ERA-Interim (Dee and Uppala, 2008). For more details and a complete overview of the SODA reanalysis methodology, the reader is referred to Carton and Giese (2008). The data set is available online at <http://www. atmos. umd.edu/ ocean/ index_files/soda3.4.1_mn_download.htm>. As ERSSTv5, here the period between 1980 and 2005 is used, with focus on the 1991 Mt. Pinatubo explosion. 


\section{$2.2 \quad$ Analysis}

Analysis has been divided in periods: in the Subsection 2.2.1 the LM eruptions from 850 to 1850, that uses CESM-LME simulation results. Described in Subsection 2.2.2 the 1991 modern eruption of Mt. Pinatubo, that includes also a comparison with the auxiliary data sets.

\subsubsection{Last Millennium eruptions analysis}

Considering the average of 15 ensemble members, 10 full forcing and 5 volcanic only, the analysis has been restricted to the period 850-1850, to exclude any $\mathrm{CO}_{2}$-induced trends in the full forcing runs. The ensemble average is used as in Goosse et al. (2005) to reduce the internal variability. All anomalies presented in the LM eruptions analysis are calculated relative to the 850-1850 mean.

Eruptions are divided into three classes according to Stevenson et al. (2016) and Gao et al. (2008). First, the authors only selected eruptions with a peak aerosol mass mixing ratio greater than $10^{-8}$. Then, the aerosol mass mixing ratio is integrated during the eruption year and two subsequent years over the northern and southern hemisphere. Lastly the ratio between them is calculated to distinguish the eruption source (Stevenson et al., 2016). From this, as described in Stevenson et al. (2016), eruptions have been classified as Northern, Southern and Tropical. In this study, analysis has been restricted to Tropical and Southern eruptions as shown in Table 2.1.

Table 2.1: Years of eruptions | Eruptions are divided in Tropical and Southern regions (from Stevenson et al., 2016).

\begin{tabular}{cc}
\hline \hline Region & Years \\
\hline Tropical & 1258 (Samalas), 1284, 1809, 1815 (Tambora) \\
Southern & $1275,1341,1452$ (Kuwae) \\
\hline \hline
\end{tabular}

For the composite analysis only the austral summer (DJF) is considered, because it is the season with less sea-ice extension in the Weddell Sea, also follows results from 
Stevenson et al. (2016). Church et al. (2005) results show that the maximum response to volcanic activity is in the summer, for both hemispheres, which is probably result of shallow mixed layers, thus simplifying heat flux change. The year of the eruption is referred as Yr 0 in the composite maps, which averaged all 7 eruption in Table 2.1 for the 15 ensemble members, therefore 105 events in total. The composite evolution starts in the year before the eruption ( $\mathrm{Yr}-1)$ and includes the 6 subsequent years $(\mathrm{Yr}+1$ to +6$)$. The difference maps between composite years are all subtracted from the year before the eruption (Yr-1), as a reference to quantify the changes due to volcanism.

All the significance levels presented are determined according to the Wilcoxon RankSum (WRS) test as in Stevenson et al. (2016). The set of the composite years (all the 105 events) are compared with the full time series from all ensemble members. This is the nonparametric version of the t-test since it only makes the assumption of independence between the time series and equal variance, but not that the data has a known distribution. The reader is referred to Gibbons and Chakraborti (2003) for detailed information about the WRS test.

To assess the evolution of the changes induced by volcanic eruptions, a superposed epoch analysis (SEA) is used. This is a common analysis tool to observe the average changes through a series of composites of multiple events as in Bothe et al. (2015); Sigl et al. (2015) and Lehner et al. (2016). It is a statistical method, that utilizes basically arithmetic calculations to resolve significant signal to noise problems. The SEA involves composing data into "key-date" and then comparing means of the composite years, in which a common response to a forcing event should emerge in the composite average (Brad Adams et al., 2003, Supplementary Material).

Analysis is divided in three subsections considering ocean depth and water mass characteristics as follows: (i) Surface, (ii) Vertical and (iii) Water Masses.

\section{Surface}

To verify the first impact of multiple volcanic eruptions on the South Atlantic Ocean SST, sea surface salinity (SSS), wind stress components, zonal wind stress (TAUX) and 
meridional wind stress (TAUY) and velocity components at the surface, zonal velocity (UVEL) and meridional velocity (VVEL) are analyzed. Zonal averages, anomaly composite maps and its significance (i.e., WRS test), application of SEA and evaluation of specific events during the LM are used.

\section{Vertical}

Potential temperature and salinity behavior are examined relative to ocean depth. Changes in specific latitudinal sections such as Greenwich Meridian (0W) and Antarctic Peninsula $(54 \mathrm{~W})$ are quantified. Moreover, a vertical Hovmöller is computed (e.g., Gleckler et al., 2006) to understand the propagation in depth of the volcanic induced signals.

Finally, for the Weddell Sea the volcanic perturbation is quantified at the location of the historical SR4 WOCE (World Ocean Circulation Experiment) transect, this section captures the inflow and outflow of Weddell circulation.

\section{Water Masses}

TS analysis (characteristic of water mass) is used, as an approach to verify if there is any signal from multiple eruptions in the water masses structure. The diagram is restricted to the Weddell Sea average, comparing each composite year with the LM climatological mean.

\subsubsection{Modern Eruption Analysis: Mt. Pinatubo}

To validate changes observed in the multiple eruption composite from the LM, the 1991 Mt. Pinatubo eruption is examined. For this analysis the study area is restricted to $70 \mathrm{~W}-30 \mathrm{E}$ and south of 50S, from 1990 to 1997. All anomalies presented for the modern eruption are calculated relative to 1980-2005 climatological mean. In addition, the anomaly time series is de-trended, as a way to minimize recent trends influence in the results. 


\section{RESULTS AND DISCUSSION}

Results and discussion are divided in three main sections. The characterization

of the LM surface properties such as SST, SSS, TAUX and TAUY, profiles of potential temperature and salinity, and a brief analysis of the CESM-LME time series are described in Section 3.1. The LM eruptions composite results are shown in Section 3.2. The last Section 3.3 is a comparison of LM results by putting the eruption of Mt. Pinatubo in context, which is directly related to the second specific objective (ii).

\subsection{General aspects of the Last Millennium}

This section is an introduction to the LM mean climatology, which is used as comparison to the perturbations due to LM great volcanic eruptions. It is subdivided in Mean Surface Climatology (Subsection 3.1.1), which also includes seasonal analysis and differences between the LM and the Present Day (PD) (1980-2005). The vertical mean state is shown in Subsection 3.1.2. Followed by a brief time series and ensemble spread analysis (Subsection 3.1.3).

\subsubsection{Mean Surface Climatology}

A comparison between the LM (850-1850) and the PD (1980-2005) periods is shown in Figures 3.1 and 3.2 for SST, SSS, TAUX and TAUY. Despite some changes in the magnitude, the spatial pattern in both periods is the same (Figures 3.1a,c and 3.2a), thus it is only shown the LM climatological mean (left-hand column) and the difference between PD and LM (right-hand column). As depicted in Figure 3.1b, SST mean climatology is significantly (at $90 \%$ level) increased $0.3^{\circ} \mathrm{C}$ in the PD than in the LM. 

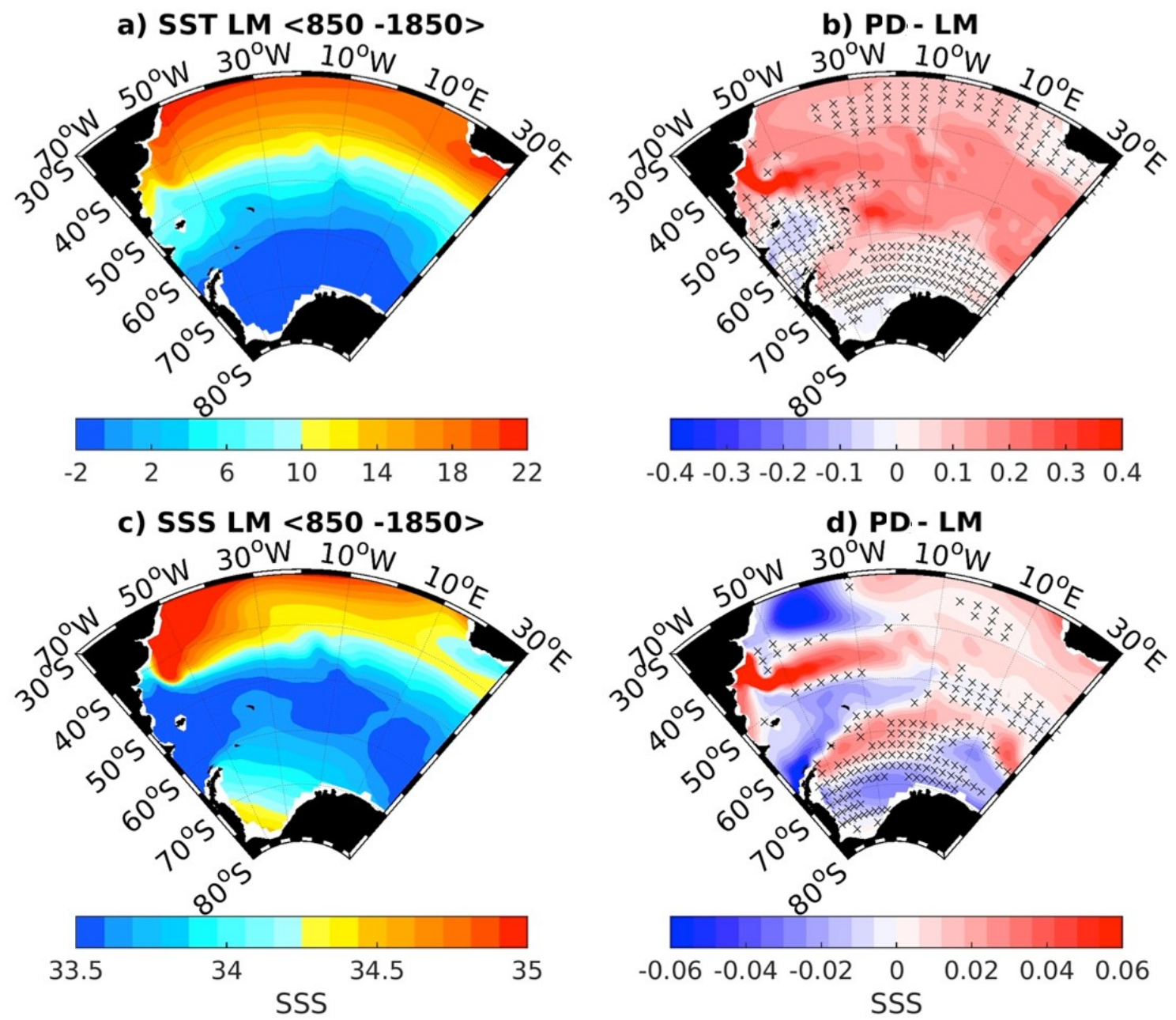

Figure 3.1: Sea surface climatological means | LM (850-1850) (a) SST $\left[{ }^{\circ} \mathrm{C}\right]$ and (c) SSS climatological means. Difference between the LM and PD (1980-2005) climatological means for (b) SST $\left[{ }^{\circ} \mathrm{C}\right]$ and (d) SSS. Significance levels are determined according to a t-test, and values that are insignificant at $90 \%$ are marked with crosses.

The same is shown for the SSS field, which presents regional positive and negative differences (Figure 3.1d). The Drake Passage has been significantly saltier (at $90 \%$ level) during the LM, at the same time that the northern Antarctic Peninsula and the South America have been fresher. The ACC region is the freshest region on the domain in contrast to further northern regions (Figure 3.1c).

Wind stress is the surface field that has changed the most from the LM to the PD. Figure $3.2 \mathrm{~b}$ shows a clear intensification of the westerlies of about $0.01 \mathrm{~N} \mathrm{~m}^{-2}$. 

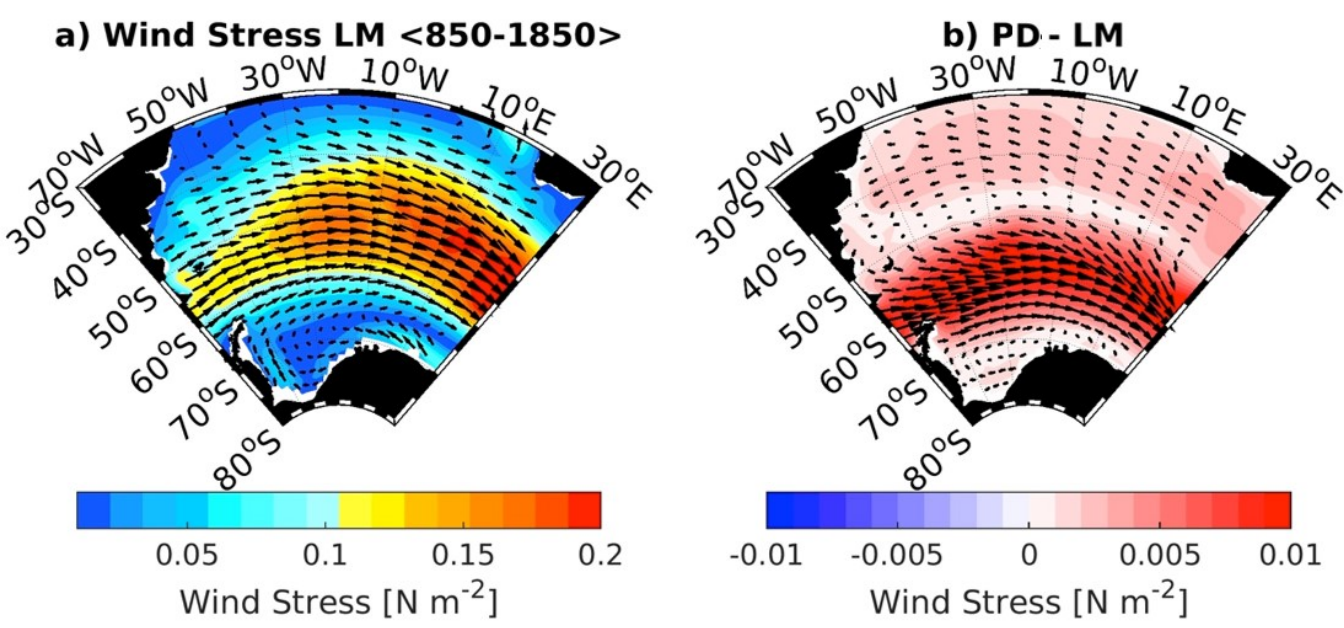

Figure 3.2: Wind stress climatological mean | Wind stress $\left[\mathrm{N} \mathrm{m}^{-2}\right]$ (a) LM (850-1850) climatological mean and (b) difference between the LM and PD (1980-2005) climatological means. The wind stress magnitude is represented in the background and the vectors represent the direction.

A quick comparison with reanalysis data (SODA) is done (figures not shown) for the common period of 1980-2005. Results point that the South Atlantic Ocean average in both data sets is in agreement. For the SST the field the average is of $10.32^{\circ} \mathrm{C}$ and $10.11^{\circ} \mathrm{C}$ for CESM-LME and SODA, respectively. The SSS averaged field is respectively 34.25 and 34.64 , while for TAUX the average is of $0.049 \mathrm{~N} \mathrm{~m}^{-2}$ and TAUY of $0.0018 \mathrm{~N}$ $\mathrm{m}^{-2}$ in CESM-LME compared to TAUX $0.042 \mathrm{~N} \mathrm{~m}^{-2}$ and $0.0033 \mathrm{~N} \mathrm{~m}^{-2}$ TAUY for SODA. In addition, CESM-LME has been validated by Fasullo et al. (2017), reproducing key features after Mt. Pinatubo eruption compared to reanalysis.

\section{Seasonal Climatology}

Results in the next sections are shown only for the austral summer (DJF) and with the focus on the LM. However, a brief seasonal description is conducted in the surface fields. Figures 3.3 and 3.4 show the mean climatology for the austral summer (DJF, left-hand column) and winter (JJA, right-hand column).

SST and SSS seasonal fields (Figure 3.3) contain the $-1.4^{\circ} \mathrm{C}$ isotherm, which is the sea water freezing point representing the sea-ice extension in the CESM-LME(Otto-Bliesner et al., 2016). The sea-ice extension is an important feature to be noticed, since our analysis includes the Weddell Sea region, that is highly susceptible to sea-ice seasonal 
variability.

Surface salinity field (Figure 3.3c,d), as the SST, also shows meaningful seasonal differences. The ACC region (45-60S) is fresher during the austral winter (JJA, Figure 3.3d) and the Weddell Sea is saltier during the austral summer (DJF, Figure 3.3d).

a) SST DJF

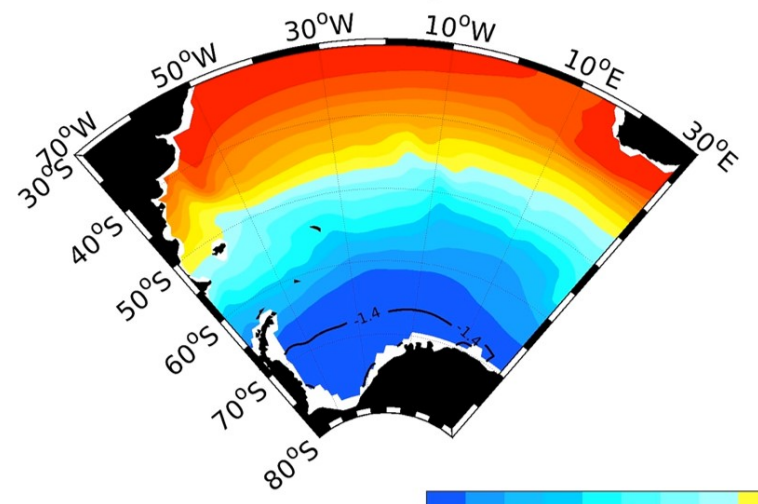

$\begin{array}{lllllllllllll}-2 & 0 & 2 & 4 & 6 & 8 & 10 & 12 & 14 & 16 & 18 & 20 & 22\end{array}$

c) SSS DJF

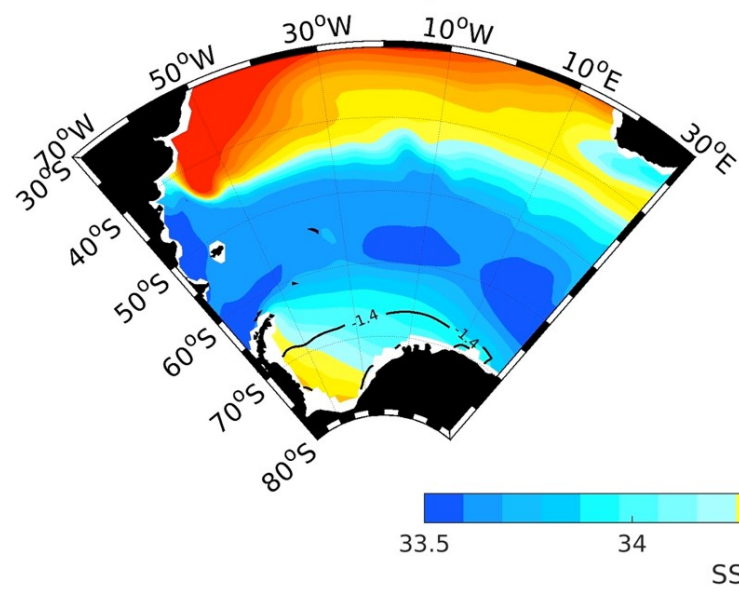

b) SST JJA

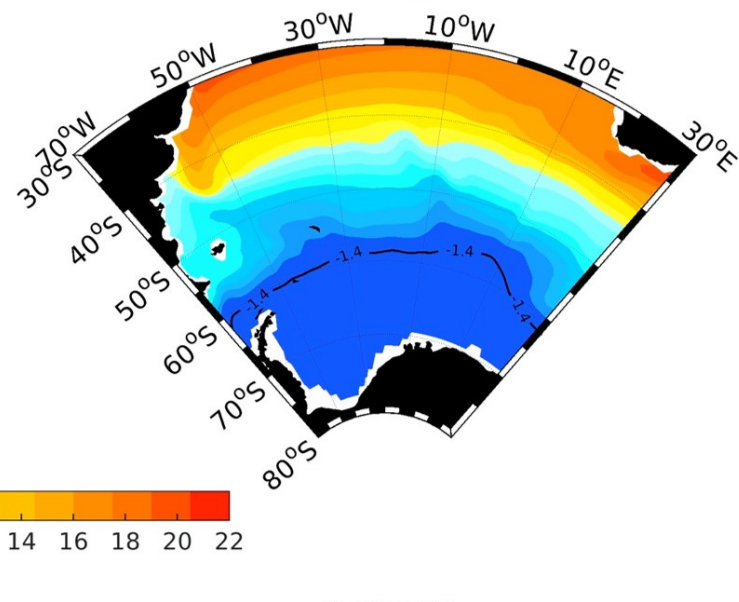

Figure 3.3: Seasonal climatological means | LM climatological mean for the SST $\left[{ }^{\circ} \mathrm{C}\right]$ field in the (a) austral summer (DJF) and (b) austral winter (JJA). The same for the SSS field (c) austral summer (DJF) and (d) austral winter (JJA). Black continuous line represent the $-1.4^{\circ} \mathrm{C}$ isotherm.

A more intense wind stress is seen during austral winter (JJA) in Figure 3.4f. With the meridional component (Figure 3.4c,d) the dominant component of the wind circulation over the Weddell Sea, mainly near the Antarctic Peninsula. The wind circulation over the Weddell Sea is a cyclonic gyre and much less intense than the westerlies belt, but is well represented. 

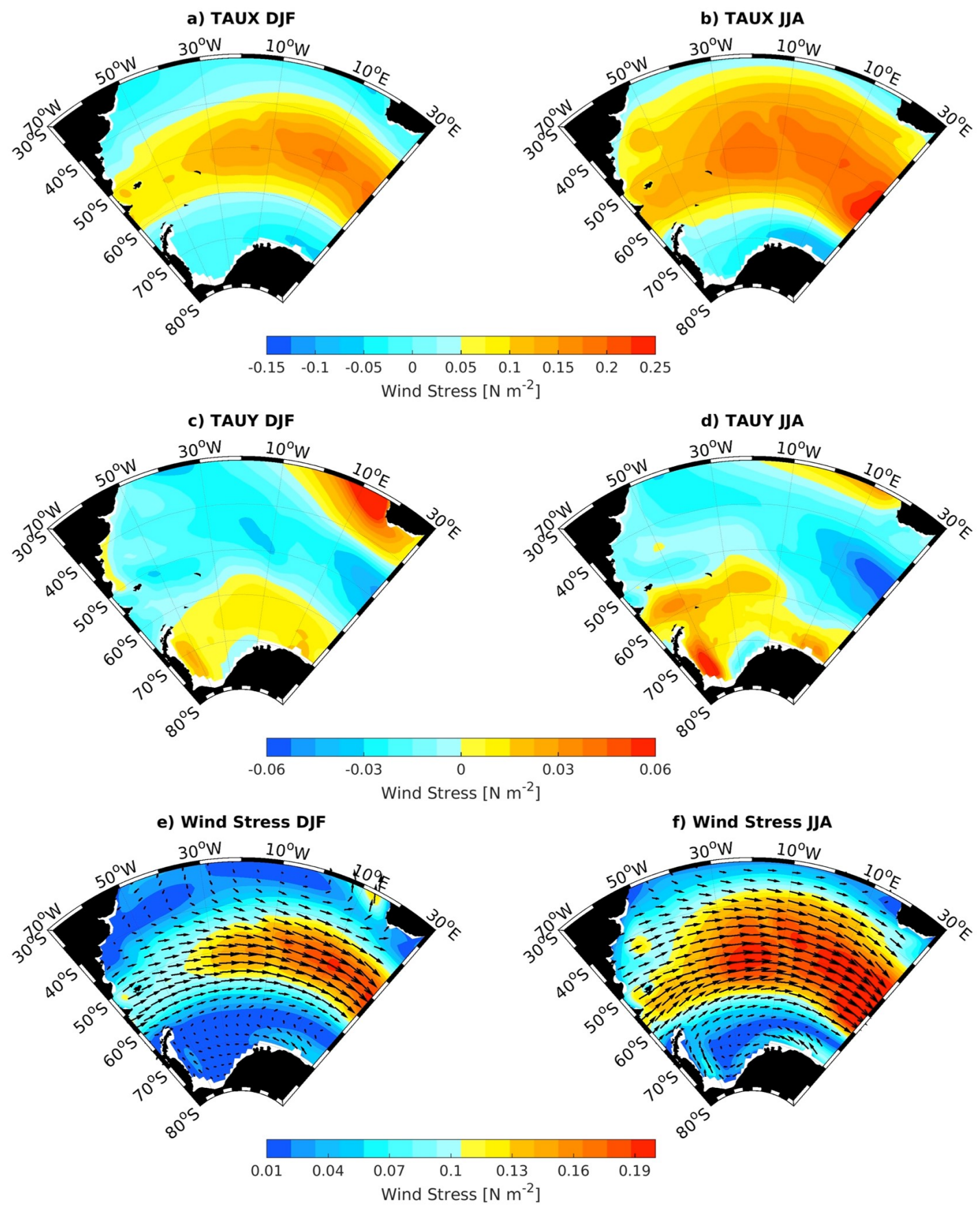

Figure 3.4: Wind stress seasonal climatological mean | LM climatological mean for the austral summer (DJF) in left-hand column (a) TAUX, (c) TAUY and (e) total wind stress $\left[\mathrm{N} \mathrm{m}^{-2}\right]$, magnitude in the background and the vectors represent the direction. Right-hand column show the austral winter (JJA), respectively (b) TAUX, (d) TAUY and (f) total wind stress. 


\subsubsection{Vertical Sections}

Zonally averaged sections of the South Atlantic Ocean are shown in Figure 3.5 during the LM austral summer (DJF) between $30 \mathrm{~S}$ and 70S, from the near surface to $3000 \mathrm{~m}$. Potential temperature and salinity sections help verify how the main water masses in the region are represented on average during this period.

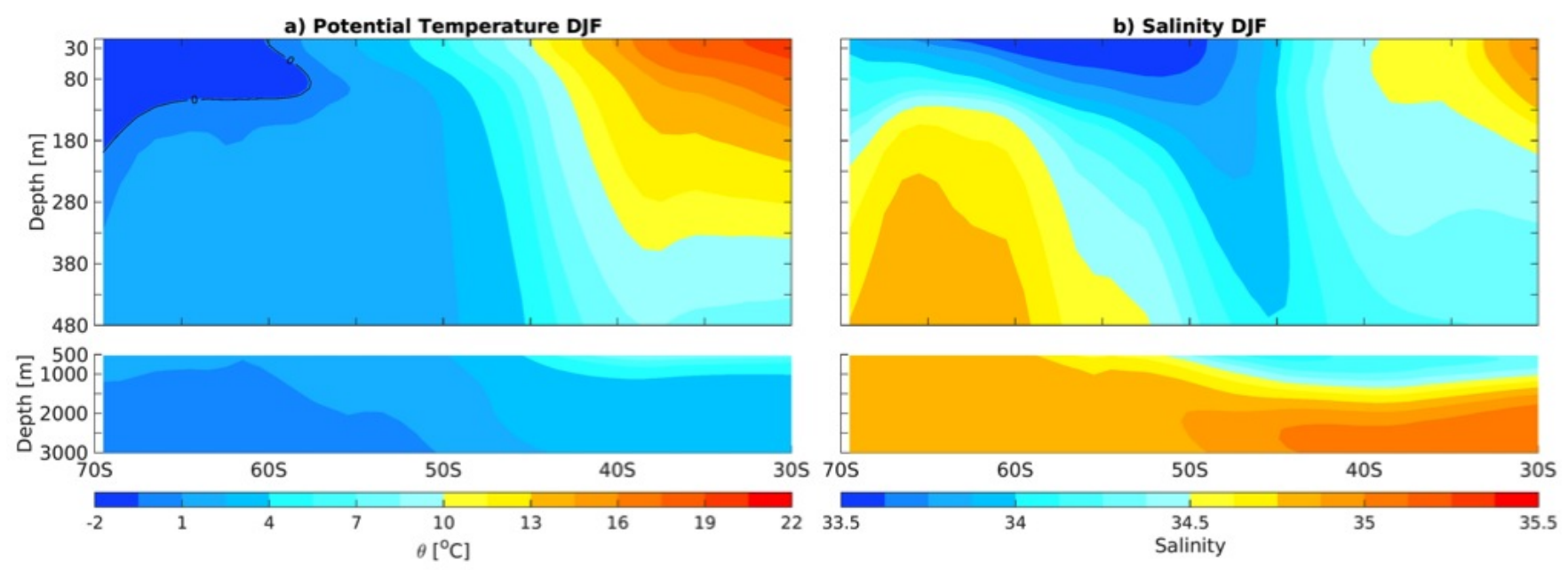

Figure 3.5: South Atlantic climatological zonal sections | (a) potential temperature $\left[{ }^{\circ} \mathrm{C}\right]$, the black line represent the $0^{\circ} \mathrm{C}$ isotherm and (b) salinity, both for the austral summer (DJF).

The potential temperature section show the expected gradient of warmer waters at the surface and north of $45 \mathrm{~S}$, accompanied by colder waters in the deeper layers and in the southernmost region (Figure 3.5a). Temperatures below $0^{\circ} \mathrm{C}$ are located south of 55S, related to Antarctic Surface Waters (Talley et al., 2011). Figure 3.5b depicts the salinity minimum, of 33.5, at the surface south of $45 \mathrm{~S}$ that spreads north representing the AAIW. The saltier water in the deeper layers represents the NADW, as compared to A12 WOCE section (Boyer et al., 2013).

To verify how CESM-LME represents the Weddell Sea water masses during the LM, the typical SR4 WOCE transect (Figure 3.6a) for the potential temperature (Figure 3.6b), salinity (Figure 3.7a) and VVEL (Figure 3.7b) are presented from the surface to $1800 \mathrm{~m}$ depth. 


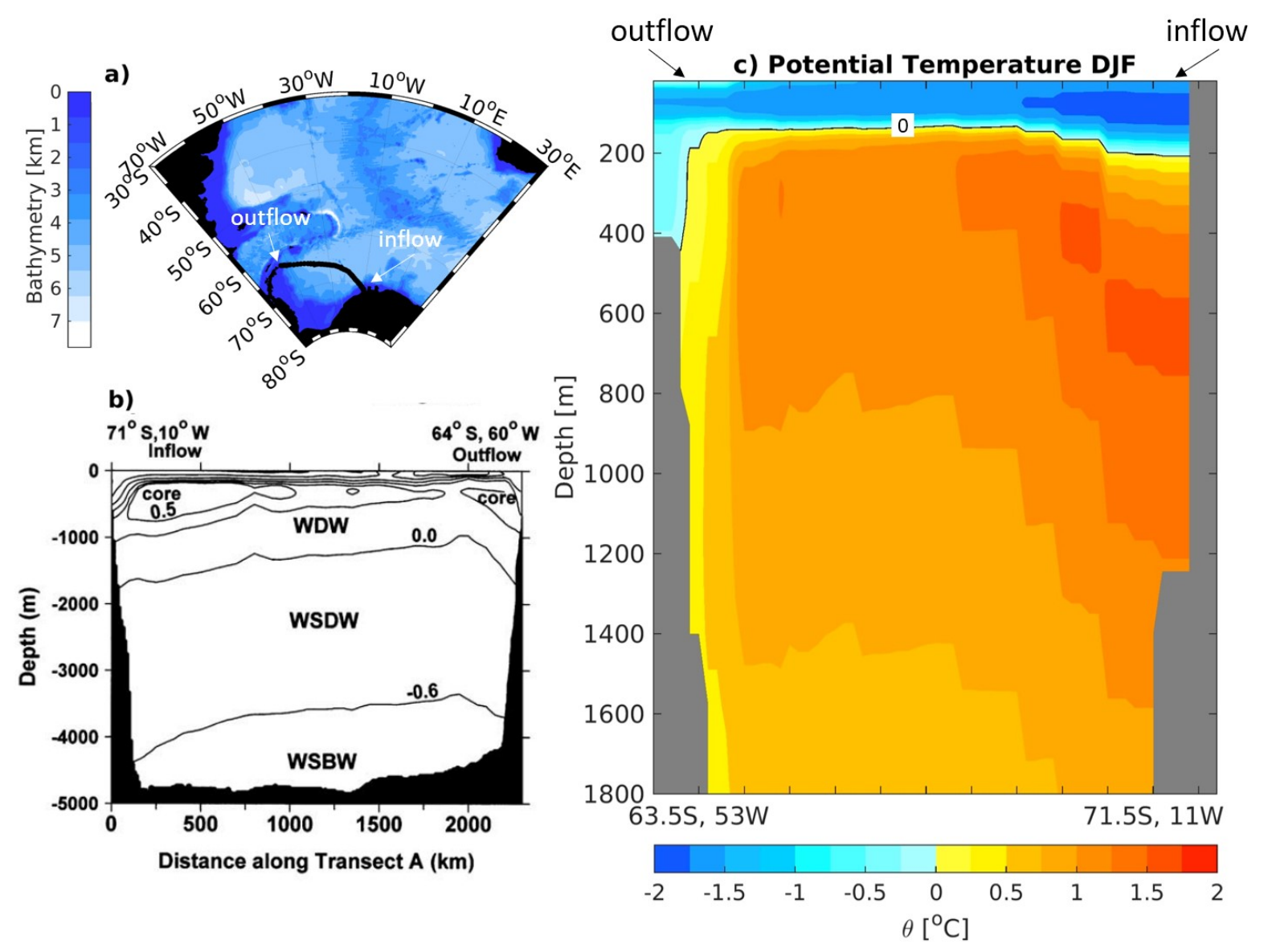

Figure 3.6: WOCE SR4 transect | (a) Bathymetry map for the Weddell Sea and South Atlantic Ocean showing the location of WOCE SR4 transect in black. (b) Figure reproduced from Robertson et al. (2002) of the typical potential temperature section along WOCE SR4 transect. From east to west, the warm core of WDW in the inflow and outflow regions are denoted as core. (c) Climatological LM mean of the potential temperature $\left[{ }^{\circ} \mathrm{C}\right]$ for the WOCE SR4 section during the austral summer (DJF). The inflow and outflow regions are marked, respectively $71.5 \mathrm{~S}, 11 \mathrm{~W}$ and $63.5 \mathrm{~S}, 53 \mathrm{~W}$.

Potential temperature shows a defined warmer core of $1.5^{\circ} \mathrm{C}$ from 200 to $1000 \mathrm{~m}$ (3.6c), which is consistent with the representation of the WDW in Figure 3.6b (Robertson et al., 2002), it also agrees with Jullion et al. (2014) (the reader is referred to Figure 2 in Jullion et al., 2014). In addition, the warmer core of the WDW is on averaged around 500m (e.g., Meredith et al., 2008; Kerr et al., 2009), which matches with Figure 3.6c. See that Figure 3.6c is mirrored from what is shown in Figure 3.6b and its section is deeper. The waters below $0^{\circ} \mathrm{C}$ are at the surface above $200 \mathrm{~m}$, representing the Continental Shelf Water (Talley et al., 2011) and the Winter Water in the eastern region (Jullion et al., 2014).

Figure $3.7 \mathrm{a}$ represents the salinity that also depicts a core below $400 \mathrm{~m}$ of saltier 
water (34.65 to 34.9), which is the WDW representation (Kerr et al., 2009; Jullion et al., 2014). Maximum salinity core is on average located around 800m (Meredith et al., 2008), agreeing with Figure 3.7a. At the surface the salinity is smaller, ranging from 34.3 to 34, approximately.

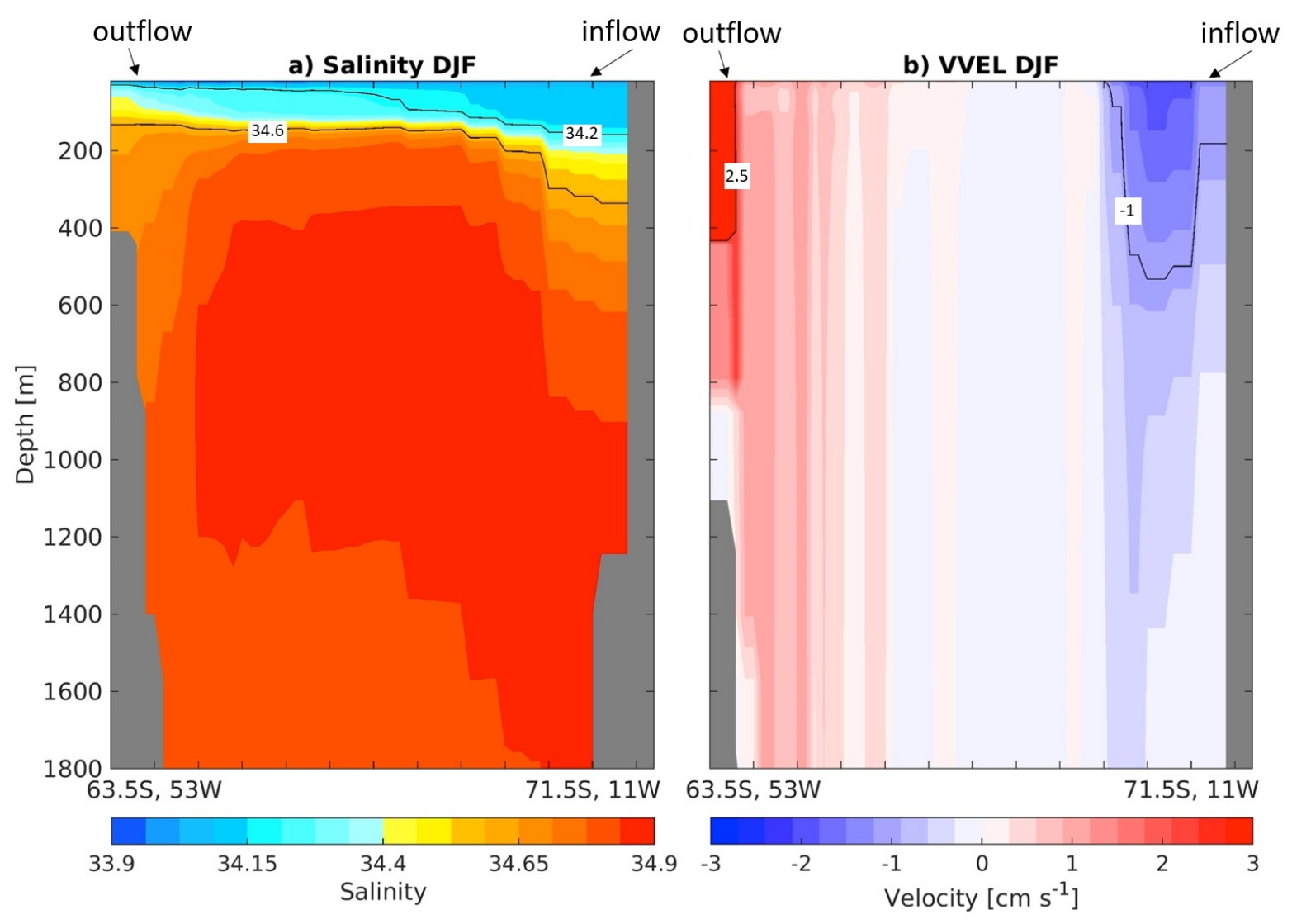

Figure 3.7: WOCE SR4 transect | LM climatological mean for (a) salinity and (b) meridional velocity $\left[\mathrm{cm} \mathrm{s}^{-1}\right]$ for the austral summer (DJF). The inflow and outflow regions are marked, respectively $71.5 \mathrm{~S}, 11 \mathrm{~W}$ and $63.5 \mathrm{~S}, 53 \mathrm{~W}$.

The meridional velocity (Figure 3.7b) corresponds to the Weddell Gyre circulation (e.g., Nicholls et al., 2009). At the subsurface the inflow region is evident in the east Weddell Sea edge $(71.5 \mathrm{~S}, 11 \mathrm{~W})$, where the VVEL reaches $\sim 1 \mathrm{~cm} \mathrm{~s}^{-1}$; and an outflow of $2.5 \mathrm{~cm} \mathrm{~s}^{-1}$ in the western region $(63.5 \mathrm{~S}, 53 \mathrm{~W})$. 


\subsubsection{Time Series}

Here the time series for the surface properties of the 15 ensemble members average and the ensemble spread ${ }^{1}$ are analyzed to quantify uncertainties and verify the volcanic signal presence (Figures 3.8 to 3.10). All time series shown are the surface average for the South Atlantic Ocean (70W-30E, south of 30S), for yearly anomalies calculated relative to the 850-2005 climatological mean. All figures show the mean standard deviation of the ensemble members (dotted line), according to Goosse et al. (2005) this gives an indication of the variability related to the ensemble set. Moreover, using it as a reference provides a measure of the robustness of the system response to the volcanic forcing.

The SST anomaly time series varies on average between -0.1 and $0.2^{\circ} \mathrm{C}$ during the $\mathrm{LM}$ and centennial features are well represented in Figure 3.8 (Crowley et al., 2008; Mann et al., 2009). Temperature shifts such as the warmer Medieval Climate Anomaly (MCA), on average shows positive anomalies of $0.1^{\circ} \mathrm{C}$ from 950 to 1250 , denoted in red. During the LIA (1400-1700) the SST anomaly is on average negative (in blue). Both periods limits are determined following Mann et al. (2009). The recent period 1980-2005, in green, shows evident warming trend of SST reaching anomalies of $0.4^{\circ} \mathrm{C}$.

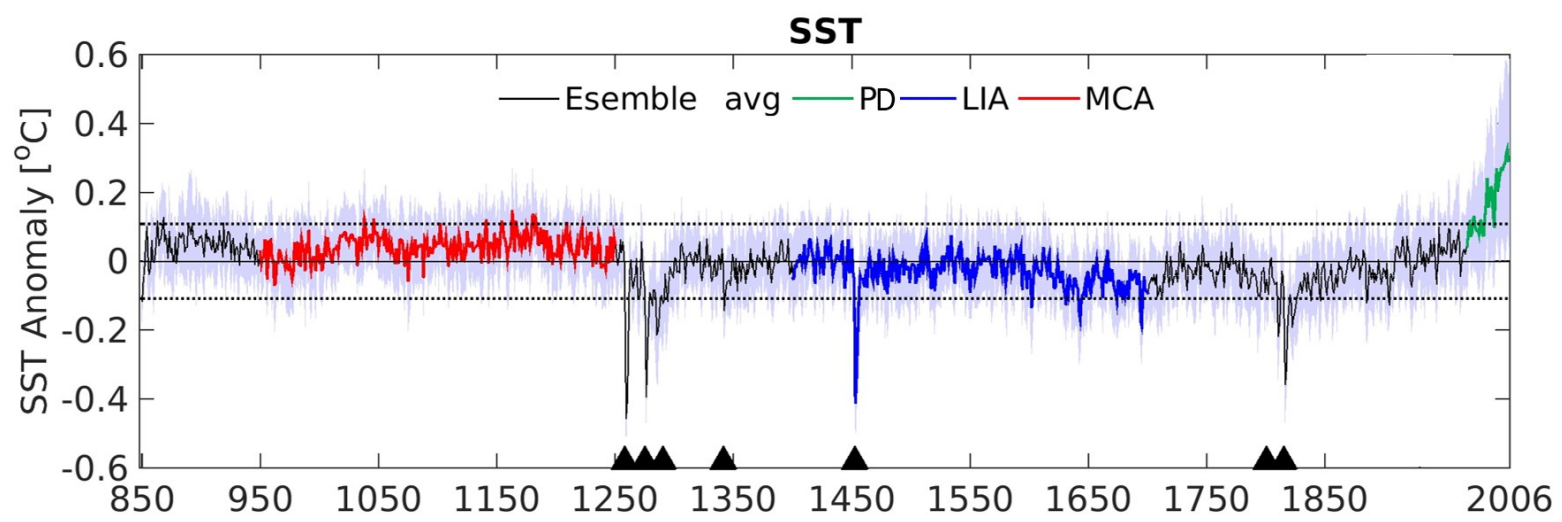

Figure 3.8: SST $\left[{ }^{\circ} \mathbf{C}\right]$ anomaly time series | Annual ensemble average and spread for $850-2005$ period. The dotted line is the \pm 1 standard deviation representing the internal variability. The black triangles represent the selected volcanic eruptions. Colors represent different periods that are described in the legend.

\footnotetext{
${ }^{1}$ The spread of the ensemble members is the standard deviation of the averaged members, which is calculated for each month of the time series.
} 
All selected years of volcanic events are marked in triangles in the x-axis in Figure 3.8. The more striking signal in the SST time series is that all volcanic events are related to an abrupt cooling (Figure 3.8). The cooling signal is expected after an eruption due to the radiative effect (e.g. Church et al., 2005; Stenchikov et al., 2009; Mignot et al., 2011; Kim and Kim, 2012; Ding et al., 2014; Stenchikov, 2016). The volcanic signal in the SST is very well represented, accounting for a small spread between the ensemble members. Also, all volcanic events show a negative anomaly greater than the internal variability, represented by the dotted line in Figure 3.8 by one standard deviation.

The largest South Atlantic Ocean average response is to the 1258 Samalas eruption, a cooling of $0.5^{\circ} \mathrm{C}$. This is one of the largest eruption during the LM, observations from proxy data show that the greatest surface cooling in this period is after the Samalas eruption (Sicre et al., 2011). A cooling of $1^{\circ} \mathrm{C}$ is observed in the whole Atlantic Ocean SST in Mignot et al. (2011), the largest magnitude in the signal is probably because of the different averaged areas. The SSS ensemble spread is shown in Figure 3.9. There are no differences between the LM periods as in the SST.

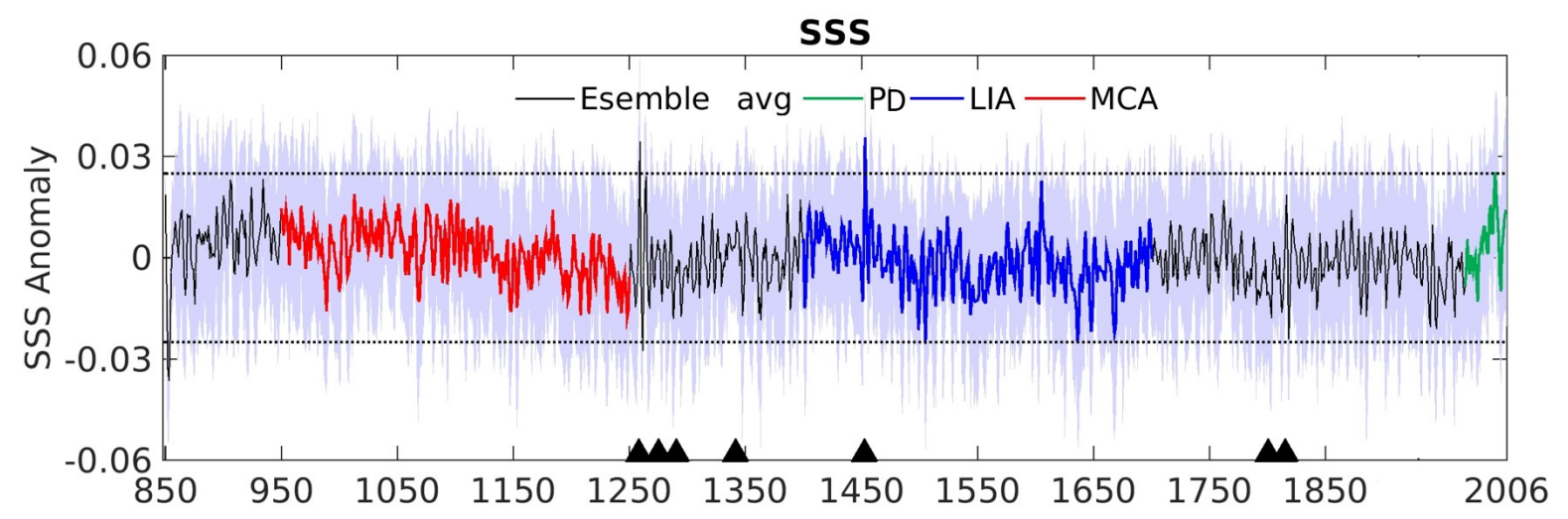

Figure 3.9: SSS anomaly time series | Annual ensemble average and spread for 8502005 period. The dotted line is the \pm 1 standard deviation representing the internal variability. The black triangles represent the selected volcanic eruptions. Colors represent different periods that are described in the legend.

However, the response due to some of the eruptions is evident. For the largest eruptions, such as Samalas (1258) and Kuwae (1452), the South Atlantic Ocean salinity presents an abrupt positive anomaly $(\sim 0.04)$ that is larger than the range of internal variability (dotted line in Figure 3.9). Other studies in regions such as the middle, 
northern high latitudes and in the Southern Ocean, have also shown an increase at the sea surface salinity after eruptions (e.g., Stenchikov et al., 2009; Kim and Kim, 2012; Ding et al., 2014; Pausata et al., 2015), fact that is consistent with a reduction of precipitation found in Trenberth and Dai (2007).

Using a fully coupled model Mignot et al. (2011) observed anomalous negative salinity after eruptions in the northern subtropics, which is consequence of increased surface freshwater fluxes (i.e., precipitation and river runoff) in the same region. The difference in the results may be related to specific regional characteristics, given the greater presence of continents in the northern subtropics compared to the southern subtropics and higher south latitudes. The TAUX and TAUY time series are represented in Figure 3.11, in which the centennial changes are not evident during the LM. Because there is a difference of approximately one order in the magnitude between each component of the wind stress $($ TAUX $>$ TAUY) the anomaly scale for each figures is different.
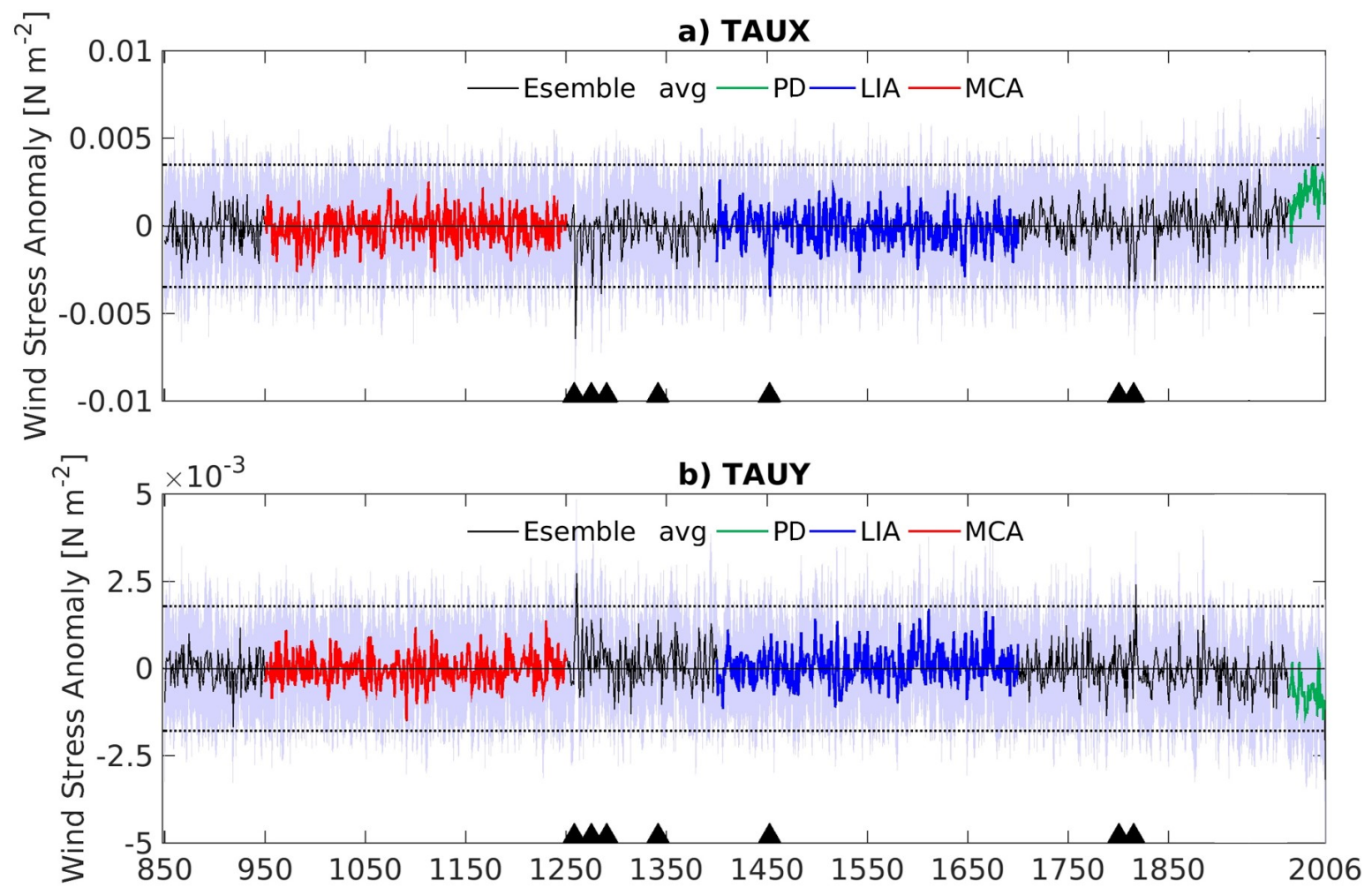

Figure 3.10: Wind stress components time series $\mid$ (a) TAUX anomaly $\left[\mathrm{N} \mathrm{m}^{-2}\right]$ and (b) TAUY anomaly $\left[\mathrm{N} \mathrm{m}^{-2}\right]$ time series of annual ensemble average and spread for $850-2005$ period. The dotted line is the \pm 1 standard deviation representing the internal variability. The black triangles represent the selected volcanic eruptions. Colors represent different periods that are described in the legend. 
The zonal wind stress response to volcanic eruptions is not clear (Figure 3.10a,b). The wind stress change is evaluated in detail in Section 3.2.1. Even though there is a large ensemble spread, in the PD the wind stress presents a positive trend (green line in Figure 3.10a), TAUX increases from the late 1950, which agrees with the positive trend in the SAM (Marshall, 2003; Thompson et al., 2011; Abram et al., 2014). In the same period TAUY decreases on average (Figure 3.10b).

\subsection{Last Millennium eruptions}

This section presents the composite results considering all seven eruptions from Table 2.1 only for the austral summer (DJF). Results are divided in Subsection 3.2.1 that shows analysis for the surface air-sea properties, including anomaly maps and LM individual events evaluation as well. Subsection 3.2.2 discusses the results related to the vertical properties such as potential temperature and salinity. A brief analysis of water masses changes due to volcanism is presented in Subsection 3.2.3. Finally, results focused on the Weddell Sea are described in Subsection 3.2.4.

\subsubsection{Surface Analysis}

\section{Zonal Average}

The composite zonal average is the first approach to observe how the air-sea properties are responding to the volcanic eruptions. It averages the whole South Atlantic Ocean defined in the study area (Section 1.2) from 30S to 70S. The continuous black line in Figures 3.11 and 3.12 represents the internal variability limit ${ }^{2}$. In the SST zonal average shown in Figure 3.11a all anomalies are negative, but there is meaningful zonal difference in the averaged volcanic response. $\mathrm{Yr}+1$ (red asterisks) displays the largest response to volcanism, fact that agrees with other studies accounting for the different averaged regions (Stenchikov et al., 2009; Balmaseda et al., 2013; Ding et al., 2014).

\footnotetext{
${ }^{2}$ Calculated as \pm 1 standard deviation based on the averaged ensemble members spread.
} 
Kim and Kim (2012) simulation results depict the largest cooling in the second year after the eruption $(\mathrm{Yr}+2)$. Contrary to Mignot et al. (2011) for the North Atlantic Ocean and Church et al. (2005) in the global average, that have observed a faster response, with surface temperatures decrease in the year of the eruption ( $\mathrm{Yr} 0$ ). This is also not observed in the South Atlantic given that during the year of the eruption (Yr 0 in blue squares) the anomaly is almost zero. Nonetheless, Mignot et al. (2011) discuss that the poleward cooling extension is stronger on the first year following the eruption, at least in the northern hemisphere, fact that agrees with results presented here.
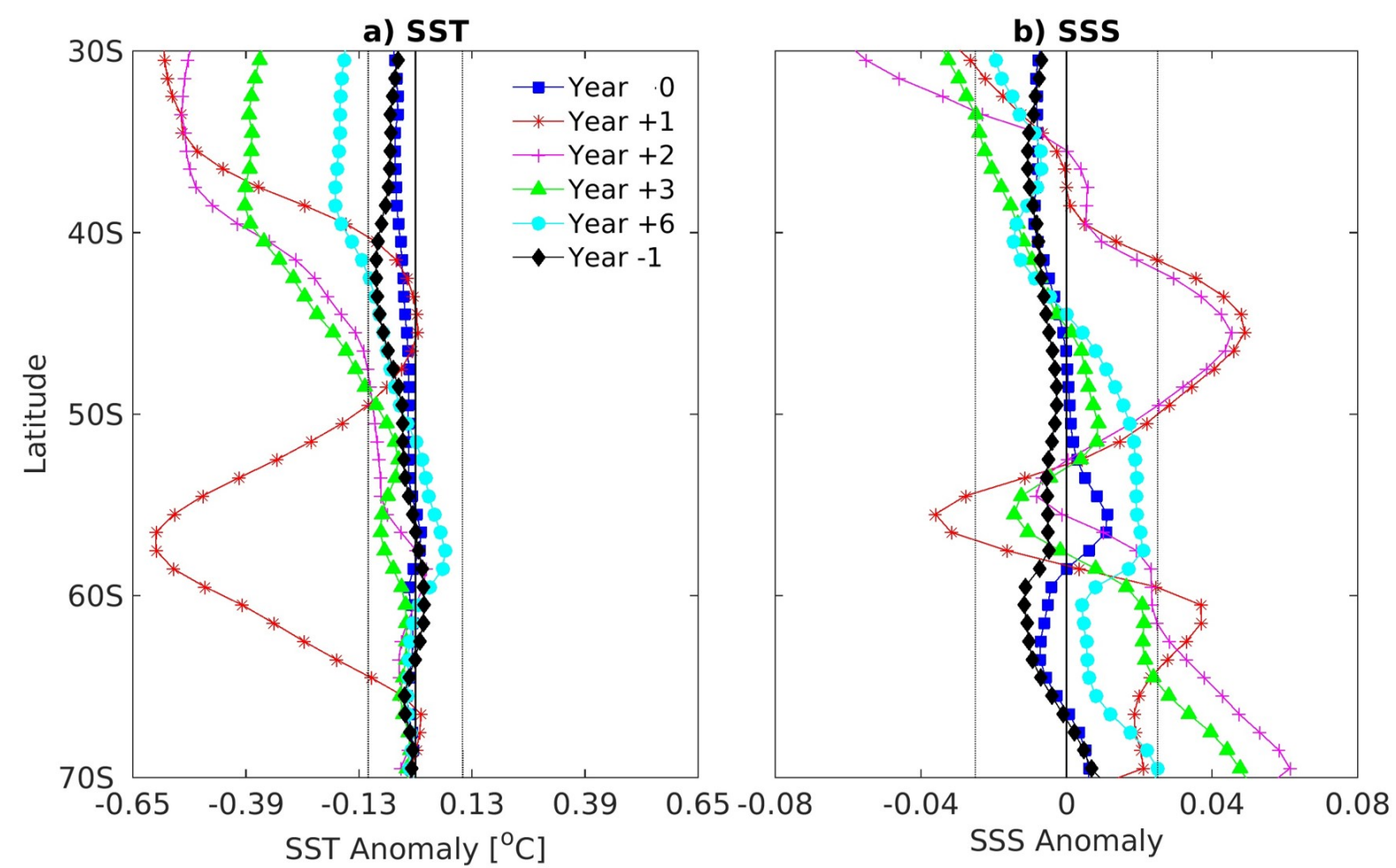

Figure 3.11: South Atlantic zonal average | (a) SST anomaly $\left[{ }^{\circ} \mathrm{C}\right]$ and (b) SSS. Each line represents a composite year that is described in the legend. The black vertical line is the \pm 1 standard deviation representing the internal variability.

SST at $\mathrm{Yr}+1$ shows a cold anomaly peak of $-0.6^{\circ} \mathrm{C}$, that is in the range of Stenchikov et al. (2009) simulation results between 1 and $0.4 \mathrm{~K}$. Fact that also agrees with Kim and Kim (2012) that have observed a cooling in their model results from 0.25 to $0.8^{\circ} \mathrm{C}$, the higher limit is for LM eruptions. The same magnitude of a negative anomaly is present in two different regions, 30S and $~ 55 \mathrm{~S}$ (Figure 3.11a). Balmaseda et al. (2013) observed with ORAs4 reanalysis for the Pacific Ocean that the greatest signal after eruptions is 
around $30 \mathrm{~N}$.

The negative anomaly in temperature around 65 S (i.e., Figure 3.11) recovers to the the background condition of $\mathrm{Yr}-1$ (black diamonds) in the second year after the eruption (Yr +2 , magenta crosses). At the same time that the northernmost $(\sim 30 \mathrm{~S})$ negative anomaly develops in 1-3 years. Pausata et al. (2015) have also observed a cooling that develops in 1-3 years after the eruption for the Pacific Ocean. Stenchikov et al. (2009) show the same for the northern hemisphere, authors discuss that this evolution happens until volcanic aerosols vanish from the atmosphere. In the CMIP5 models the evolution of the cooling due to volcanism is faster, the cooling is the lowest 1-2 years following eruptions (Ding et al., 2014). However, Ding et al. (2014) mention a longer relaxation time of SST back to its pre-eruption value of 5 to 7 years, which is close to what observed in this study. The difference in the recovery time in each latitude suggests that the perturbation due to volcanic eruptions in polar regions (south of 50S) may recover faster than in the subtropical regions (north of 50S).

On the other hand, changes in the SSS (Figure 3.11b) are not as evident as the SST ones. The $\mathrm{Yr}+1$ and +2 (red asterisks and magenta crosses, respectively) depict the same response to the volcanic event, mainly in the region between 40-50S with positive anomalies reaching 0.06. Stenchikov et al. (2009) have also observed in simulations an increase in salinity in the middle northern latitudes, which is consistent with reduction of precipitation (Trenberth and Dai, 2007). Using results from CMIP5, Ding et al. (2014) have observed increased sea surface salinity after the 1871-2005 eruptions. Anomalies come back to the background Yr-1 (black diamonds) and also get smaller than the internal variability, immediately at $\mathrm{Yr}+3$ (green triangles). This is different from what is seen in the SST behavior, that is out of the internal variability range, in the northernmost domain, even in $\mathrm{Yr}+6$. 
During the first year after the eruption $(\mathrm{Yr}+1)$, a negative anomaly of -0.04 around $55 \mathrm{~S}$ is also observed. This agrees with negative anomaly in the northern subtropics during the year following the eruption shown in Mignot et al. (2011). The authors attribute this anomaly to greater freshwater fluxes due to eruptions. In addition, Kim and Kim (2012) discuss the contribution of modified ocean convection related to changes in the SST, in the contrasting zonal salinity anomalies. The Southern Ocean is a region of positive SSS anomaly after eruptions (Kim and Kim, 2012), which is also observed in Figure 3.11b. A positive anomaly of 0.04 in $60 \mathrm{~S}$ during $\mathrm{Yr}+1$ that extends into $\mathrm{Yr}+2$ spreads poleward reaching values of 0.06 in its southernmost extension.

Both, zonal (TAUX) and meridional (TAUY) wind stress responses to the volcanic event are very well defined in the first year after the eruption $(\mathrm{Yr}+1$, red asterisks in Figure 3.12). Figures 3.12a and 3.12b, TAUX and TAUY respectively, show the largest anomalies located in the same latitudes, however with opposing signs.
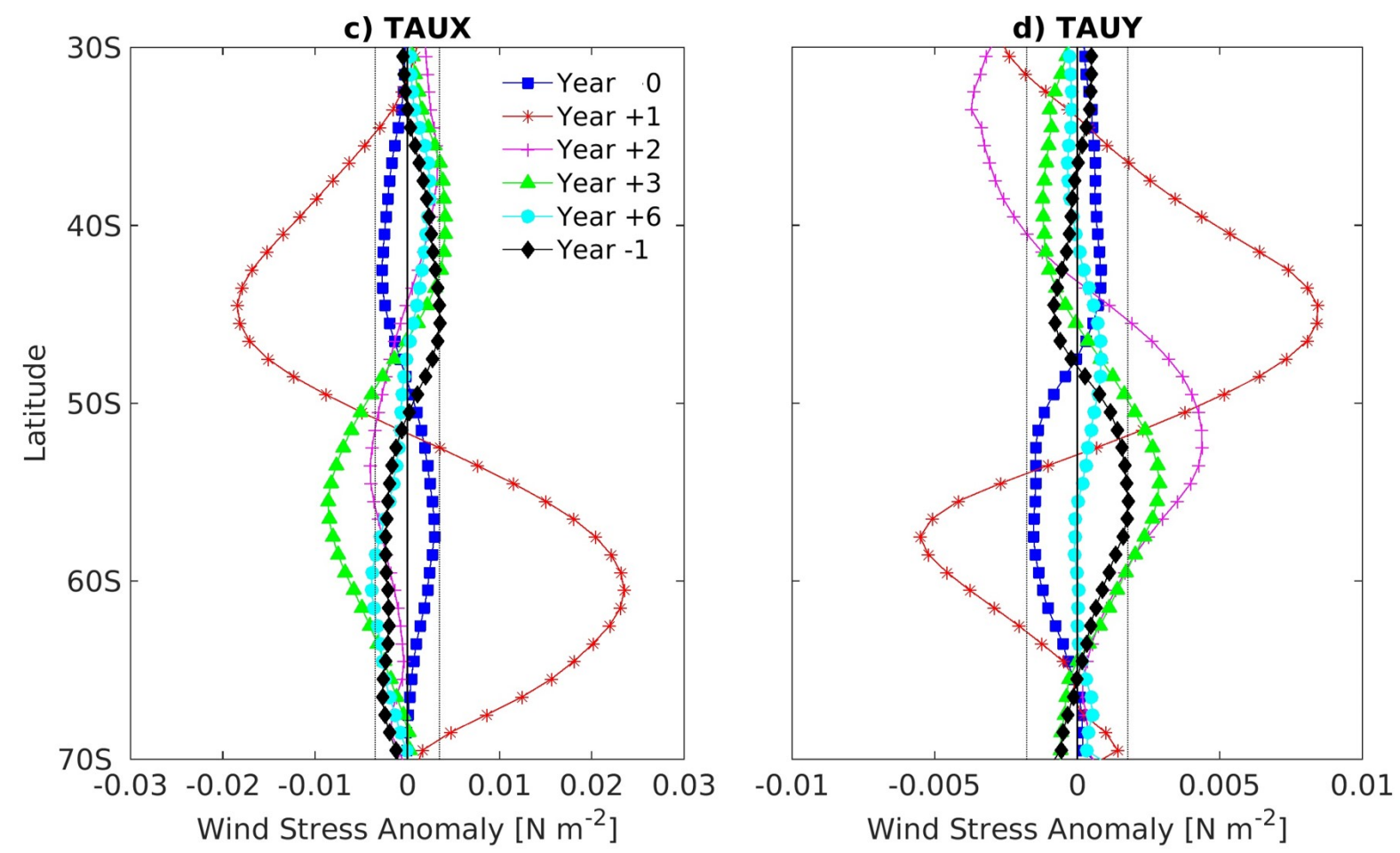

Figure 3.12: South Atlantic zonal average | (a) TAUX anomaly $\left[\mathrm{N} \mathrm{m}^{-2}\right]$ and (b) TAUY $\left[\mathrm{N} \mathrm{m}^{-2}\right]$. Each line represents a composite year that is described in the legend. The black vertical line is the \pm 1 standard deviation representing the internal variability. 
During $\mathrm{Yr}+1$ TAUX shows a positive anomaly of $0.025 \mathrm{~N} \mathrm{~m}^{-2}$ that peaks at $60 \mathrm{~S}$, while at $45 \mathrm{~S}$ the anomaly is negative $0.02 \mathrm{~N} \mathrm{~m}^{-2}$ (Figure $3.12 \mathrm{a}$ ). Results also show that TAUY largest anomaly happens during $\mathrm{Yr}+1$, with maximum values at $45 \mathrm{~S} \sim 0.01 \mathrm{~N}$ $\mathrm{m}^{-2}$, while at $60 \mathrm{~S}$ the anomaly is negative $0.006 \mathrm{~N} \mathrm{~m}^{-2}$ (Figure $3.12 \mathrm{~b}$ ). Both, TAUX and TAUY zonal average anomalies decrease in the subsequent years, getting closer to the background condition of Yr -1 (black diamonds) at Yr -3 (green triangles). Although Kim and Kim (2012) do not find any volcanic related changes in the wind circulation, present results suggest an increase in the wind magnitude after eruption (e.g., Stenchikov et al., 2009; Karpechko et al., 2010; Zanchettin et al., 2014; Stenchikov, 2016). Next, composite maps analysis focus in understanding the southern hemisphere wind changes after the eruptions, since this subject that is still in debate.

\section{Composites Maps}

Examination of the surface spatial distribution of the anomalies is useful to verify if the volcanic eruptions have a different impact depending on the region and to verify how it changes from one year to the other. Figures 3.13 to 3.16 represent air-sea properties starting in composite $\mathrm{Yr}+1$, since the volcanic response is not significant at $90 \%$ level in the year of the explosion (Yr 0). TAUX and TAUY composite maps are only shown between $\mathrm{Yr}+1$ and $\mathrm{Yr}+4$ (Figures 3.13 and 3.14), because these are the years that have greater areas where the anomaly is significant at $90 \%$ level.

Zonal wind stress anomalies are the largest in the first year after the eruption as seen in Figure 3.13a and in Figure 3.12a as well. Both results depict anomalies that are consistent with Stenchikov et al. (2009). The authors point to a decrease of TAUX at 50S, where this core of the tropospheric jet is located, and an increase at 70S. Results (Figure 3.13a) show significant negative anomaly at $45 \mathrm{~S}$ and positive anomaly at $65 \mathrm{~S}$, suggesting a poleward shift of the westerlies. This poleward shift of the prevailing westerlies is further explored in Section 3.2.4. Even after smaller eruptions than those of the LM, such as Mt. Pinatubo and El Chichón, westerlies intensification is seen (Karpechko et al., 2010). In contrast, other studies do not report changes in the zonal wind in any region of the 
globe, such as Kim and Kim (2012). For the southern hemisphere, Robock et al. (2007) also do not report tropospheric circulation changes due Mt. Pinatubo eruption.

a) $\mathrm{Yr}+1$

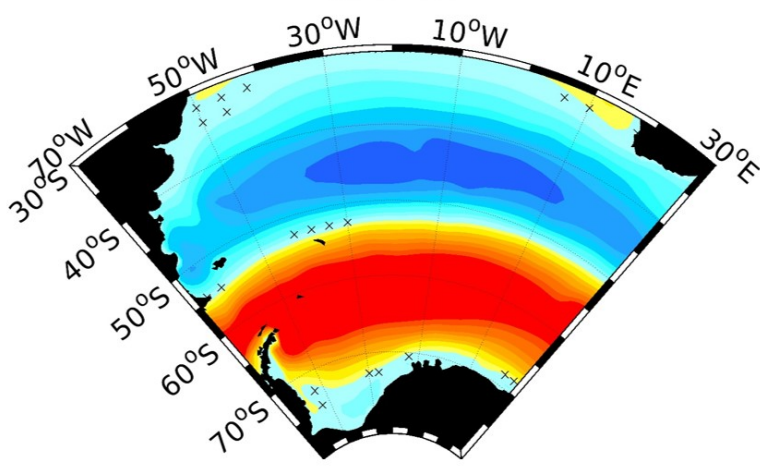

c) $\mathrm{Yr}+3$

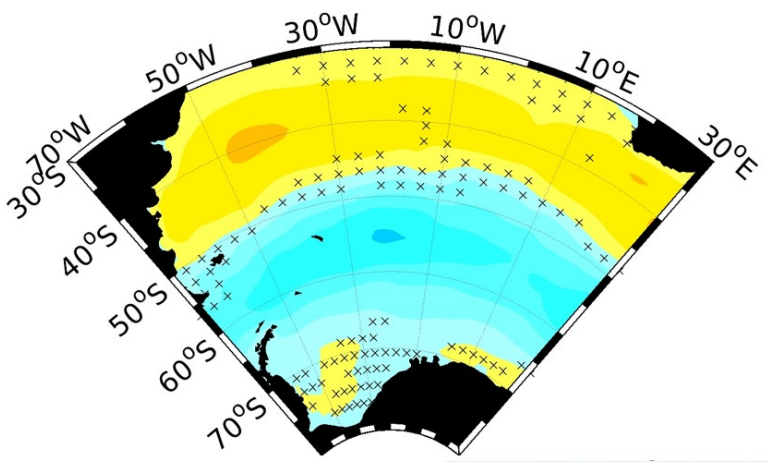

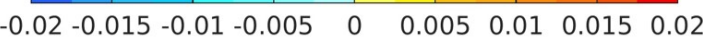

Zonal Wind Stress Anomaly $\left[\mathrm{N} \mathrm{m}^{-2}\right.$ ] b) $\mathbf{Y r}+2$

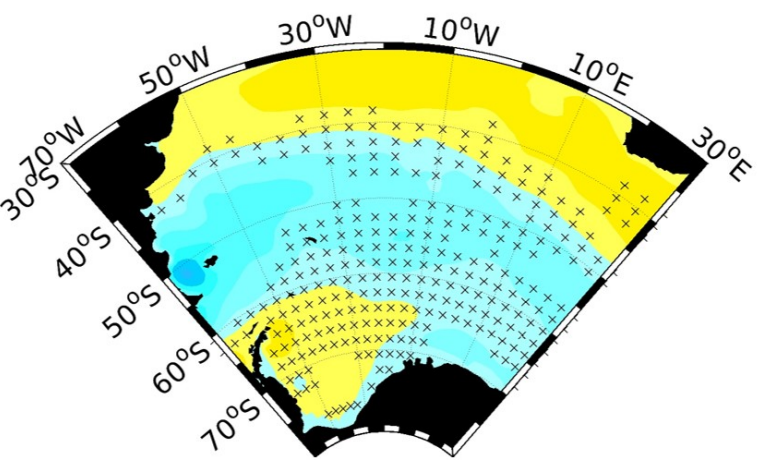

d) $\mathbf{Y r}+4$

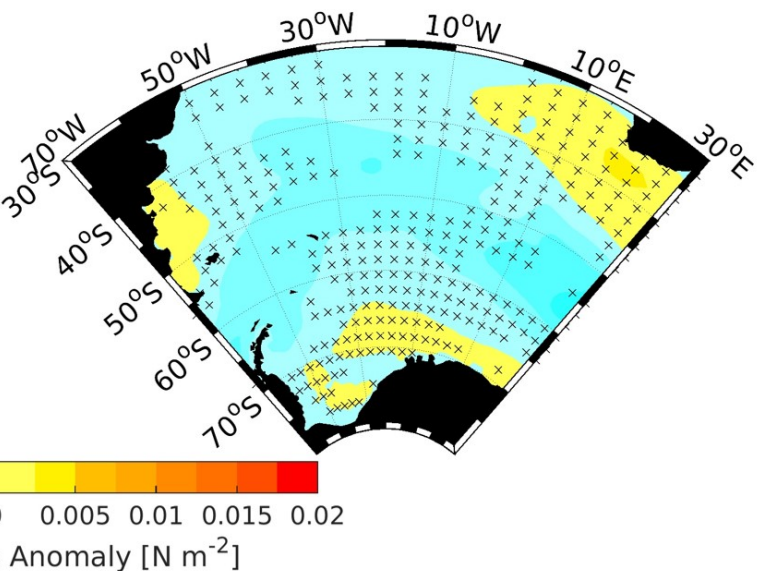

Figure 3.13: Zonal wind stress composites $\mid$ TAUX $\left[\mathrm{N} \mathrm{m}^{-2}\right]$ response to selected eruptions for (a) Yr +1 , (b) Yr +2 ,(c) $\mathrm{Yr}+3$ and (d) $\mathrm{Yr}+4$. Shown only for the austral summer (DJF). Significance levels are determined according to the WRS test, and values that are insignificant at $90 \%$ are marked with crosses.

Alterations in the wind system are expected after large eruptions, because of the heating of the tropical stratosphere by volcanic aerosols (Robock, 2000; Timmreck, 2012). This results in a stronger meridional temperature gradient (Robock, 2000; Roscoe and Haigh, 2007), then, via thermal wind balance, it translates to strengthened polar vortex, as observed in the northern hemisphere (Robock et al., 2007; Otterå, 2008; Timmreck, 2012), thus stronger winds (Karpechko et al., 2010). Results from here are in agreement with what is expected from the dynamical atmosphere response to volcanic activity.

During $\mathrm{Yr}+2$ (Figure 3.13b) the anomaly decays reaching values around $0.004 \mathrm{~N} \mathrm{~m}^{-2}$, but continues significant at $90 \%$ level. After, during the third subsequent year $(\mathrm{Yr}+3$, Figure 3.13c) the negative anomaly seems to have been displaced to the south, while the 
positive anomaly in the Weddell Sea region is not significant anymore. During $\mathrm{Yr}+4$ (Figure 3.13d) only some portions of the field are still significant. This suggests that for the zonal wind stress the volcanic signal persist up to $\mathrm{Yr}+3$.

Note that the ENSO connection with the wind circulation and volcanic activity is not examinated in this work. Li et al. (2013) discuss that ENSO is not that important before 1880. Moreover, McGraw et al. (2016) point to a more positive SAM index, which implies a more intense westerly circulation, after major tropical volcanic eruptions regardless of ENSO state. Thus, results are relevant even if ENSO is not taken into account.

The meridional wind stress perturbation shows an interesting pattern at $\mathrm{Yr}+1$ (Figure 3.14a), a significant positive anomaly of $0.01 \mathrm{~N} \mathrm{~m}^{-2}$ in the northernmost region from $30 \mathrm{~S}$ to $50 \mathrm{~S}$ and in the Weddell Sea eastern boundary. This is accompanied by a negative anomaly of the same magnitude in the south of Weddell Sea, specifically in the northern Antarctic Peninsula. Changes in the TAUY seems to be related to the poleward shift of the westerlies, which is further explored in Section 3.2.4

The same TAUY positive anomaly in the Weddell Sea is present during the second subsequent year (Figure 3.14b), however in the northern Antarctic Peninsula there is a positive anomaly of $0.0075 \mathrm{~N} \mathrm{~m}^{-2}$. At the same time that the northernmost region shows a small $\left(-0.0025 \mathrm{~N} \mathrm{~m}^{-2}\right)$, but significant negative anomaly. During $\mathrm{Yr}+3$ (Figure 3.14c) most of the anomalies in the study region are not significant. In the following year the anomalies are significant again, but smaller than during $\mathrm{Yr}+1$, probably not related to the volcanic response (Figure 3.14d). Although TAUY anomalies last less (only to Yr +2) than TAUX, the response to volcanism is meaningful. In addition, it has been little explored before, yet its an important wind component of the Weddell circulation. 

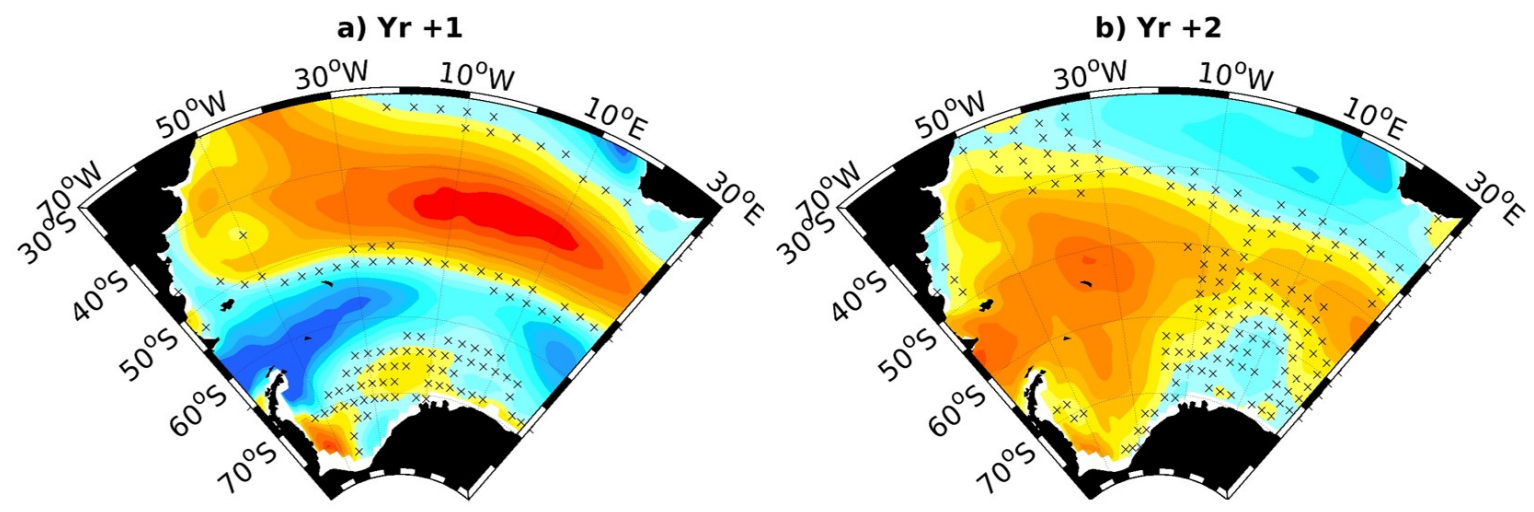

c) $\mathbf{Y r}+3$

d) $\mathbf{Y r}+4$

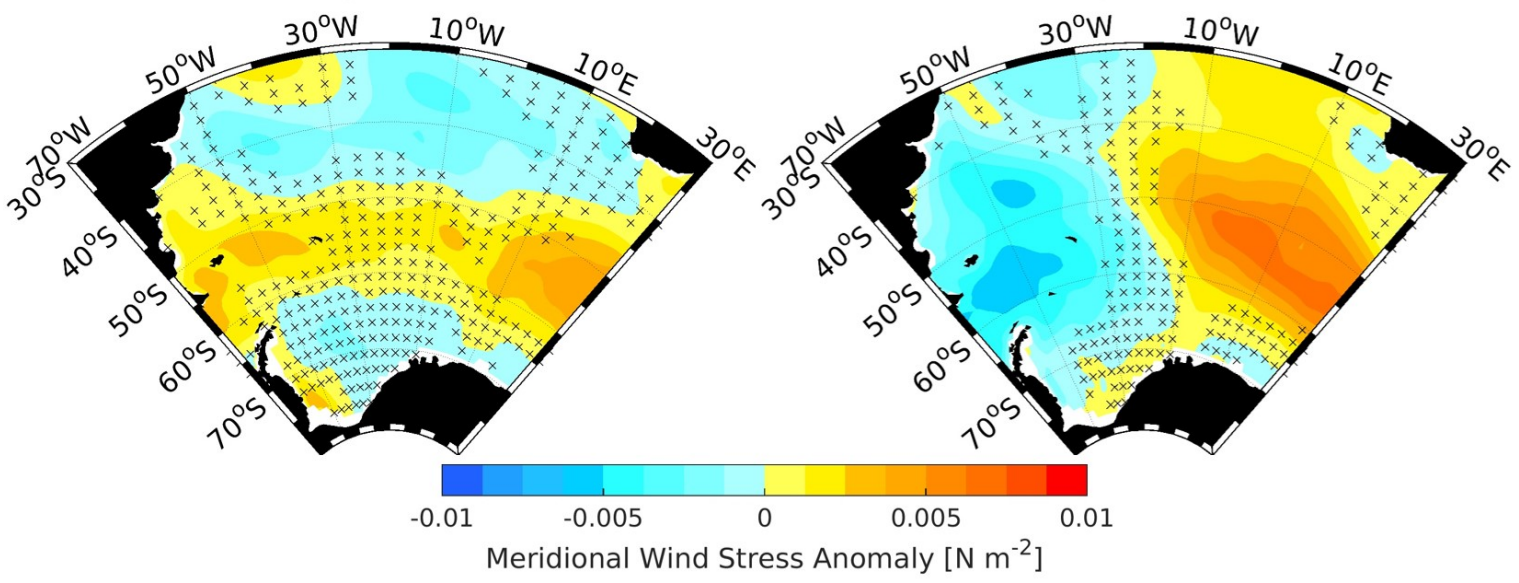

Figure 3.14: Meridional wind stress composites | TAUY $\left[\mathrm{N} \mathrm{m}^{-2}\right]$ response to selected eruptions for (a) $\mathrm{Yr}+1$, (b) $\mathrm{Yr}+2$,(c) $\mathrm{Yr}+3$ and (d) $\mathrm{Yr}+4$. Shown only for the austral summer (DJF). Significance levels are determined according to the WRS test, and values that are insignificant at $90 \%$ are marked with crosses.

SST and SSS composite results are shown between $\mathrm{Yr}+1$ and $\mathrm{Yr}+5$ in Figures 3.15 and 3.16. The cold anomaly north of $60 \mathrm{~S}$ in the SST field shown in Figure 3.15a is what is expected as the thermodynamic response to volcanic explosions (e.g., Robock, 2000; Church et al., 2005; Stenchikov et al., 2009; Mignot et al., 2011; Timmreck, 2012; Ding et al., 2014; Pausata et al., 2015; Stenchikov, 2016). Figure 3.15a shows negative anomalies ranging between 0.2 and $0.8^{\circ} \mathrm{C}$. However, a significant positive temperature anomaly in the Weddell Sea is also seen in $\mathrm{Yr}+1$, that reaches $0.8^{\circ} \mathrm{C}$. $\mathrm{Yr}+2$ (Figure $3.15 \mathrm{~b}$ ) still shows a strong negative anomaly in the northernmost region, the positive temperature anomaly in the Weddell Sea seems to have spread and is less intense. The same is observed in $\mathrm{Yr}+3$ (Figure 3.15c). A plausible mechanism explaining the anomalous positive SST after eruptions is discussed in Section 3.2.4. 

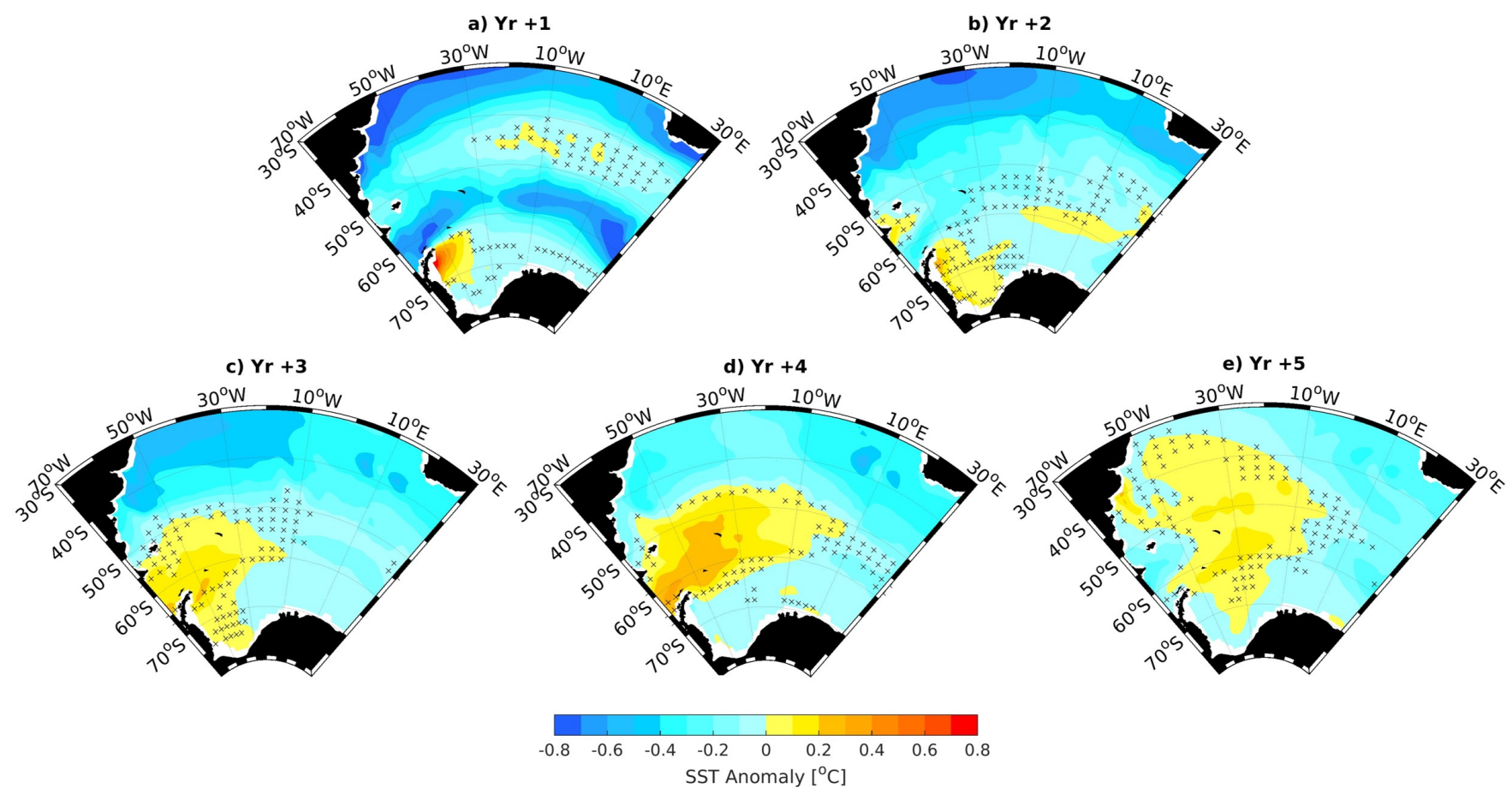

Figure 3.15: SST composites $\mid \mathrm{SST}\left[{ }^{\circ} \mathrm{C}\right]$ response to selected eruptions for (a) $\mathrm{Yr}+1$, (b) $\mathrm{Yr}+2$,(c) $\mathrm{Yr}+3$, (d) $\mathrm{Yr}+4$ and (e) $\mathrm{Yr}+5$. Shown only for the austral summer (DJF). Significance levels are determined according to the WRS test, and values that are insignificant at $90 \%$ are marked with crosses.

During $\mathrm{Yr}+4$ (Figure 3.14d) the cold anomaly in the north domain has become smaller than in $\mathrm{Yr}+1$, yet significant. In the same year there is a warm plume in the Drake Passage, which is also observed in Mignot et al. (2011), significant from years +3 to +5 .

In the following year (Figure 3.15e, $\mathrm{Yr}+5$ ) anomalies are similar to the previous year, only with decreased warm surface anomaly. Thus, the volcanic signal in the SST persists from four to five years after the eruption, fact that agrees with Church et al. (2005) results. On the other hand, Stenchikov et al. (2009) and Kim and Kim (2012) have observed SST recovery in the third year after the eruption. In fact, the signal persistence seems to be very dependent on the region, which points to the importance of regional analysis following eruptions.

In the SSS field, during $\mathrm{Yr}+1$ (Figure 3.16a), there is significant positive anomaly of 0.14, which shows two cores: one in the northern Weddell Sea near the Antarctic Peninsula and the other at 40S. The overall increased surface salinity after eruptions 
agrees with previous studies (e.g., Stenchikov et al., 2009; Kim and Kim, 2012; Ding et al., 2014; Stenchikov, 2016). Even though the anomalies are not located in regions of dense water formation, the cold and saltier anomalies after eruptions have been suggested as an important factor responsible for strengthening the AMOC (Otterå et al., 2010; Mignot et al., 2011; McGregor et al., 2015; Pausata et al., 2015).
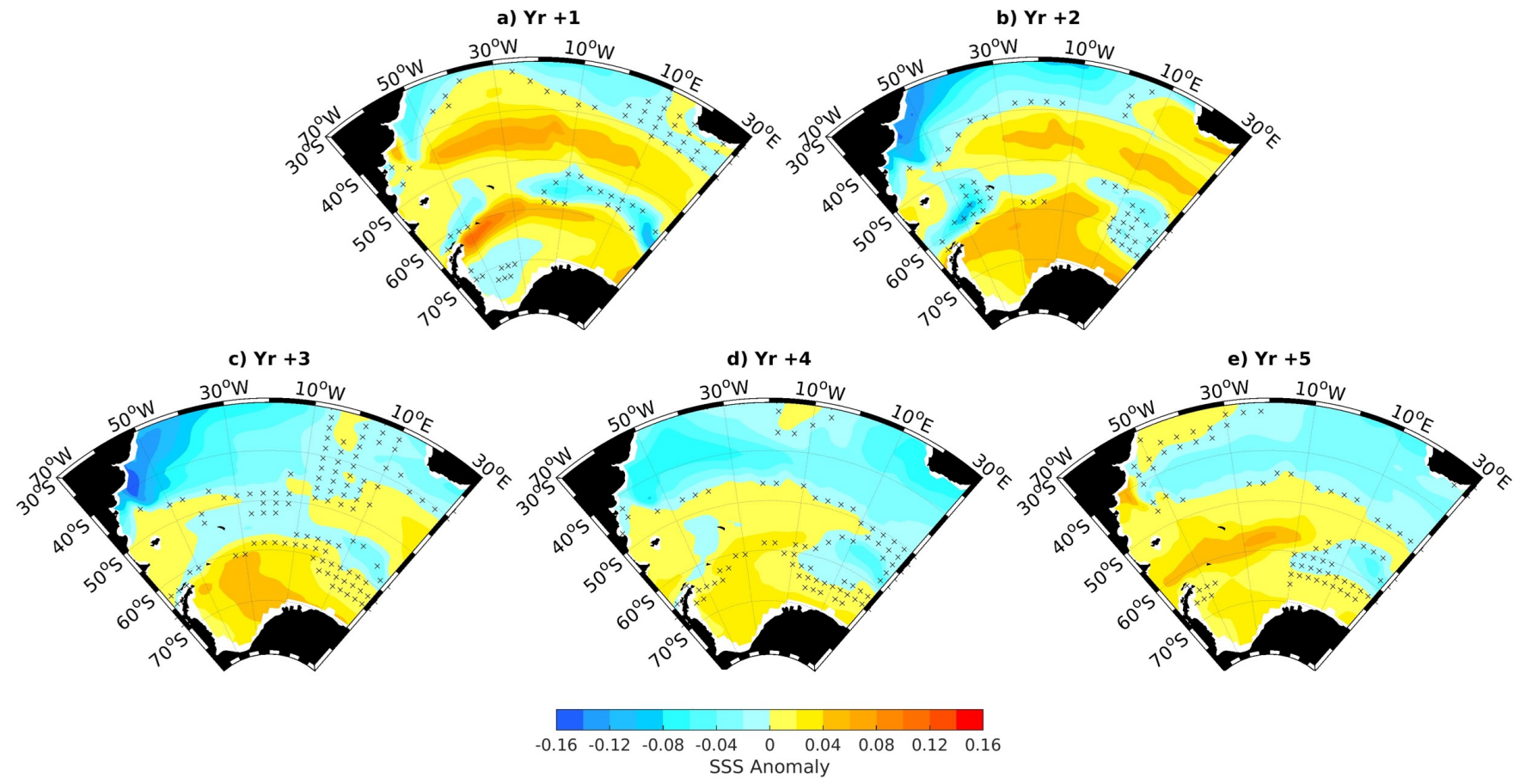

Figure 3.16: SSS composites | SSS response to selected eruptions for (a) Yr +1 , (b) Yr +2 , (c) $\mathrm{Yr}+3$, (d) $\mathrm{Yr}+4$ and (e) $\mathrm{Yr}+5$. Shown only for the austral summer (DJF). Significance levels are determined according to the WRS test, and values that are insignificant at $90 \%$ are marked with crosses.

In the next year $(\mathrm{Yr}+2$, Figure 3.16b), the salty cores remain almost the same, but are accompanied by a fresher anomaly of $\sim 0.1$ at the South American coast. At $\mathrm{Yr}+3$ and +4 almost the same pattern of weaker positive anomaly in the Weddell Sea can be seen in Figures 3.16c and 3.17d, but during $\mathrm{Yr}+3$ there is a stronger negative anomaly. Mignot et al. (2011) observed a negative sea surface salinity anomaly as well, but in the northern subtropics, that was attributed to increased freshwater inputs. At the same time, Trenberth and Dai (2007) discuss a decrease in global precipitation and discharge. Further studies are necessary to understand the mechanism that controls the negative salinity near South America in Earth System Models, which is not the present focus.

Finally, during $\mathrm{Yr}+5$ (Figure 3.16e) there is still large regions showing significant, 
but small anomalies, therefore the salinity seems to recover approximately within the same period as the SST. This is different, from what is observed in Figure 3.21b, that shows salinity recovery after $\mathrm{Yr}+3$, because of the averaged area that probably masks the real spreading of the spatial anomaly.

\section{Last Millennium Individual Events}

Two specific eruptions are analyzed to verify if there is volcano location dependency in the air-sea properties response. All seven eruptions (Table 2.1) have been tested and two representative ones from different location and intensities were chosen. The representative tropical eruption is the well known Tambora explosion on 10 April 1815 in the Indonesia region. For the south hemisphere 1341 eruption is chosen (see Figure 2.2), the specific location of this eruption is not known. The individual events are shown only for the first and second austral summers after each eruption $(\mathrm{Yr}+1$ and +2$)$.

In the Tambora eruption the wind stress, shown in Figure $3.17 \mathrm{c}, \mathrm{f}$, has intensified during the first austral summer after the eruption, as the same seen in the composite analysis (Figure 3.13a). In the following year the anomaly gets weaker. The SST (Figure 3.17a) also shows a pattern very similar to the composite average during the first year after the eruption (Figure 3.15a), a cold anomaly in the northernmost region that reaches $0.6^{\circ} \mathrm{C}$ and the anomalous warming in the Weddell Sea near the Antarctic Peninsula. However, it also shows a positive temperature anomaly in the central region of the South Atlantic Ocean, between $40 \mathrm{~S}$ and 50S, that is not evident in the composite average. 

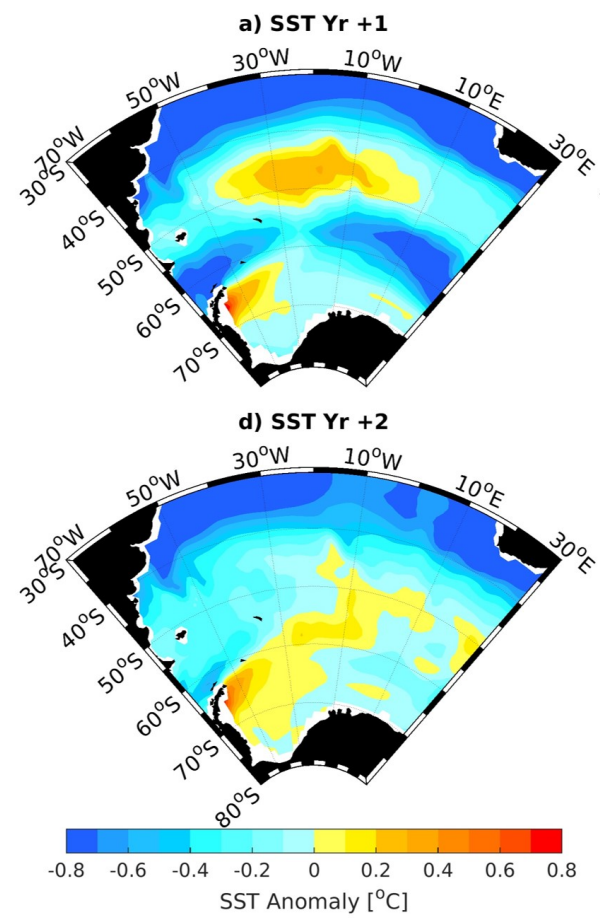

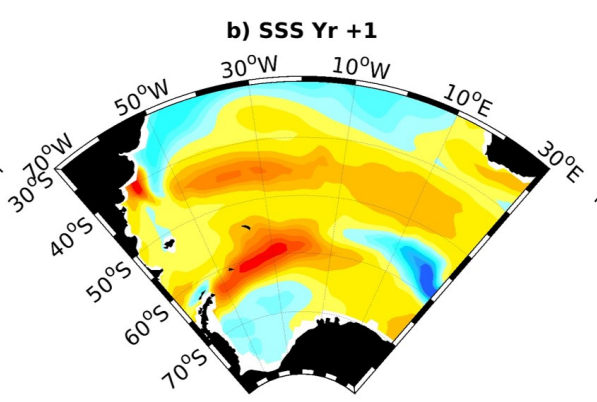

e) SSS Yr +2

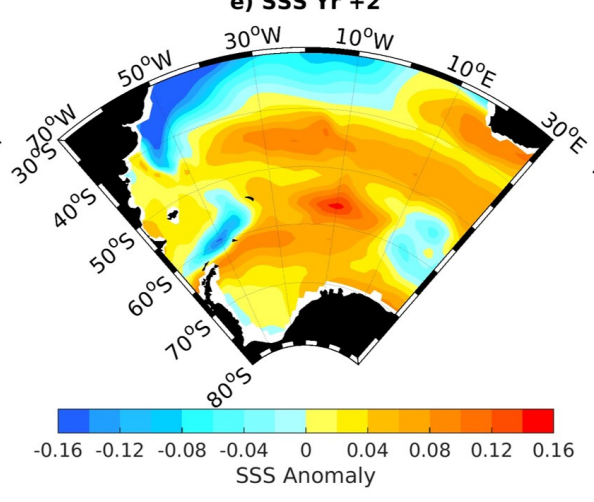

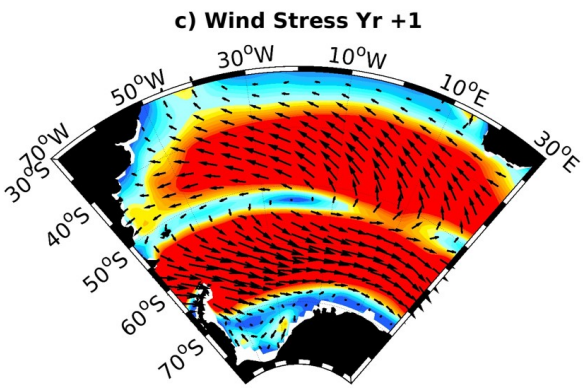

f) Wind Stress $\mathrm{Yr}+2$

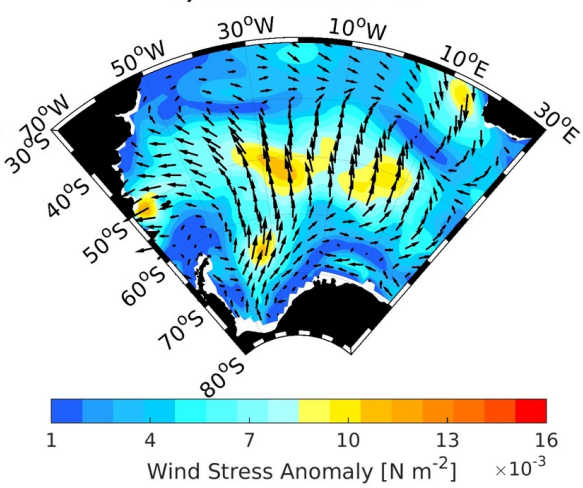

Figure 3.17: Tambora (1815) eruption | Response for $\mathrm{Yr}+1$ (first line) and $\mathrm{Yr}+2$ (second line) for $[(\mathbf{a}),(\mathbf{d})] \operatorname{SST}\left[{ }^{\circ} \mathrm{C}\right],[(\mathbf{b}),(\mathbf{e})] \operatorname{SSS}$ and $[(\mathbf{c}),(\mathbf{f})]$ wind stress $\left[\mathrm{N} \mathrm{m}^{-2}\right]$ in which the magnitude is in the background and vectors represent the direction.

In the following year $(\mathrm{Yr}+2$, Figure $3.17 \mathrm{~d})$ the positive temperature anomaly present in the Weddell Sea remains with the same magnitude. This is different from what is shown in the composite pattern, where the SST anomaly has decreased to half. It also seems to have spread northward mixing with the central anomaly present since $\mathrm{Yr}+1$. Surface salinity (Figure 3.17a,e) shows a similar pattern to the composite average, strong positive anomalies 0.16 mainly in the northern Antarctic Peninsula and a core in 40-50S. In addition to a fresh anomaly of the same magnitude at the South American coast that appears only in the second subsequent year.

As shown in Figure 3.18c,f, wind stress response to the 1341 eruption have also shown a positive anomaly. Even though this volcanic eruption was weaker than the Tambora explosion, the wind stress positive anomaly is of the same magnitude, but covering a smaller area. The same happens for SSS (Figure 3.18b,e), with positive anomalies covering almost the whole domain in $\mathrm{Yr}+1$, decreasing in the following year. 


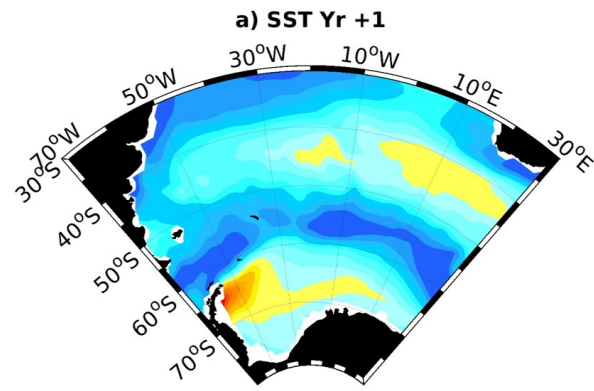

d) SST Yr +2

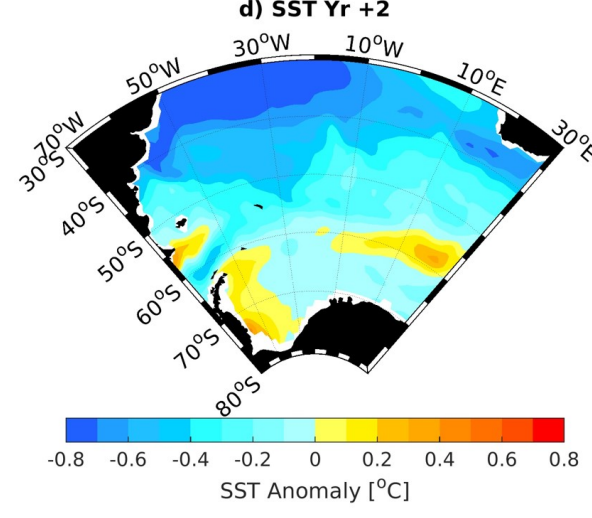

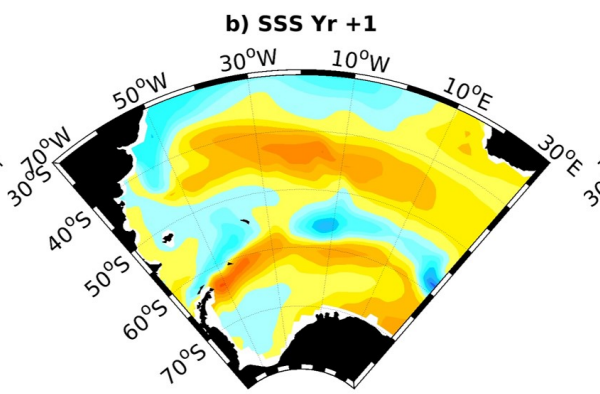

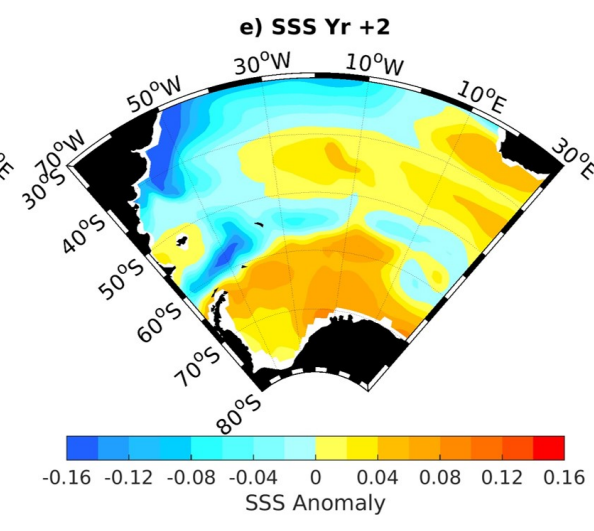

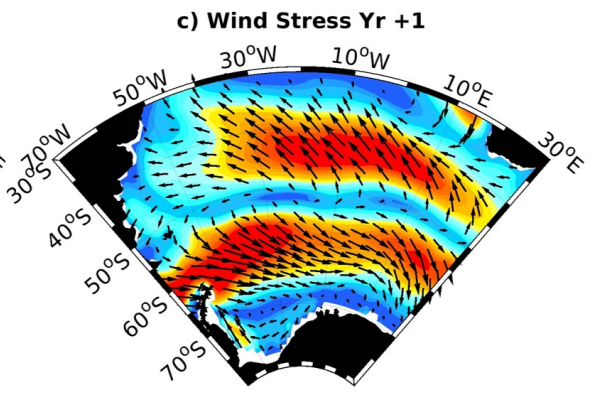

f) Wind Stress $\mathrm{Yr}+2$

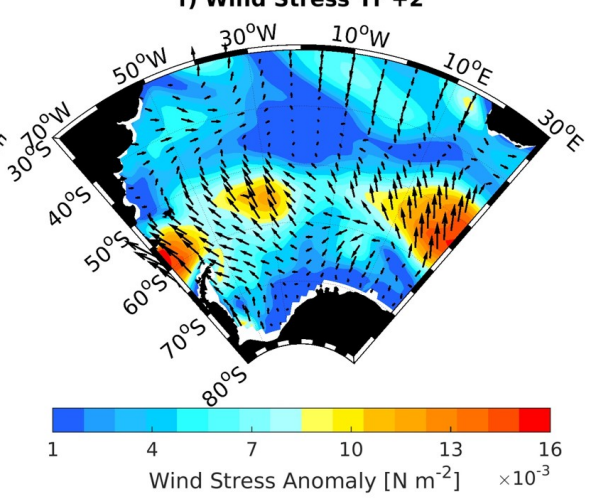

Figure 3.18: 1341 eruption | 1341 eruption response for $\mathrm{Yr}+1$ (first line) and $\mathrm{Yr}+2$ (second line) for $[(\mathbf{a}),(\mathbf{d})] \operatorname{SST}\left[{ }^{\circ} \mathrm{C}\right],[(\mathbf{b}),(\mathbf{e})] \mathrm{SSS}$ and $[(\mathbf{c}),(\mathbf{f})]$ wind stress $\left[\mathrm{N} \mathrm{m}^{-2}\right]$ in which the magnitude is in the background and vectors represent the direction.

The SST shows the same warming in the Weddell Sea region during the first year after the eruption (Figure 3.18a), however the cold anomaly is much more spread out in the region, reaching values of $0.8^{\circ} \mathrm{C}$. This may be related to the volcano location that is in the southern hemisphere, so there is a stronger response in SST to the radiative effect. During $\mathrm{Yr}+2$ (Figure 3.18d) the cold anomaly is zonal north of 50S, at the same time that the positive anomaly has decreased and spread to the Weddell Sea interior.

Therefore, the individual volcanic eruptions from the LM show overall the same pattern of the composite average. Even though some differences have been pointed, the anomalous warming in the Weddell Sea is present in all, thus it is not an effect of the composite method. The size of the eruption affect the air-sea properties response (Meronen et al., 2012; Sigl et al., 2015), results (e.g., Figure 3.18c and 3.17c) show eruption size dependency in the wind response. However, the size dependency may be masked by the different volcano location. 


\subsubsection{Vertical Analysis}

\section{Vertical Sections}

Composite years of the potential temperature section in the Greenwich Meridian (0W) are shown in Figure 3.19. The vertical sections starts from the first $15 \mathrm{~m}$, that is the first vertical level from the CESM-LME, to 3000m depth. There is an evident cold anomaly of $0.4^{\circ} \mathrm{C}$, mostly from $15 \mathrm{~m}$ to $100 \mathrm{~m}$ depth, between $60-50 \mathrm{~S}$ and $40-30 \mathrm{~S}$ that starts at $\mathrm{Yr}+1$ (Figure 3.19a). Fact that is consistent with Ding et al. (2014) findings, the authors have estimated a effective mixing depth in which the cooling is distributed of $85 \mathrm{~m}$. Stenchikov et al. (2009) have pointed that the cold water begins to penetrate to depth around 40S, which agrees with what is observed in this vertical section. The anomalies spread into depth first north of 50S, implying that the subtropical regions are probably responding first to the eruptions.

In the following year ( $\mathrm{Yr}+2$, Figure 3.19b) the cold anomaly has spread its signal in depth. South of $50 \mathrm{~S}$ the anomaly near the surface disappears, but there is still a cold core between 100 and $250 \mathrm{~m}$. In contrast to the region north of 60S, where the cold anomaly is deeper around 1000m. As described in Mignot et al. (2011) and Kim and Kim (2012) the cold anomaly reaches its largest depth 2 to 3 years after the eruption, which is explained by deep convective mixing. Even during $\mathrm{Yr}+6$ there is still a small cold anomaly $\left(\sim-0.1^{\circ} \mathrm{C}\right)$ at depth. There are not changes in the isopycnals.

The potential temperature section near the Antarctic Peninsula (54W) has been also analyzed to verify the spreading of the positive temperature anomaly already observed at the surface (Figure 3.20). Contrary to the Greenwich Meridian section, during the first year after the eruption (Figure $3.20 \mathrm{a})$ there is a positive temperature anomaly $\left(0.4^{\circ} \mathrm{C}\right)$ south of $60 \mathrm{~S}$, from $15 \mathrm{~m}$ to $100 \mathrm{~m}$. At the same time, the cold anomaly of $0.4^{\circ} \mathrm{C}$ north of $60 \mathrm{~S}$ is present as in the $0 \mathrm{~W}$ section, spreading to $100 \mathrm{~m}$ depth. 

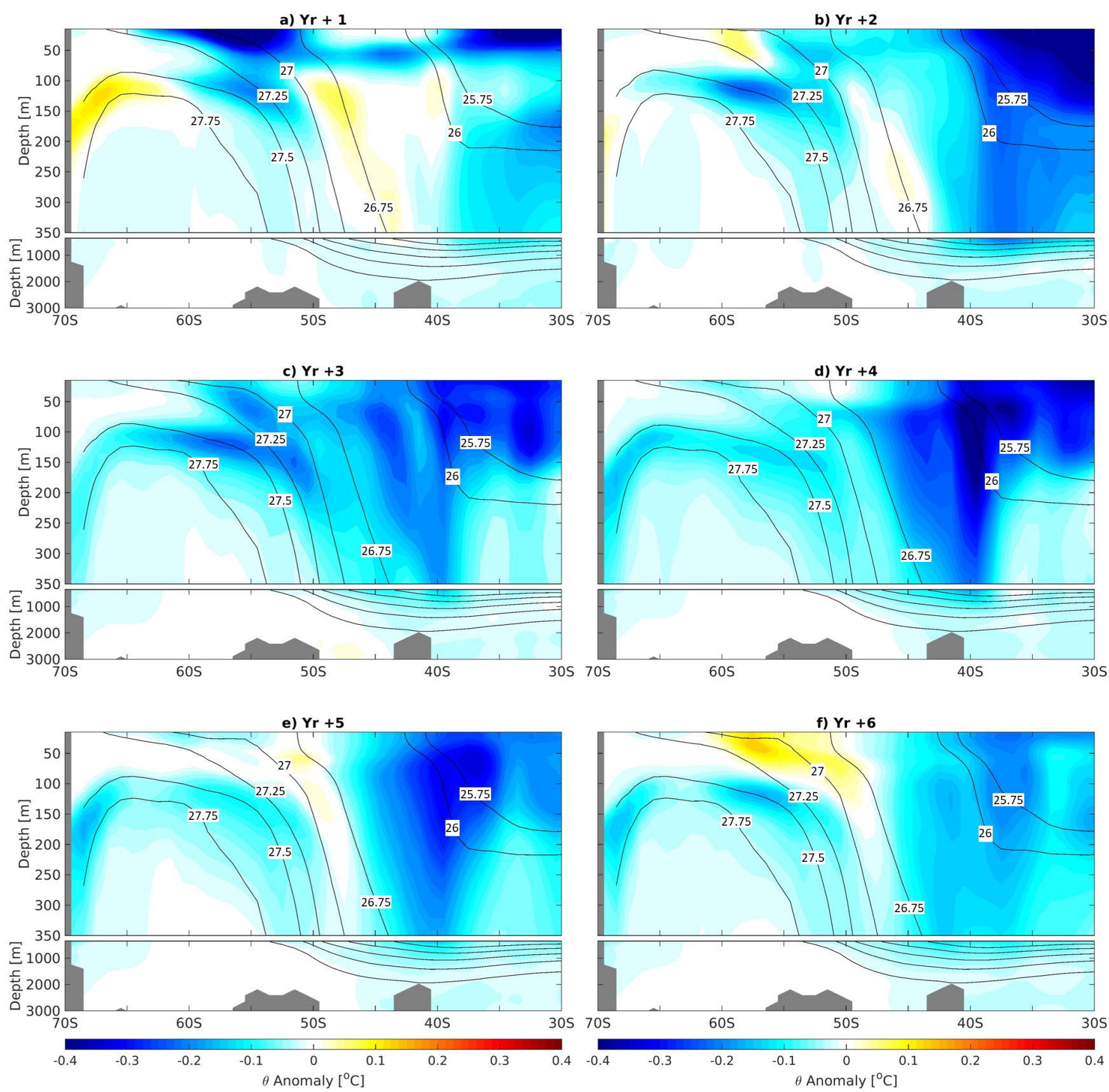

Figure 3.19: Greenwich Meridian (0W) section | Composite potential temperature $\left[{ }^{\circ} \mathrm{C}\right]$ response to the selected eruptions. From $\mathrm{Yr}+1$ to $\mathrm{Yr}+6$ after the eruption, respectively $[(\mathbf{a})-(\mathbf{f})]$. Black lines represent isopycnals.

In the second austral summer after the eruption (Figure 3.20b) the positive temperature anomaly has weaken and disappears from the surface at $\mathrm{Yr}+4$, staying only at the subsurface (Figure 3.20d). The positive temperature anomaly seems to sink because of the increased salinity in the same region, which is shown in Figure 3.21 and further discussed in the vertical Hovmöller subsection. 

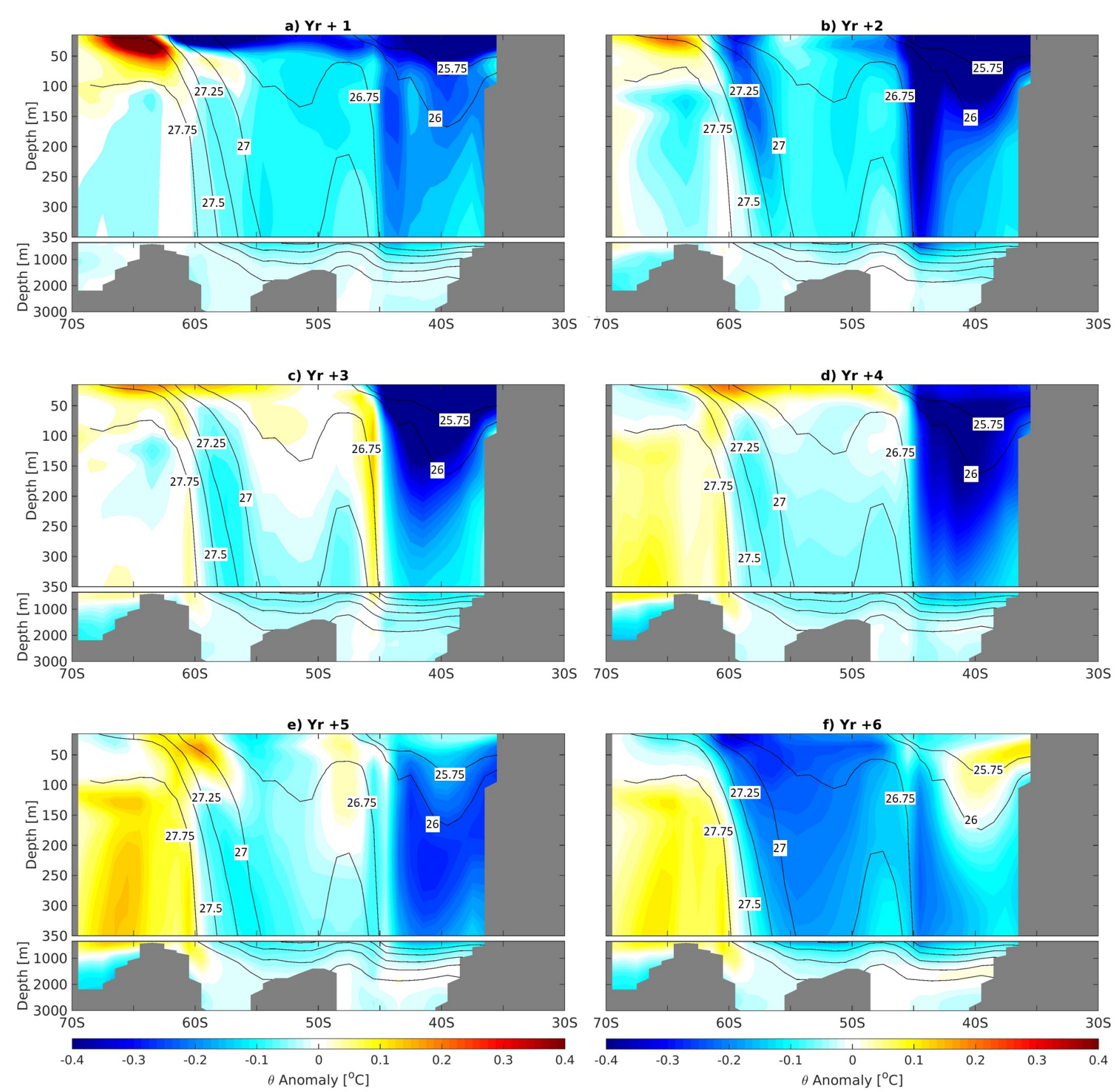

Figure 3.20: Antarctic Peninsula (54W) section | Composite potential temperature $\left[{ }^{\circ} \mathrm{C}\right]$ response to the selected eruptions. From $\mathrm{Yr}+1$ to $\mathrm{Yr}+6$ after the eruption, respectively [(a)-(f)]. Black lines represent isopycnals.

At the same time, the cold anomaly of $0.35^{\circ} \mathrm{C}$ seems to spread to even deeper layers $\sim 1000 \mathrm{~m}$, as also noted by Ding et al. (2014). In this section the anomalies, independent of their signal, respect the isopycnals distribution as in the $0 \mathrm{~W}$ section. At $\mathrm{Yr}+5$ (Figure 3.20e) a positive anomaly smaller than $0.1^{\circ} \mathrm{C}$ is located at the subsurface between 100 and $1000 \mathrm{~m}$ depth. 
At $\mathrm{Yr}+6$ (Figure 3.20f) the cold anomaly at the surface has been displaced southward (between 45-60S). Different from what is observed at 0W, in which the cold anomaly during $\mathrm{Yr}+6$ only spreads south up to 45S. Fact that agrees with Kim and Kim (2012) results of the cold signature persistence around 50S. The difference in the anomaly spreading in each vertical section is probably related to the latitude where the isopycnals reach the surface. Although there are differences in both sections, the cold anomaly is still meaningful at $\mathrm{Yr}+6$ with values ranging $0.06-0.3^{\circ} \mathrm{C}$. Thus, the subsurface recovery time scale is longer, because of the absence of air-sea fluxes (Delworth et al., 2005). In addition, it may show a cumulative effect from near placed eruptions such as 1809 and 1815.

The cold anomaly that penetrates the layers around $1000 \mathrm{~m}$ is small $\sim 0.025^{\circ} \mathrm{C}$, agreeing with Ding et al. (2014) that found 0-1000m negative temperature anomalies of roughly 0.03K. Stenchikov et al. (2009) and Kim and Kim (2012) have observed smaller values of $0.005^{\circ} \mathrm{C}$. However, the signal in the deeper layers is better evaluated in averages of the OHC as in Church et al. (2005), because the changes are very small and hard to separate from internal variability. The cooling signal is detected even in layers deeper than $2000 \mathrm{~m}$ (Stenchikov et al., 2009; Stenchikov, 2016). However, it is not yet meaningfully observed in this analysis, which is probably due to the short analysis period, considering that the spreading of the cold signal to the deeper ocean may take 15-20 years (Church et al., 2005; Stenchikov et al., 2009).

Most of the literature focuses only in the temperature signal spreading into depth, here the salinity anomaly is analyzed for the same sections (Figures 3.21 and 3.22). The salinity behavior along depth is not as well defined as temperature, but it still respects the isopycnal distribution. For the Greenwich Meridian section, at Yr +1 (Figure 3.21a) a positive salinity anomaly (0.05) appears at the surface south of $40 \mathrm{~S}$ approximately to $100 \mathrm{~m}$ depth. North of $40 \mathrm{~S}$ there is a fresher anomaly $(-0.03)$ from $15 \mathrm{~m}$ to $150 \mathrm{~m}$ depth. 

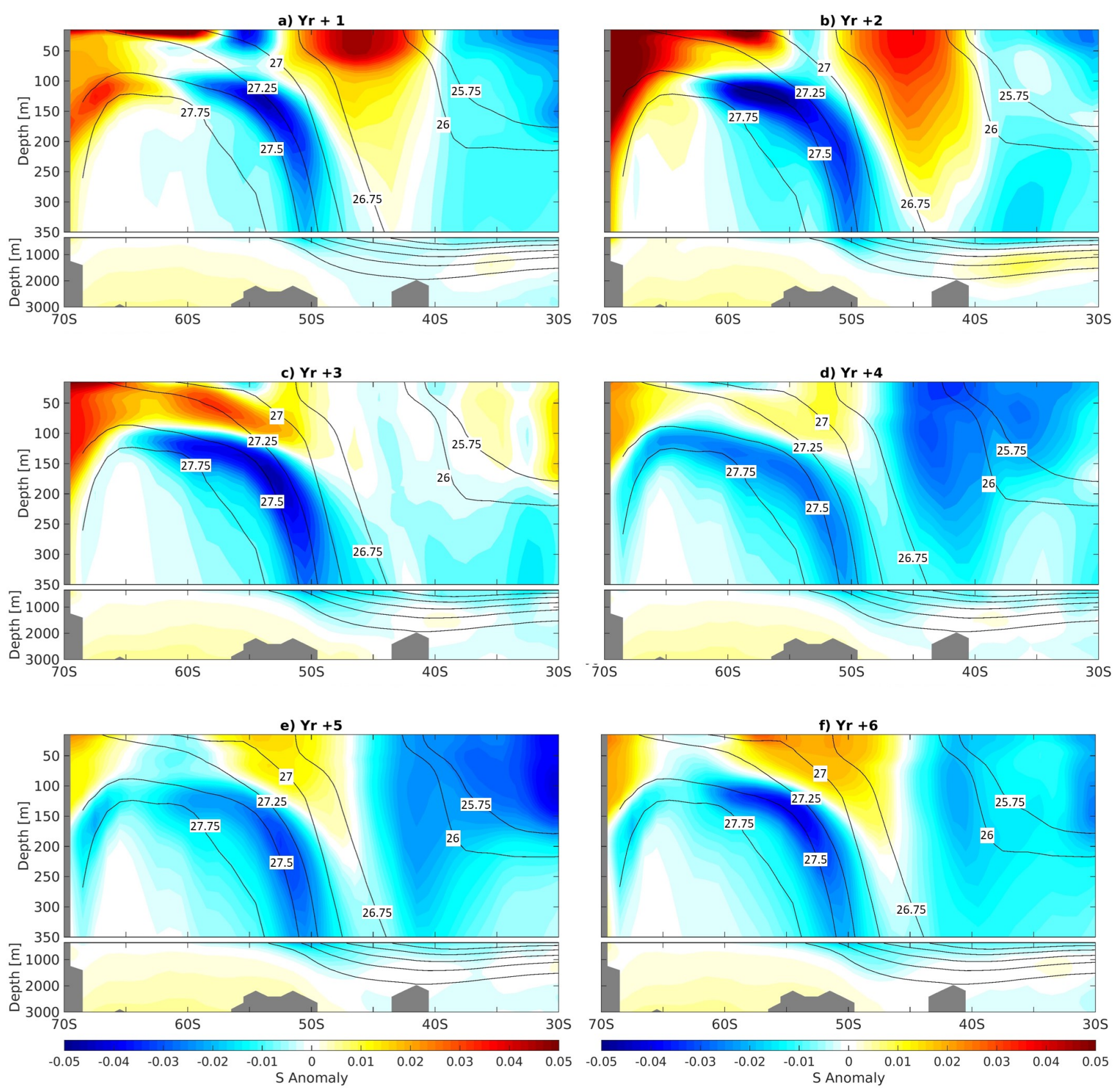

Figure 3.21: Greenwich Meridian (0W) section | Composite salinity response to the selected eruptions. From $\mathrm{Yr}+1$ to $\mathrm{Yr}+6$ after the eruption, respectively [(a)-(f)]. Black lines represent isopycnals.

In deeper layers $100-250 \mathrm{~m}$, following the 27.25 isopycnal, there is also a negative anomaly of 0.05 , which seems to spread to even deeper layers and shift to the south in the subsequent years (Figure 3.21a,b,c). At Yr +3 (FIgure 3.21c) the saltier anomaly is confined in the southernmost region reaching only $\sim 200 \mathrm{~m}$ depth. After this year the positive anomaly is much weaker (Figure $3.21 \mathrm{~d}, \mathrm{e}, \mathrm{f}$ ). 
For the Antarctic Peninsula section (Figure 3.22), a similar patter emerges. In the first year after the eruption (Figure 3.22a) a saltier anomaly is concentrated at the surface ( 50m) south of $60 \mathrm{~S}$ and the fresh anomaly is near the surface north of $40 \mathrm{~S}$, but with smaller magnitude $(\sim-0.01)$ and in deeper layers it extends to 60S.
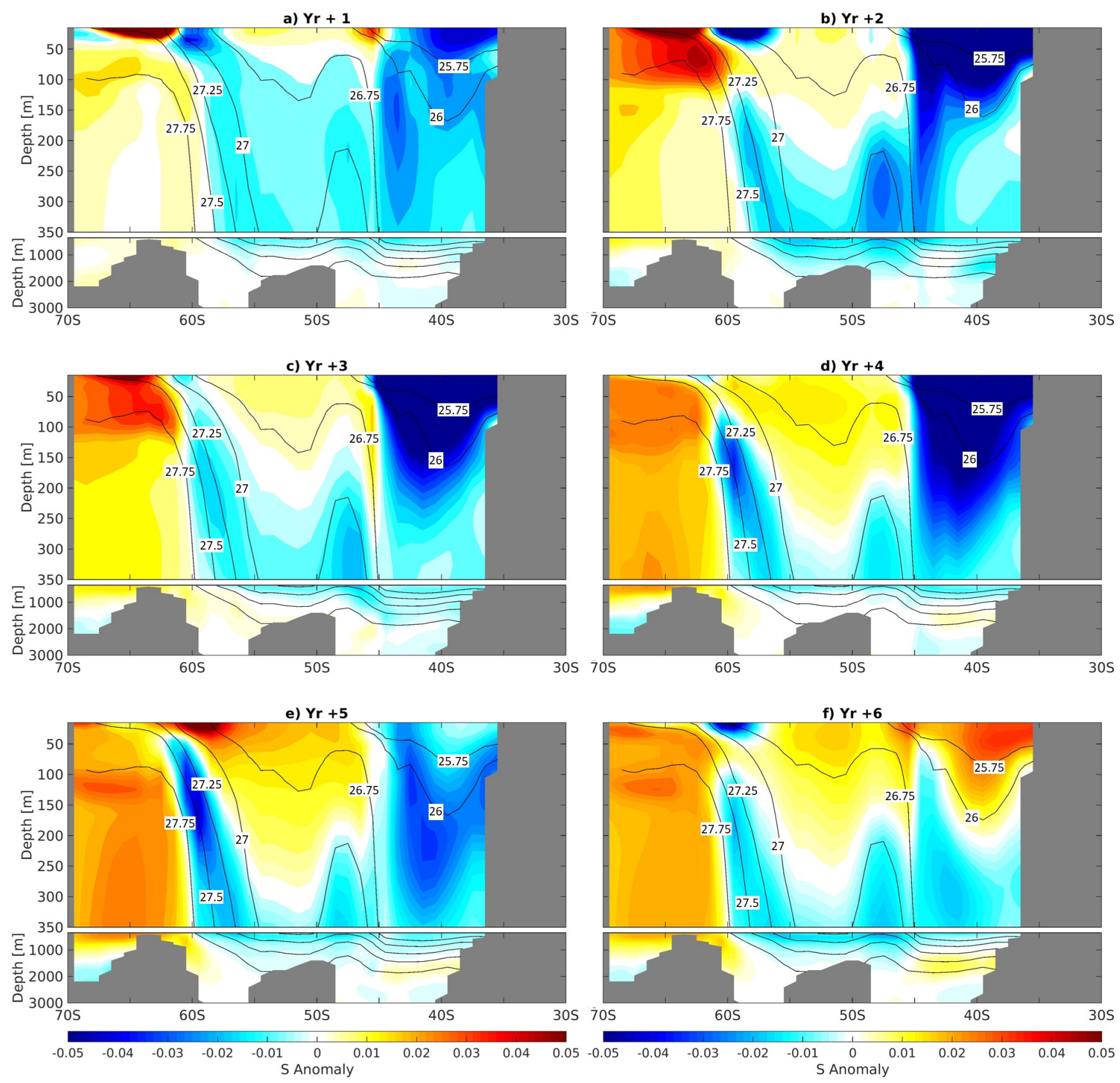

Figure 3.22: Antarctic Peninsula (54W) section | Composite salinity response to the selected eruptions. From $\mathrm{Yr}+1$ to $\mathrm{Yr}+6$ after the eruption, respectively [(a)-(f)]. Black lines represent isopycnals. 
During the subsequent year (Figure 3.22) the saltier anomaly extends into deeper layers $\sim 1000 \mathrm{~m}$ and keeps the same until $\mathrm{Yr}+6$ (Figure 3.22f). The positive anomaly is no longer found at the surface layer at $\mathrm{Yr}+4$ (Figure $3.22 \mathrm{~d}$ ) south of $60 \mathrm{~S}$. There is smaller positive anomaly at the surface north of $60 \mathrm{~S}$, which has spread in $\mathrm{Yr}+6$ (Figure 3.22f). This is different from what is observed in the $0 \mathrm{~W}$ section, that has a negative anomaly in this region for all composites years (Figure 3.21). At $\mathrm{Yr}+6$ anomalies remain meaningful, suggesting that salinity is probably perturbed for as long as temperature.

Both salinity sections show roughly a similar pattern of positive anomaly near the surface and a negative anomaly in the deeper layers, mostly in the regions where isopycnals reach the surface $\sim 45-60 \mathrm{~S}$ and $50-65 \mathrm{~S}$ for $0 \mathrm{~W}$ and $54 \mathrm{~W}$, respectively. This may be explained by increased convection, which moves fresher surface water down and saltier subsurface water upwards (Kim and Kim, 2012). Even though the anomalies in the salinity and potential temperature vertical sections are significant, the isopycnal distribution does not change between the composite years.

\section{Hovmöller}

To better understand if and how the anomalies are spreading in the subsequent composite years, vertical Hovmöller diagrams (Figure 3.24) for two different regions (Figure 3.23). The $\mathrm{y}$-axis is the depth and the $\mathrm{x}$-axis is the sequence of the composite years from $\mathrm{Yr}-3$ to the $\mathrm{Yr}+9$. The dotted vertical line is the year of the eruption ( $\mathrm{Yr}$ 0). The oceanic region boundaries are 0-10E and 30-34S (Figure 3.24a,b) and the Antarctic Peninsula region is an average of $60-48 \mathrm{~W}$ and $61-67 \mathrm{~S}$ (Figure $3.24 \mathrm{c}, \mathrm{d}$ ). It should be taken into account that the behavior is slightly different from the meridional sections, since this is an averaged area. 


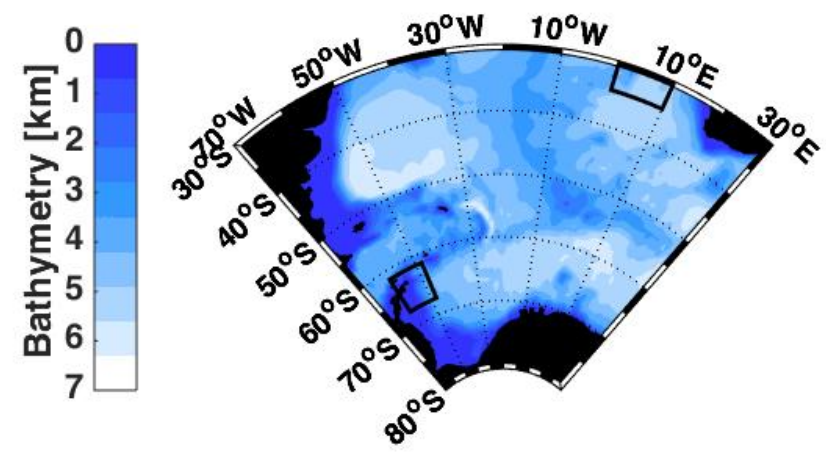

Figure 3.23: Location of the averaged areas in the Hovmöller | Bathymetry map for the Southern Ocean Atlantic sector showing the location of selected regions for the Hovmöller. Antarctic Peninsula region (60-48W,61-67S) and the oceanic region (0-10E,30$34 \mathrm{~S})$
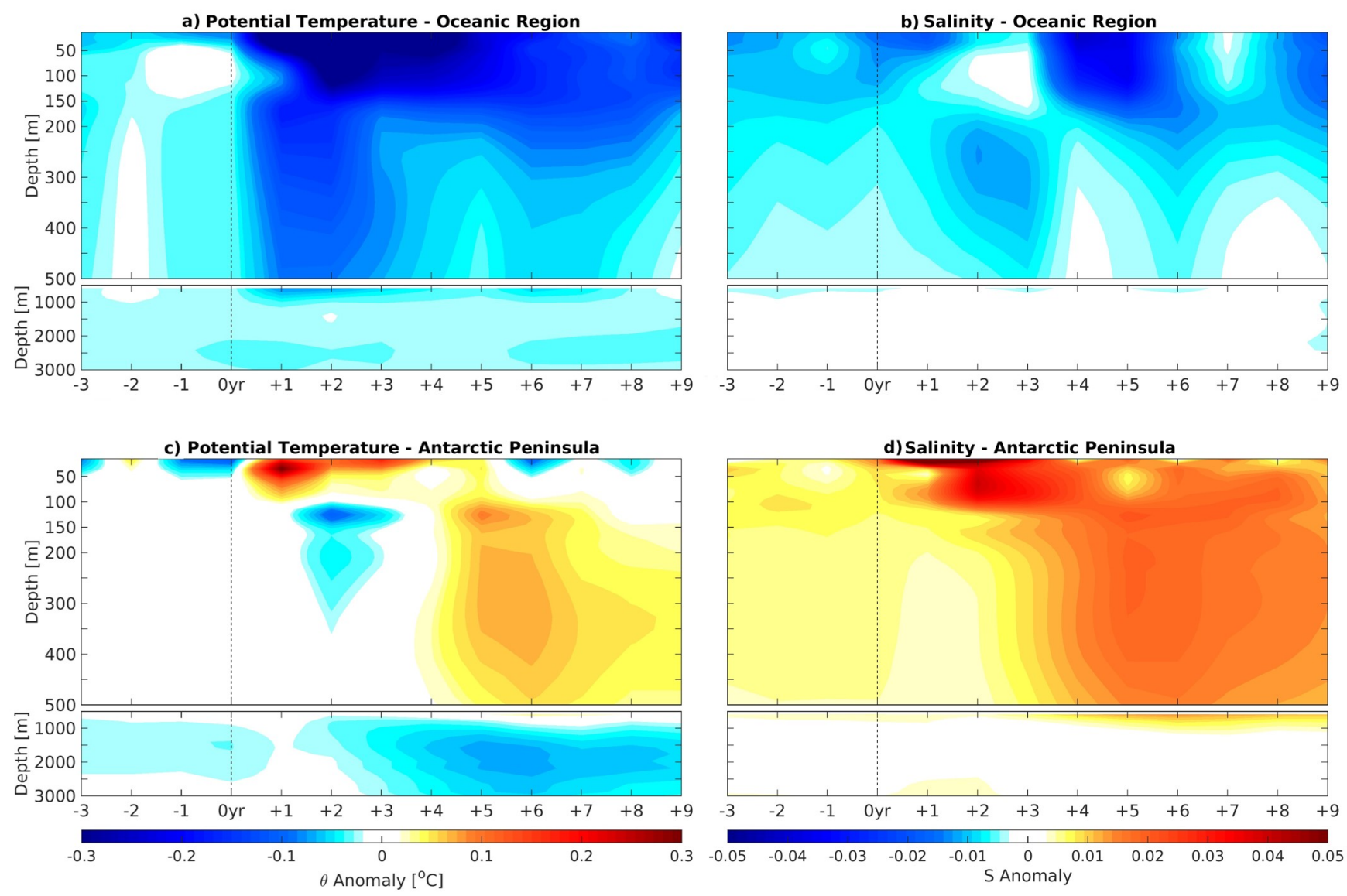

Figure 3.24: Vertical Hovmöller | Potential temperature $\left[{ }^{\circ} \mathrm{C}\right]$ on the left-hand column and salinity on the right-hand column. $[(\mathbf{a}),(\mathbf{b})]$ for the Antarctic Peninsula region (60$48 \mathrm{~W}, 61-67 \mathrm{~S})$ and $[(\mathbf{c}),(\mathbf{d})]$ the oceanic region $(0-10 \mathrm{~W}, 30-34 \mathrm{~S})$. The dotted vertical line marks the eruption year. 
These regions show opposite behavior after volcanic eruptions. The oceanic region shows a negative anomaly of $-0.3^{\circ} \mathrm{C}$ in the following year after the eruption that is in the layer between surface and $100 \mathrm{~m}$ depth (Figure 3.24a). It starts to penetrate into the deeper ocean in the second year after the eruption, showing values of $-0.16^{\circ} \mathrm{C}$ spreading to $\sim 500 \mathrm{~m}$. This anomaly decreases at the surface only after the fifth subsequent austral summer, but on the deeper layers it remains $\sim-0.16^{\circ} \mathrm{C}$. In the layers deeper than $1000 \mathrm{~m}$ the anomaly is present, values of $-0.06^{\circ} \mathrm{C}$, but is not possible to say if it is related just to the volcanic eruptions.

On the other hand, in the Antarctic Peninsula region (Figure 3.24c), after the eruption there is a positive temperature anomaly between the surface and $100 \mathrm{~m}$. The $0.3^{\circ} \mathrm{C}$ anomaly spreads at the surface to the third subsequent austral summer. From $\mathrm{Yr}+4$ the anomalies at the surface have faded, but in the layers deeper than $150 \mathrm{~m}$ a positive temperature anomaly of about $0.08^{\circ} \mathrm{C}$ is present.

Deeper than $1000 \mathrm{~m}$ there is a cold anomaly of $-0.06^{\circ} \mathrm{C}$ starting somewhat at $\mathrm{Yr}+4$ that gets weaker but extends to $\mathrm{Yr}+9$. This could be related to the spreading of the cold anomaly present in other regions at the surface to deeper layers (i.e., north of 50S). The cold anomaly in deeper layers may last several decades to centuries (Stenchikov et al., 2009; McGregor et al., 2015; Pausata et al., 2015; Stenchikov, 2016), which is not evaluated in the present analysis because there is a superposition of the eruptions composites, further analysis considering individual eruptions are required to verify and isolate the volcanic signal in the deeper layers at decadal and longer time-scales.

The salinity anomaly in the oceanic region (Figure 3.24b) is mostly negative, while at the Antarctic Peninsula region it is positive (Figure 3.24d). In the oceanic region (Figure $3.24 \mathrm{~b})$, there is a negative anomaly $(\sim-0.02)$, however it is difficult to separate from the background condition of the years before the eruption, that also have shown a negative anomaly of the same magnitude. The largest anomaly in this region occurs at $\mathrm{Yr}+3$ of about 0.05 and spreads to $200 \mathrm{~m}$ depth. This anomaly is found in the deeper layers $\sim 500 \mathrm{~m}$ in $\mathrm{Yr}+5$, but with smaller values.

The response in salinity to volcanism in the Antarctic Peninsula (Figure 3.24d) region 
is a positive anomaly of 0.05 that starts in the first year after the eruption. This anomaly from the surface to $150 \mathrm{~m}$ remains the same until $\mathrm{Yr}+3$, after it gets weaker (0.02) and spread into deeper layers around $500 \mathrm{~m}$. Note that the positive potential temperature anomaly seems to follow the positive salinity anomaly in the Antarctic Peninsula region, which suggests that the salinity may control the sinking of this water. Therefore, even though the positive potential temperature anomaly is not sufficiently dense to sink, it is forced to sink in the following years (i.e., $\mathrm{Yr}+3$ to +4 ) because of the increased in density related to the saltier anomaly also present in the same region.

Another point to notice is the background condition, the years before the eruption (i.e., $\mathrm{Yr}-1$ and -2), for each region its different, thus the background condition could play an important role (Zanchettin et al., 2013). In addition, in both regions the salinity and temperature anomalies remain meaningful even at $\mathrm{Yr}+9$, suggesting that the recovery from volcanic eruption could take at least a decade Church et al. (2005); Gleckler et al. (2006); Ding et al. (2014). At the same time, there is superposition of some events, therefore, the Hovmöller diagram after year +6 could be showing a cumulative signal from successive eruptions.

\subsubsection{Water Masses Analysis}

To verify if any of the significant anomalies at the surface would be able to impact and modify water masses, the averaged Weddell Sea TS diagram is analyzed, shown in Figure 3.25. The WDW is well represented, even if it is slightly warmer, up to $1.5^{\circ} \mathrm{C}$, compared to Nicholls et al. (2009). The only changes that are observed in the composite years occur in the first $\sim 200 \mathrm{~m}$. This could be explained by the longer time scale necessary for a change at the surface to penetrate into the ocean deeper layers (Church et al., 2005; Gleckler et al., 2006). Even during $\mathrm{Yr}+9$ it is not possible to see meaningful changes in layers deeper than $500 \mathrm{~m}$ in this TS diagram analysis.

The small changes are hard to differentiate from the climatological average (thick grey line), even in the zoom for the first 200m (Figure 3.25b). The Yr +2 (magenta line) shows 
larger changes compared to the climatological average. Most of the difference is located approximately at $75 \mathrm{~m}$, showing a slightly increase in the salinity and temperature. This is related to the first response due to volcanic events (see Figure 3.16 and 3.22), since the larger anomalies have been observed to spread all the way to $200 \mathrm{~m}$.

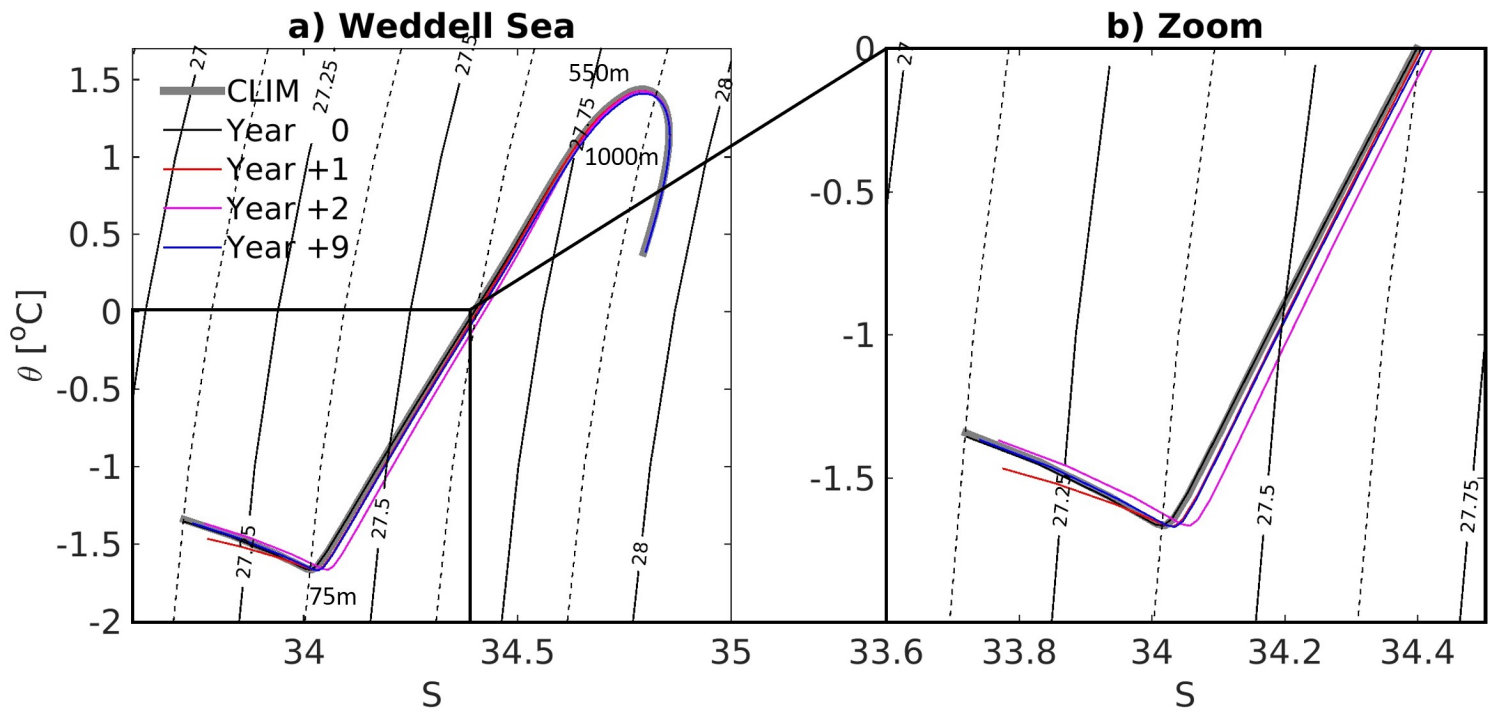

Figure 3.25: TS diagram for the Weddell Sea | (a) Averaged Weddell Sea TS diagram from surface to $2000 \mathrm{~m}$. (b) Zoom for the first $\sim 100 \mathrm{~m}$. Climotological mean for the LM is represented as the thick black line and different colors represent each composite year that is described in the legend.

Even at $\mathrm{Yr}+9$ the TS diagram has not shown changes in the deeper layers, such as the WDW. Thus, the increase in some water production as the $10 \%$ increase in AABW production identified by Kim and Kim (2012), is probably not related to changes in precursors water masses of AABW formation or in these water masses thermohaline characteristics. Therefore, further analysis are needed to verify if volcanism would be able to imprint meaningful modifications in water masses hydrographic characteristics.

\subsubsection{Regional Analysis: Weddell Sea}

A special focus is given to the anomalous warming in the Weddell Sea related to volcanic events, which has not been observed before. This section present results and discussion of a regional analysis in which the dynamical aspects of this anomalous feature is explained. Figure 3.26 depicts the same composite anomaly for SST and SSS at Yr +1 , only the significant regions at $90 \%$ are shown. The wind stress anomaly is superposed in 
vectors.

It is expected that the aftermath of a volcanic event is an overall cooling of the surface (Church et al., 2005; Ding et al., 2014; Stenchikov, 2016). This cooling acts to offset the warming of the PD (Delworth et al., 2005; Gleckler et al., 2006), the anomalous warming observed here would imply in opposite impact, as it would increase the anthropogenic warming. Together with the warming, there is a positive salinity anomaly almost at the same region, but spread eastward. This anomalous positive salinity after the eruption could be linked to an anomalous sea-ice expansion (i.e., increased brine rejection) that was discussed by Zanchettin et al. (2014). The authors observed that the Antarctic sea-ice goes through an initial expansion phase during integration of the first and second years, followed by a retraction after an eruption. The expansion phase would increase the sea surface salinity through more brine rejection.
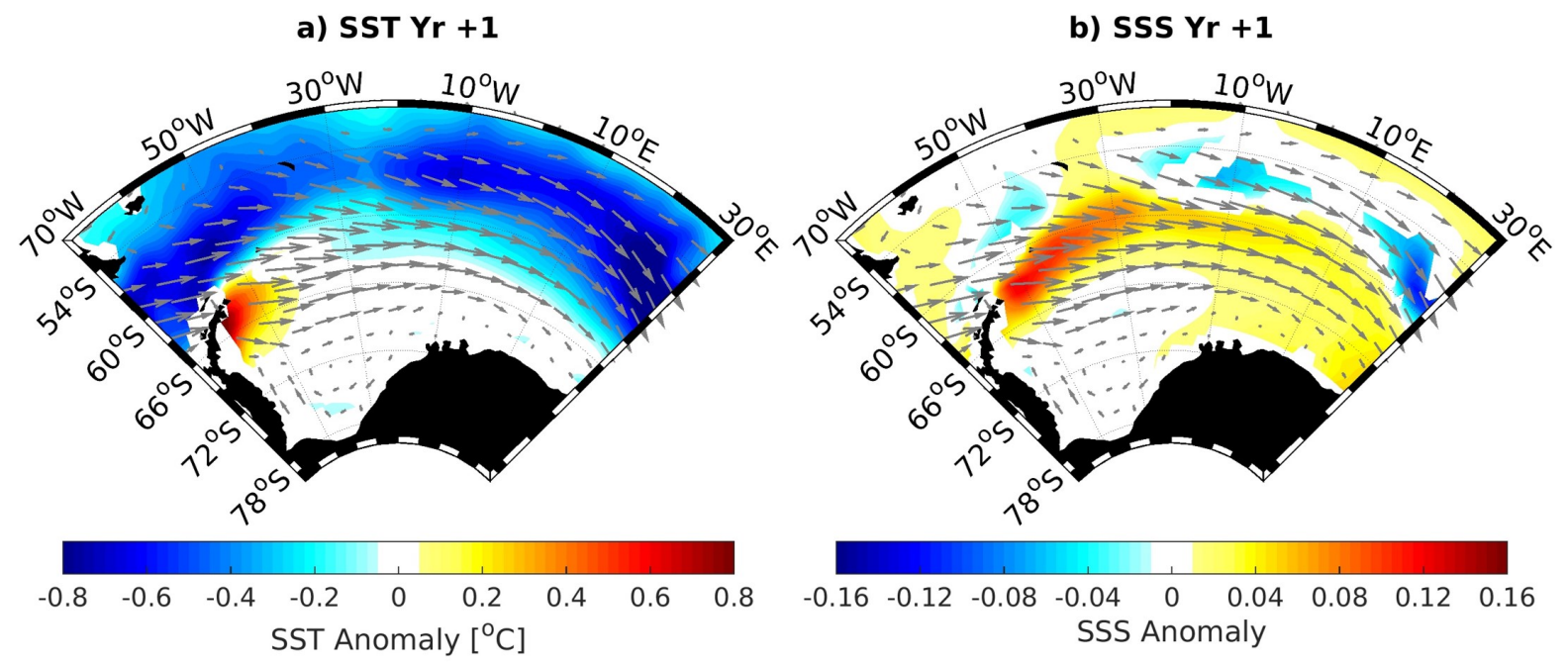

Figure 3.26: Regional Weddell Sea composites | Composite response to the selected eruptions only showing DJF $\mathrm{Yr}+1$ for $(\mathbf{a}) \mathrm{SST}\left[{ }^{\circ} \mathrm{C}\right]$ and (b) SSS anomalies. Vectors show the wind stress anomaly. It is only shown regions that are significant at $90 \%$ according to the WRS test.

The wind stress anomaly reveals an intensified westerly flow (represented by vectors in Figure 3.26), which is further explored in Figures 3.27 and 3.28. The meridional wind stress in the Weddell Sea climatological austral summer is a northward flow that inverts its direction in the northernmost portion of the Antarctic Peninsula (continuous line in Figure 3.27a). Due to volcanic eruption, the response in TAUY is a negative anomaly in 
the northern Antarctic Peninsula (Figure 3.27b). This anomaly is sufficient to invert the circulation in this region as shown in Figure 3.27c that is the sum of the climatological LM austral summer and the anomaly field during the year after the eruption $(\mathrm{Yr}+1)$. The continuous line is the zero TAUY from the climatological austral summer and the dotted line is the zero TAUY impacted by volcanic explosion.

a) TAUY LM Climatology

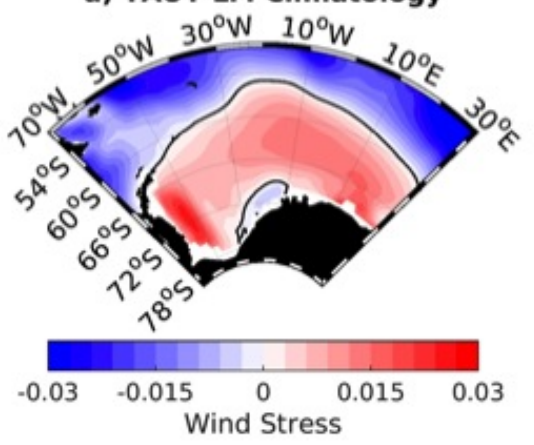

d) TAUX Climatology

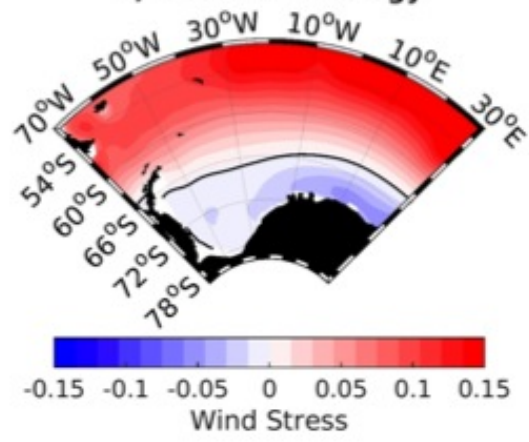

b) $\mathrm{Yr}+1$ Anomaly

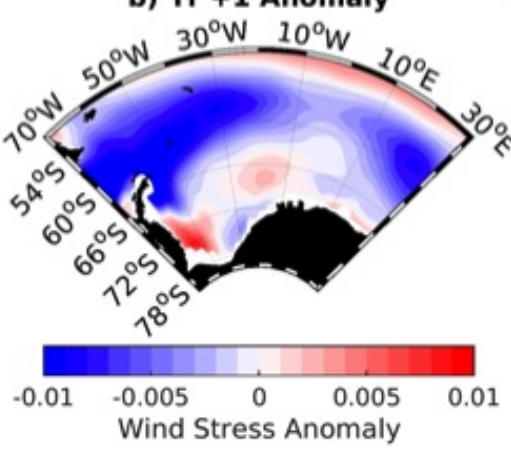

e) $\mathrm{Yr}+1$ Anomaly

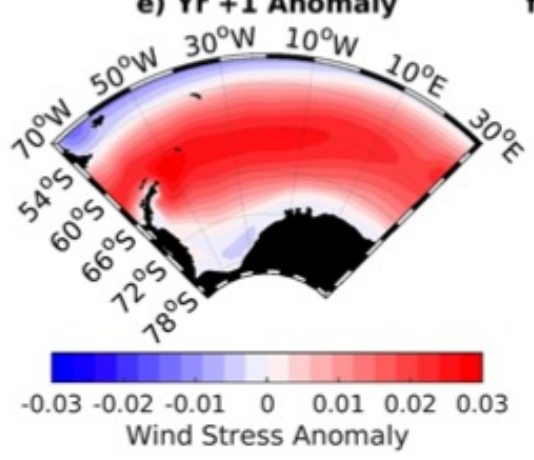

c) $<$ LM Climatology $>+<\mathrm{Yr}+1$ Anomaly $>$

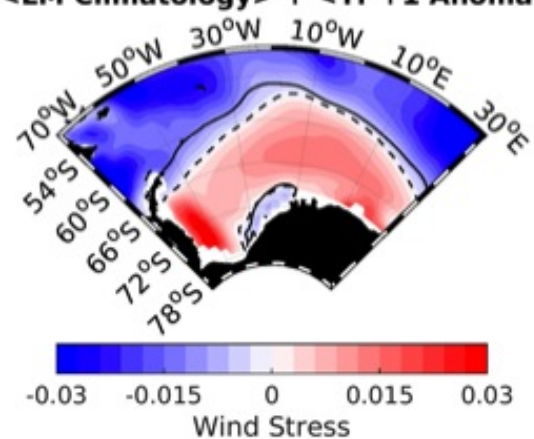

f) $<$ LM Climatology $>+<\mathrm{Yr}+1$ Anomaly $>$

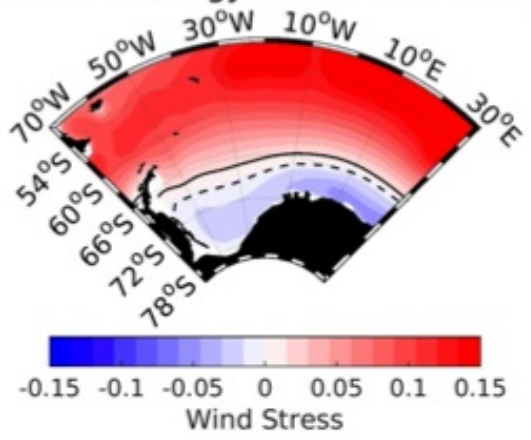

Figure 3.27: Wind stress response at $\mathbf{Y r}+\mathbf{1} \mid$ The right-hand column is the LM climatological mean, the central column the $\mathrm{Yr}+1$ anomaly and the left-hand column the sum of both for $[(\mathbf{a}),(\mathbf{b}),(\mathbf{c})]$ TAUY $\left[\mathrm{N} \mathrm{m}^{-2}\right]$ and $[(\mathbf{d}),(\mathbf{e}),(\mathbf{f})]$ TAUX $\left[\mathrm{N} \mathrm{m}^{-2}\right]$. The continuous line represent the zero contour for LM climatological mean and the dotted line the zero contour resultant from the year after the eruption perturbation.

At the same time, the zonal wind stress also significantly changes, as can be seen in Figure $3.27 \mathrm{c}$,d,e. In the following austral summer after the eruption TAUX southernmost extension, represented by the continuous line in Figure 3.27d, has dislocated southward (dotted line in Figure 3.27c). It is also observed that the zonal wind stress has intensified in $\sim 20 \%\left(0.03 \mathrm{~N} \mathrm{~m}^{-2}\right)$.

The southward migration of the prevailing westerlies is also shown in Figure 3.28, that presents the TAUX zonal average for the austral summer climatology (continuous black line), the composite $\mathrm{Yr}+1$ (magenta line) and the composite $\mathrm{Yr}+8$ (dotted blue line). 
The polar shift of the westerlies of almost $2^{\circ}$ shown by the horizontal lines is clearly seen. The horizontal lines in Figure 3.28 elucidates the associated maximum zonal wind stress position $^{3}$ of the LM austral summer climatology and averaged composite $\mathrm{Yr}+1$.

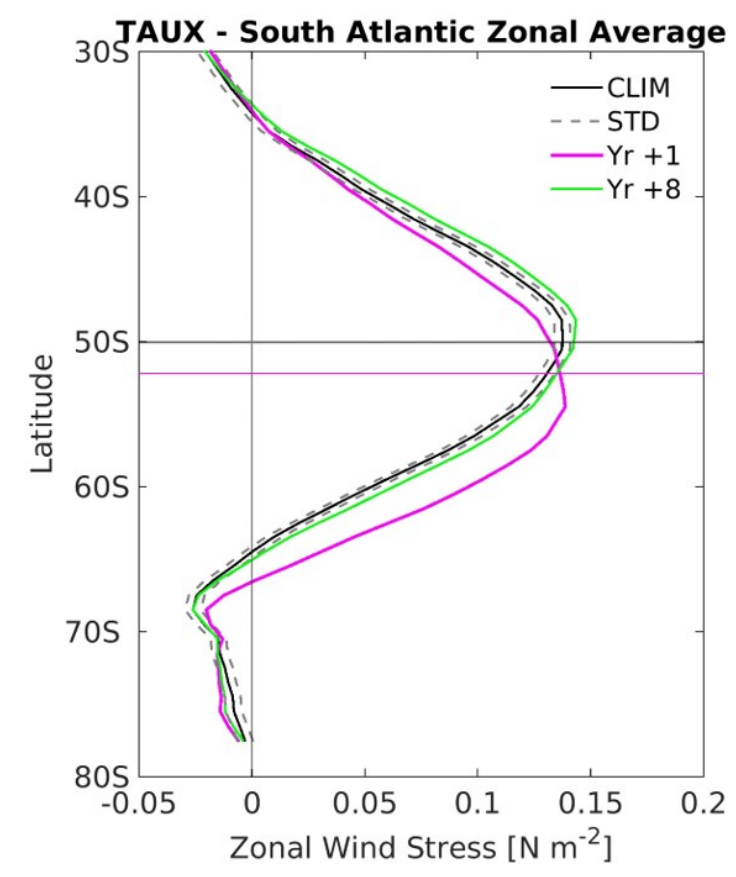

Figure 3.28: Zonal wind stress $\left[\mathrm{N} \mathrm{m}^{-2}\right]$ zonal average for the South Atlantic Ocean | The black line is the LM climatological mean for DJF, the ensemble spread is represented by the dotted line, in magenta is the year after the eruption $(\mathrm{Yr}+1)$ and in green 8 years after the eruption $(\mathrm{Yr}+8)$. The vertical lines represent the associated maximum zonal wind stress position for the climatology (black line) and $\mathrm{Yr}+1$ (magenta line).

Westerlies southward shift after the eruption have been observed before (Stenchikov et al., 2009; Karpechko et al., 2010) in different simulations. Schneider et al. (2009) rather than a poleward shift, discuss an equatorward shift of the westerlies in post-eruption scenario in the CCSM3. McGraw et al. (2016), on the other hand, using the CESM Large Ensemble experiment (LENS) suggest that the westerlies southward shift is in fact a response after eruptions, however they discuss that the internal variability overwhelm this change.

The differences between the northern Antarctic Peninsula (60-48W and 61-67S) and an oceanic region (12-26E and 53-59S) is explored. The specific regions are shown in Figure 3.29a. A standardized SEA comparing SST, SSS and TAUX composite evolution

\footnotetext{
${ }^{3}$ The associated maximum zonal wind stress position is calculated from the weighted averaged method.
} 
for both regions is shown in Figure 3.29b,c.
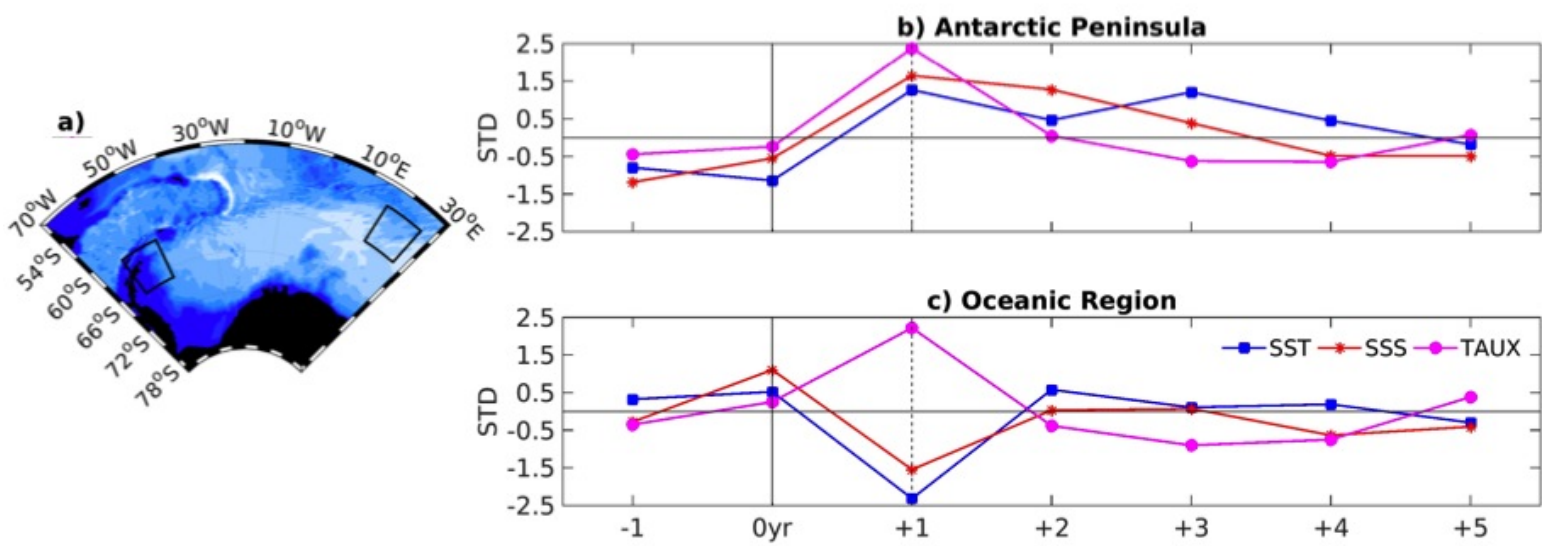

Figure 3.29: Superposed Epoch Analysis | (a) Bathymetry map for the Southern Ocean Atlantic sector showing the location of selected regions for SEA. (b) Antarctic Peninsula region averaged between $60-48 \mathrm{~W}$ and $61-67 \mathrm{~S}$ and (c) oceanic region averaged between 12-26E and 53-59S. In [(a), (b)] the vertical continuous line marks the year of the eruption ( $\mathrm{Yr} 0)$ and the dotted line the first year after the eruption $(\mathrm{Yr}+1)$.

All air-sea properties show changes of the same magnitude in the first austral summer after the eruption ( $\mathrm{Yr}+1$ vertical dotted line in Figure 3.29a,b). Immediately in the subsequent year the anomalies start to decay and by the $\mathrm{Yr}+5$ get back to magnitude comparable to the year before the eruption ( $\mathrm{Yr}-1)$. Changes after the eruption are of 1.5 standard deviation in both regions, but with different signals. The northern Antarctic Peninsula shows positive anomaly for all properties, contrasting with the oceanic region that presents negative SST and SSS anomaly and positive TAUX anomaly. Despite the same wind response after the eruption, the oceanic properties respond differently.

SST perturbation observed in the oceanic region is the expected cooling response due to the radiative effect of volcanic eruptions (Robock, 2000; Church et al., 2005; Ding et al., 2014; Pausata et al., 2015; Stenchikov, 2016). Instead the surface warming near the Antarctic Peninsula in the Weddell Sea may be controlled by changes at the surface winds. The significant wind stress field change immediately impact the ocean surface velocity (Figure 3.30). 
a) Velocity DJF

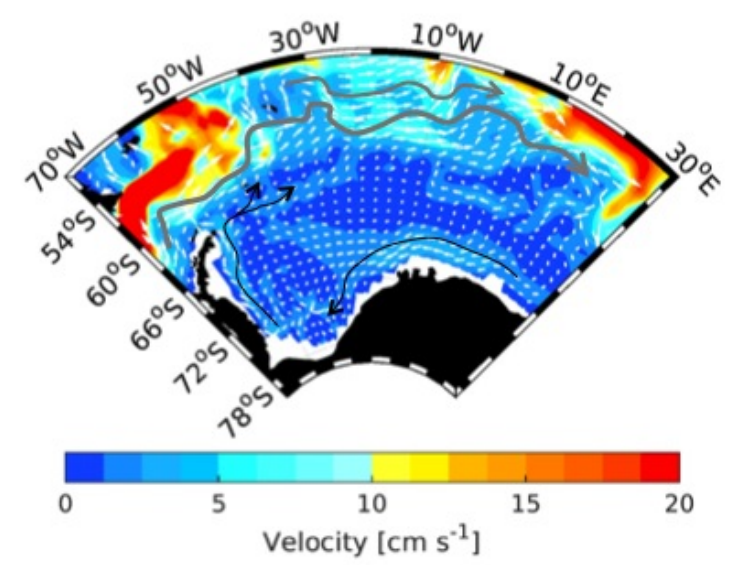

b) VVEL DJF

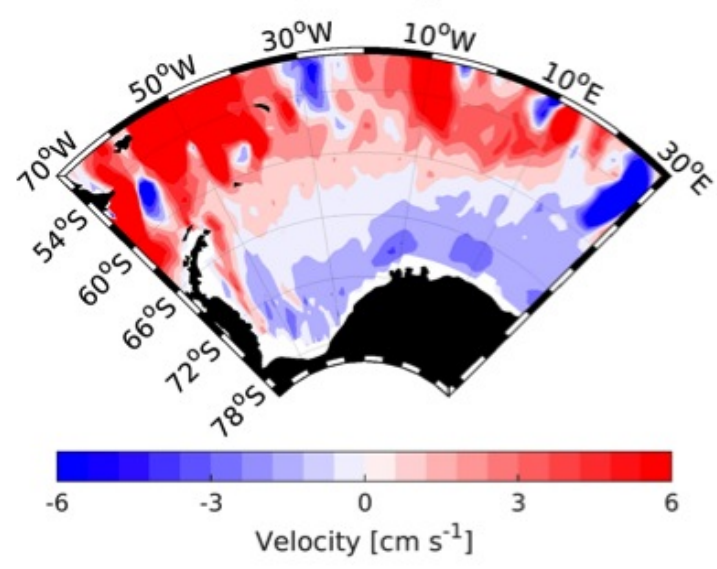

d) VVEL Yr +1

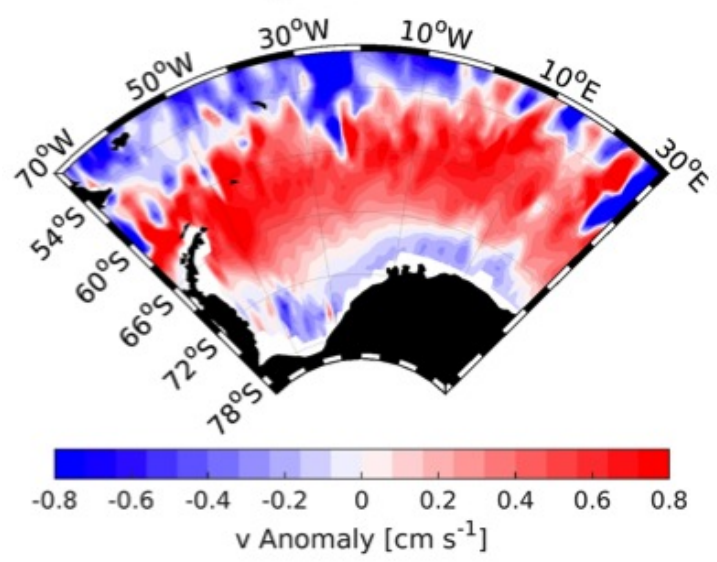

c) UVEL DJF

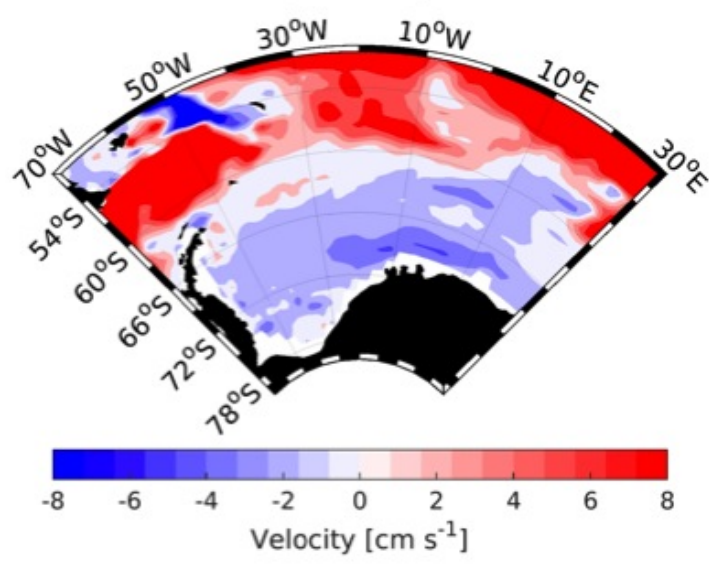

e) UVEL Yr +1

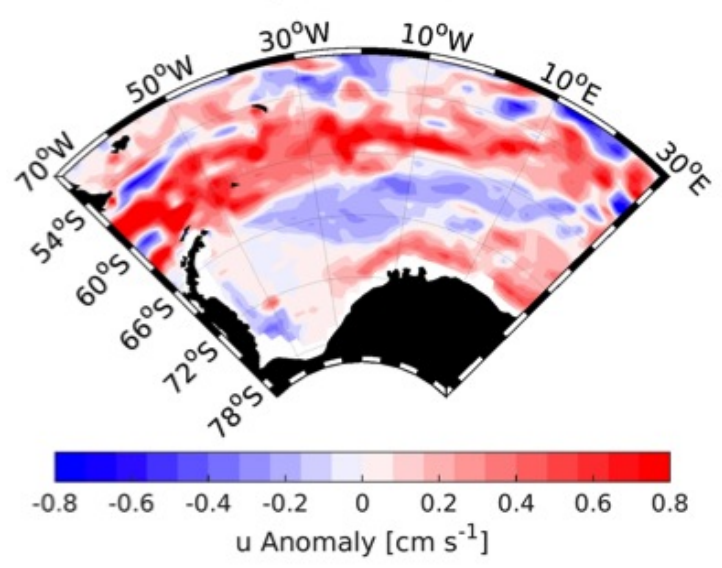

Figure 3.30: Surface ocean velocities | (a) Surface ocean velocity DJF climatological mean for the LM, the background is the magnitude $\left[\mathrm{cm} \mathrm{s}^{-1}\right]$, the white vector represent the direction, the black arrows represent the Weddell Gyre circulation and the grey arrows the southern extension of the ACC. [(b), (c)] Velocity components, VVEL $\left[\mathrm{cm} \mathrm{s}^{-1}\right]$ and UVEL $\left[\mathrm{cm} \mathrm{s}^{-1}\right]$ respectively, DJF climatological mean field for the LM. [(d), (e)] Associated anomaly in the VVEL $\left[\mathrm{cm} \mathrm{s}^{-1}\right]$ and UVEL $\left[\mathrm{cm} \mathrm{s}^{-1}\right]$ fields, respectively due to volcanism during the year after the eruption $(\mathrm{Yr}+1)$. 
The austral summer climatological velocity at the surface is shown in Figure 3.30a, the thick grey arrows represent the southern extent of the ACC that is stronger than the surface Weddell Gyre represented in black thin arrows. Each velocity component is represented in Figure 3.30b,c, and the anomalies due to volcanic explosion at $\mathrm{Yr}+1$ are depicted in Figure 3.30d,e. The UVEL and VVEL surface anomalies represent a 10\% to $\sim 14 \%$ increase in the flow, respectively, mainly in the southern extent of the ACC (Figure 3.30a), which agrees with Kim and Kim (2012). While, somehow the Weddell Gyre is a bit weaker, decrease of $\sim 8 \%$ in its zonal component in the eastern domain near the Antarctic continent. The VVEL near the Antarctic Peninsula after the eruption is highly influenced by the ACC southern extension flux.

The stronger ACC southern extent is enhancing mixing in the northern Antarctic Peninsula region. There is not any warmer water at the surface coming to the Weddell region. Thus, the positive temperature anomaly from Figure 3.26a is probably explained by deeper layer circulation. To explore this, the typical SR4 WOCE transect $^{4}$ (Figure 3.6a) that covers both the inflow and outflow regions of the Weddell Gyre is examined.

Temperature anomaly shows (Figure 3.31a) small increase of $0.08^{\circ} \mathrm{C}$ in the inflow region, deeper than 200m. In the northern hemisphere, Zhong et al. (2011) observe a subsurface warming after sequenced eruptions which is attributed to weakened convection, a similar mechanism may explain the subsurface heating of this region. At the same time, in the outflow region the positive anomaly is concentrated in layers shallower than $100 \mathrm{~m}$, which suggests that the water getting in the Weddell Gyre subsurface is slightly warmer, but the water that is at the subsurface outflow is not. This is probably related to the observed changes at the subsurface circulation in the Weddell Sea (Figure 3.31b).

Figure 3.31b shows the VVEL anomaly along the depth for the first year after the eruption. During $\mathrm{Yr}+1$, there is a negative anomaly in the subsurface outflow region of $\sim 0.12 \mathrm{~cm} \mathrm{~s}^{-1}$ that reaches $400 \mathrm{~m}$ deep. At the same time, at the surface and easterly dislocated a positive anomaly of the same magnitude. This shows that the outflow

\footnotetext{
${ }^{4}$ The closest model grid points from the original stations in SR4 WOCE transect have been selected to this analysis.
} 
velocity has decreased in the original position in $16 \%$. The anomalous positive VVEL in the surface is related to the increased southward ACC extension showed in Figure
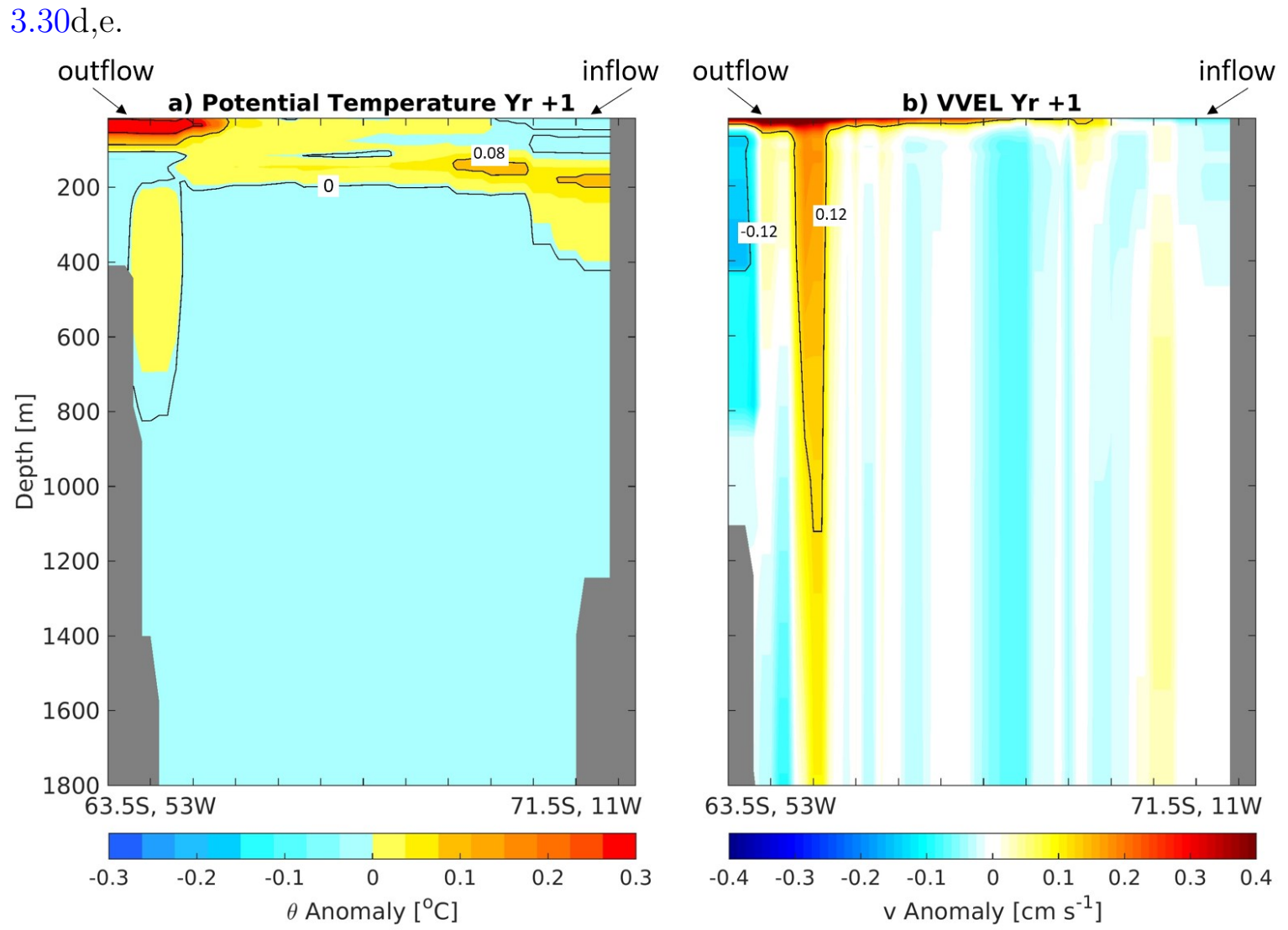

Figure 3.31: WOCE SR4 transect | Composite response to the selected eruptions during the first year after the eruption $(\mathrm{yr}+1)$ for $(\mathbf{a})$ potential temperature anomaly $\left[{ }^{\circ} \mathrm{C}\right]$ and (b) VVEL anomaly $\left[\mathrm{cm} \mathrm{s}^{-1}\right]$. The inflow and outflow regions are marked, respectively $71.5 \mathrm{~S}, 11 \mathrm{~W}$ and $63.5 \mathrm{~S}, 53 \mathrm{~W}$.

Therefore, the anomalous warm surface responds more strongly not to the radiative forcing, but to changes in the ocean dynamics in the first austral summer after the eruption $(\mathrm{Yr}+1)$ :

1. Winds: Along the outflow region in the Weddell Sea, the northward winds are pushed southwards with the southward (negative) anomalies north of the Antarctic Peninsula extending west. At the same time, the westerlies are stronger and shift south into most of the Weddell Sea.

2. Surface Circulation: As a response to the wind changes, the ACC southern extension is stronger, enhancing mixing at the surface outflow region. Therefore, the Weddell 
Gyre outflow region is more influenced by the ACC southern extension.

3. Subsurface Circulation: At the subsurface layer, $\sim 600 \mathrm{~m}$ depth, the Weddell Gyre outflow is weakened and the inflow region is somehow warmer $\left(0.08^{\circ} \mathrm{C}\right)$. This means that some of the subsurface water that is supposed to be exported out of the Weddell Gyre has been trapped in the region near the Antarctic Peninsula.

4. This scenario of enhanced mixing and the warmer subsurface water accumulated in the outflow region is bringing up warmer and saltier subsurface waters (i.e., WDW). This waters get trapped at the surface outflow region because of the reversed meridional wind anomalies and the southward shifted westerlies.

The schematics on Figure 3.32 represent in summary the suggested mechanism.

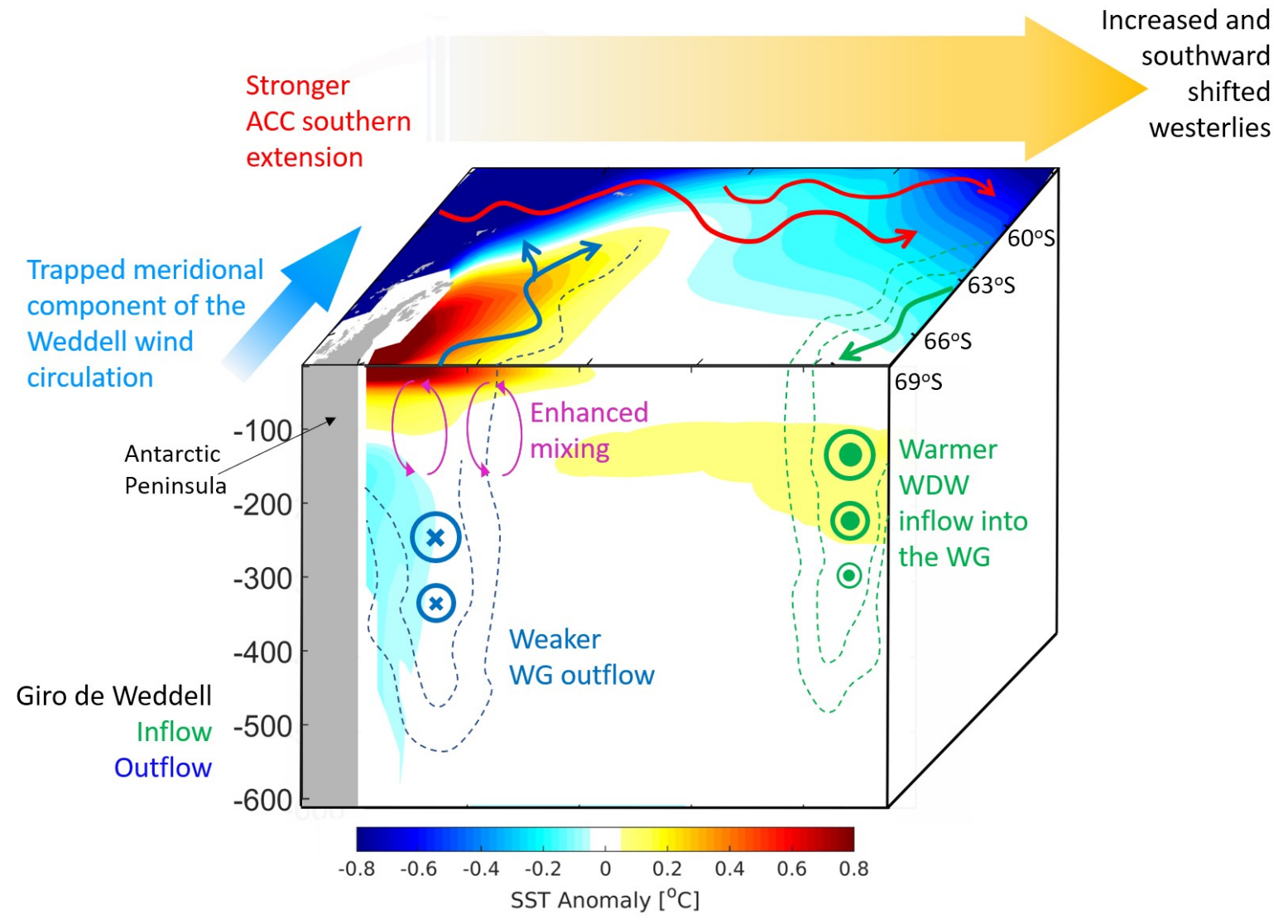

Figure 3.32: Schematics from the suggested mechanism in the Weddell Sea near the Antarctic Peninsula | The surface and vertical section in the SR4 transect represent the temperature anomaly for the year after the eruption $(\mathrm{Yr}+1)$. The wind circulation is represented (yellow and blue arrows), the inflow and outflow of the Weddell Gyre in green and blue, respectively. 
The idea is that the positive SST anomaly resulting from volcanic eruptions, observed at the northern part of the Antarctic Peninsula is a result of the Weddell Sea ocean dynamics. It is explained by the Weddell Gyre response to the southward shift and strengthening of the westerlies together with the southward wind anomalies at the outflow region. At this region, warm and salty WDW waters, through convective mixing, reaches surface layers. Because of the anomalous wind, the outflow is stifled leading to the positive SST anomaly detected.

\subsection{Modern Eruption: Mt. Pinatubo}

To test if the model results have an impact on the real world, the ocean response to Mt. Pinatubo eruption in 1991 is investigated using observations and ocean reanalysis (ERSSTv5 and SODA, respectively). The fact that this eruption was considerably smaller than the LM eruptions and that the ocean response is also a result of increased post industrial GHG and ozone depletion forcing is being considered.

If the anomalous warming after an eruption is observed in the $\mathrm{PD}$, the volcanic forcing could actually enhance the warming response associated with anthropogenic forcing at the Weddell Sea and Antarctic Peninsula. The SST spatial pattern evolution for the Mt. Pinatubo eruption from the CESM-LME, ERSSTv5 observed product and SODA ocean reanalysis are shown in Figure 3.33. 

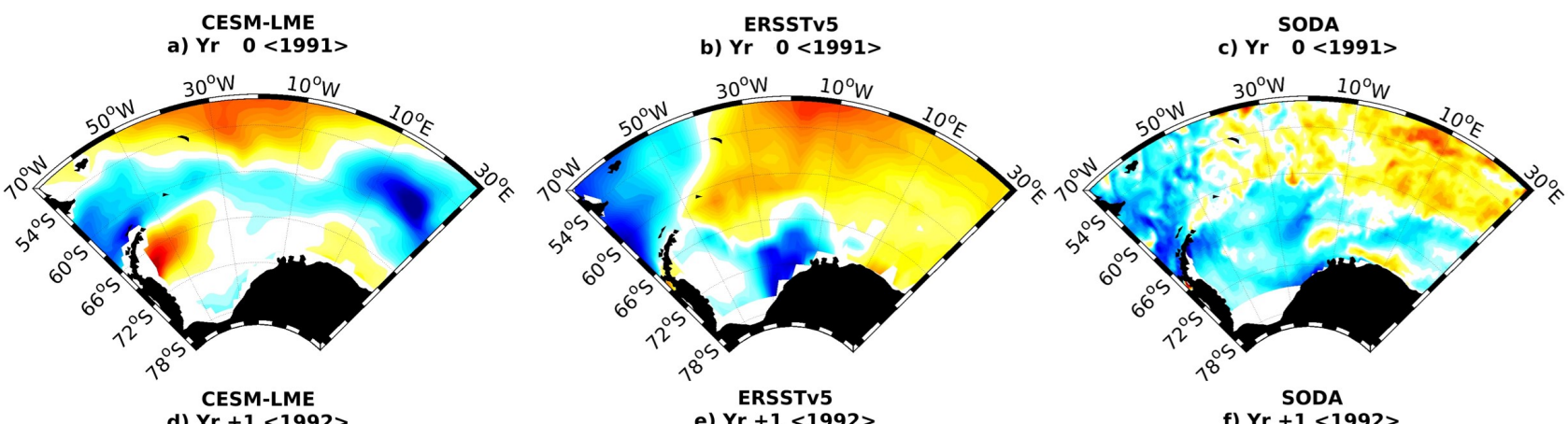

d) $\mathrm{Yr}+1<1992>$

ERSSTV5
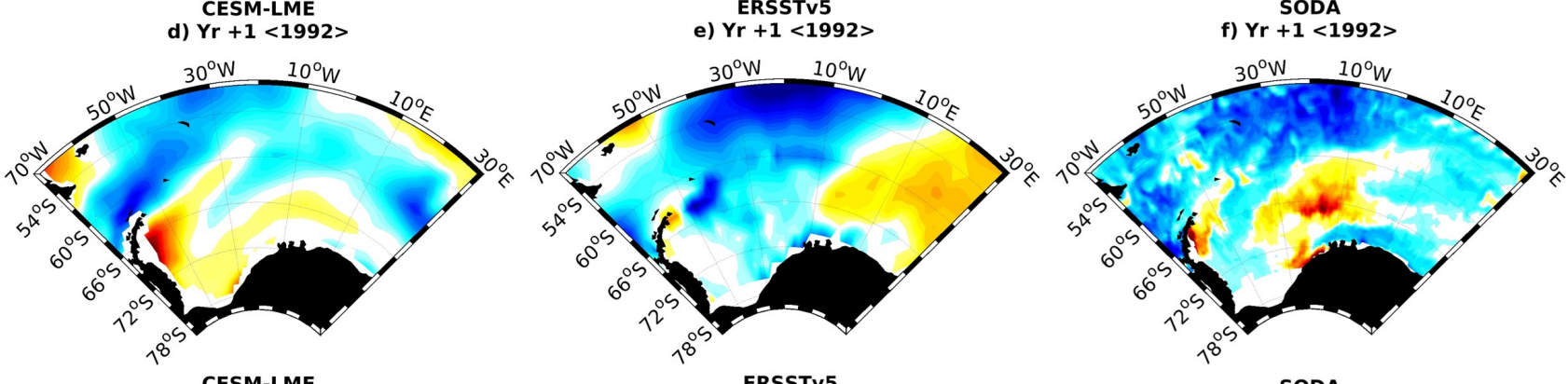

g) $\mathrm{Yr}+2<1993>$

h) $\mathrm{Yr}+2<1993>$

i) $\mathrm{Yr}+2<1993>$
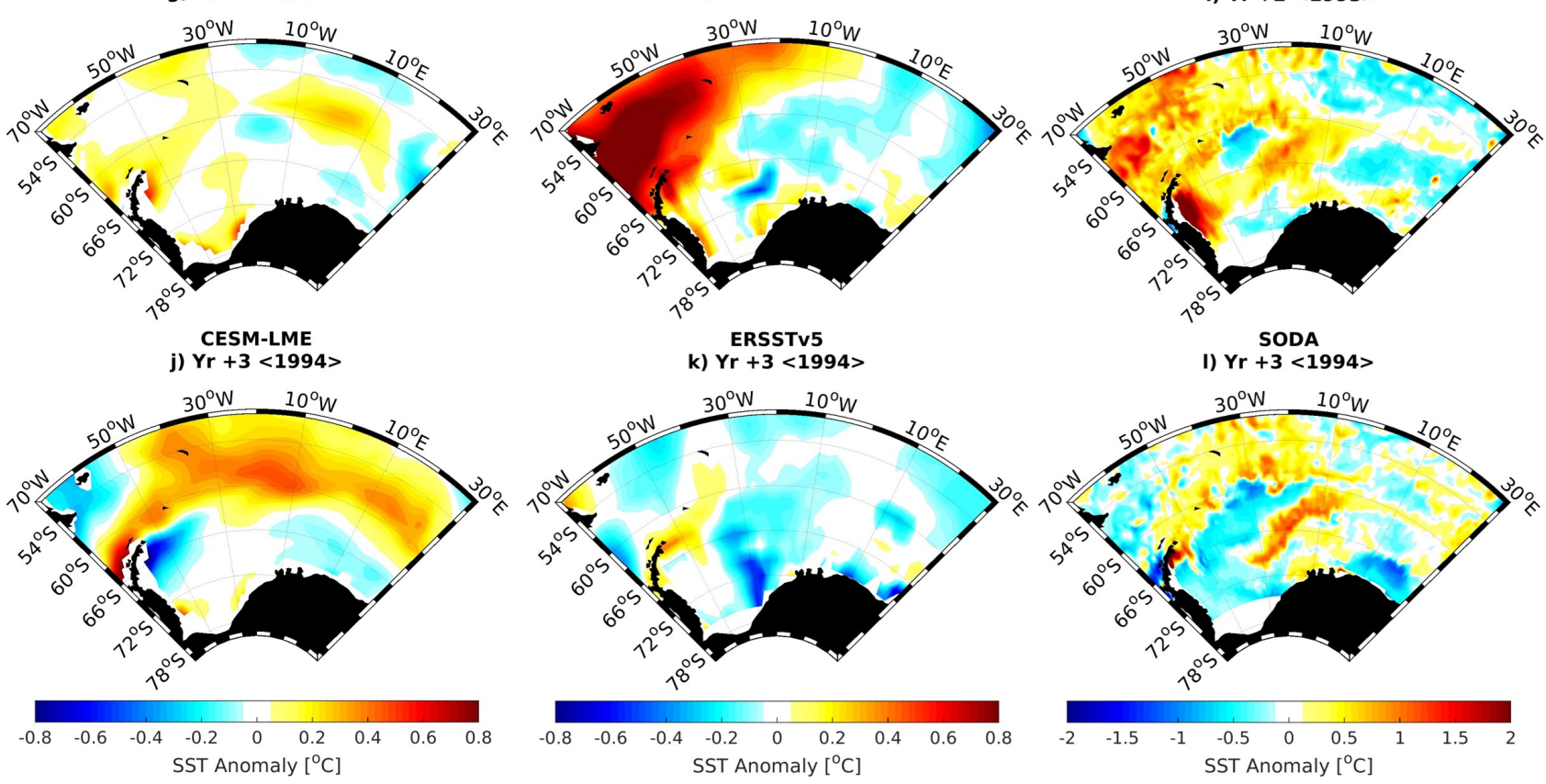

Figure 3.33: SST $\left[{ }^{\circ} \mathbf{C}\right]$ response to Mt. Pinatubo eruption | Left-hand column for CESM-LME [(a), (d), (g), (j)], central column for ERSSTv5 [(b), (e), (h), (k)] and right-hand column for SODA [(c), (f), (i), (l)]. Each line represent different years from 1991 (Yr 0, the eruption year) to $1994(\mathrm{Yr}+3)$.

Mt. Pinatubo explosion response in CESM-LME shows signals during the year of the eruption (Yr 0, 1991 Figure 3.33a). In this year a positive temperature anomaly of $0.8^{\circ} \mathrm{C}$ is present in the Weddell Sea and between $54 \mathrm{~S}$ and $66 \mathrm{~S}$ there is a cold anomaly of on average $0.6^{\circ} \mathrm{C}$. North of $54 \mathrm{~S}$ there is a positive temperature anomaly that is probably not related to the volcanic eruption. In the first austral summer after the eruption (1992, 
Figure 3.33d) the same pattern is present and in the second year (1993, Figure 3.33g) it starts to fade, the warm surface anomaly in the Antarctic Peninsula is of $0.4^{\circ} \mathrm{C}$. The $\mathrm{Yr}$ +3 (1994, Figure 3.33j) shows a cold anomaly in the Weddell Sea and a positive anomaly in the northern portion of the region.

Results from ERSSTv5 for the year of eruption (1991, Figure 3.33b) show positive anomalies, mostly west of $40 \mathrm{~W}$, which are probably related to the anthropogenic effect. Mt. Pinatubo cooling effect starts in the first year after the eruption $(\mathrm{Yr}+1,1992$ Figure 3.33e), in this same year a small region next to the Antarctic Peninsula has warmed. This warming is larger at $\mathrm{Yr}+2(1993$, Figure $3.33 \mathrm{~h})$ reaching $0.8^{\circ} \mathrm{C}$, but is accompanied by a large warming of the same magnitude at the Drake Passage. During Yr +3 (1994, Figure 3.33k) the anomaly at the Drake Passage disappears, however the positive temperature anomaly in the Weddell Sea is still present. Finally, shown in Figure 3.33 right-hand column, results from SODA depict overall similar anomalies pattern, albeit larger values with a maximum SST anomaly of $2^{\circ} \mathrm{C}$. During the eruption year (1991, Figure 3.33c) SODA shows a similar pattern to ERSSTv5. The warm surface anomaly near the Antarctic Peninsula only appears in the second subsequent austral summer $\left(\mathrm{Yr}+2\right.$, 1993 Figure 3.33i) reaching values of $1.5^{\circ} \mathrm{C}$. At $\mathrm{Yr}+3$ (1994, Figure 3.331) the Weddell Sea anomaly is smaller.

All data sets compared here have shown the expected cooling pattern, the magnitude is larger than other studies, which may be related to the study region. For example, Church et al. (2005) have shown model results of $0.4^{\circ}$ negative anomaly, while observations are of the order of $\sim 0.3^{\circ} \mathrm{C}$. Also for model simulations, a cooling of $0.25^{\circ} \mathrm{C}$ is observed in Mignot et al. (2011) and Kim and Kim (2012). Furthermore, Ding et al. (2014) have observed in CMIP5 a global average cooling of $0.3^{\circ} \mathrm{C}$. CESM-LME and ERSSTv5 agree more closely to previous studies than the results from SODA, which may be linked to the SODA higher spatial resolution.

Differences between each year and a background reference field (Yr -1, 1990) are also shown in Figure 3.34. During Mt. Pinatubo eruption the background conditions are highly influenced by anthropogenically forcings (Gleckler et al., 2006; Zanchettin et al., 
2013), therefore the background condition may influence even more than during the LM.
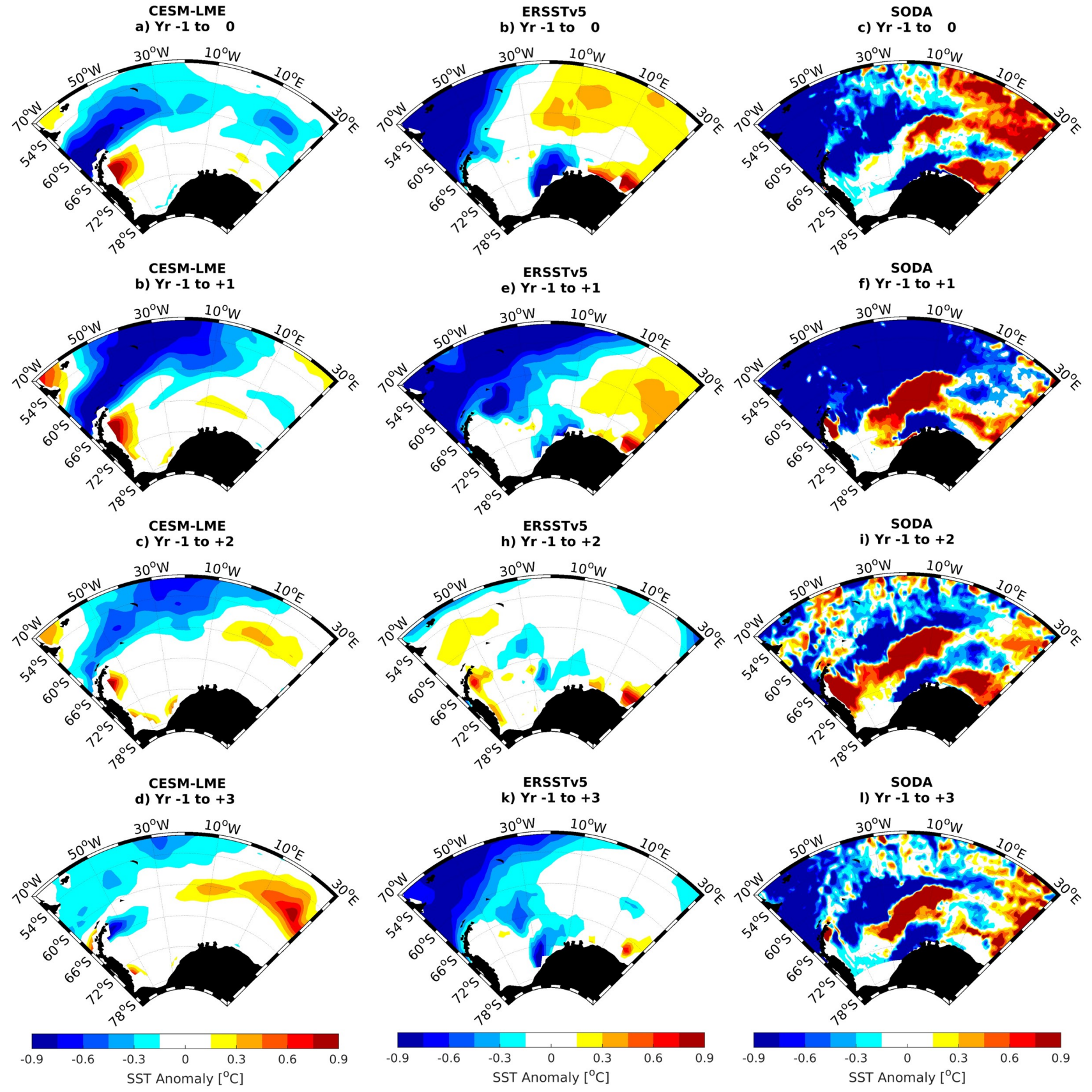

Figure 3.34: SST $\left[{ }^{\circ} \mathrm{C}\right]$ differences relative to the year before the Mt. Pinatubo eruption (1991) | Left-hand column for CESM-LME $[(\mathbf{a}),(\mathbf{d}),(\mathrm{g}),(\mathbf{j})]$, central column for ERSSTv5 [(b), (e), (h), (k)] and right-hand column for SODA [(c), (f), (i), (l)]. Each line represent different years from 1991 (Yr 0, the eruption year) to $1994(\mathrm{Yr}+3)$.

Considering the difference between Yr -1 (1990) and all other years in the CESM-LME (Figure 3.34 left-hand column) it is evident that the only region that has warmed after Mt. Pinatubo eruption is the Weddell Sea. Except for a small region in the northeast domain that shows warming in 1994 . The positive temperature anomaly is present in 
this results from 1991 to 1993 , with difference of $0.9^{\circ} \mathrm{C}$ from the background.

The ERSSTv5 (Figure 3.34 central column) shows warming compared to the year before Mt. Pinatubo eruption in the northeast domain in the year of the eruption (1991) and during the first year after the eruption (1992). However, in $\mathrm{Yr}+2$ (1993, Figure 3.34h) there is a $0.9^{\circ} \mathrm{C}$ warming in the Weddell Sea. The difference between the $\mathrm{Yr}-1$ (1990) and all other years for SODA (Figure 3.34 right-hand column) shows the same warming in the northeast domain during the year of the eruption. The warming pattern in the Weddell Sea starts at $\mathrm{Yr}+1$ (1992, Figure 3.34f) and is still present at $\mathrm{Yr}+2(1993$, Figure 3.34i). At $\mathrm{Yr}+2$ the difference in relation to the year before the eruption (1990) reaches $0.9^{\circ} \mathrm{C}$ and is spread out in the Weddell Sea. Most of the domain shows a cooling pattern, except some regions, such as between $60-72 \mathrm{~S}$ and $30-10 \mathrm{~W}$, that shows positive difference relative to 1990 .

As discussed in Section 3.2.4 the time series for two contrasting regions are shown for SST in Figure 3.35. In the Antarctic Peninsula region (Figure 3.35a) the larger signal after the eruption occurs in the second subsequent year $(\mathrm{Yr}+2,1993)$. This signal is a positive anomaly, which differs in magnitude between the data sets. As seen in Figure 3.33 right-hand column SODA shows larger anomalies, but all data sets have warmed after Mt. Pinatubo eruption in this region. During 1991 austral summer the anomaly is almost zero for ERSSTv5 and CESM-LME, but in the SODA results there is a negative anomaly of $0.5^{\circ} \mathrm{C}$

On the other hand, the oceanic region (Figure 3.35b) contrasts with the Antarctic Peninsula, where during $\mathrm{Yr}+2$ (1993) all data sets show zero anomaly. The larger response occurs in the year of the eruption (1991), but the data sets diverge. SODA shows a positive anomaly of $0.5^{\circ} \mathrm{C}$, while CESM-LME shows a negative anomaly of the same magnitude. 


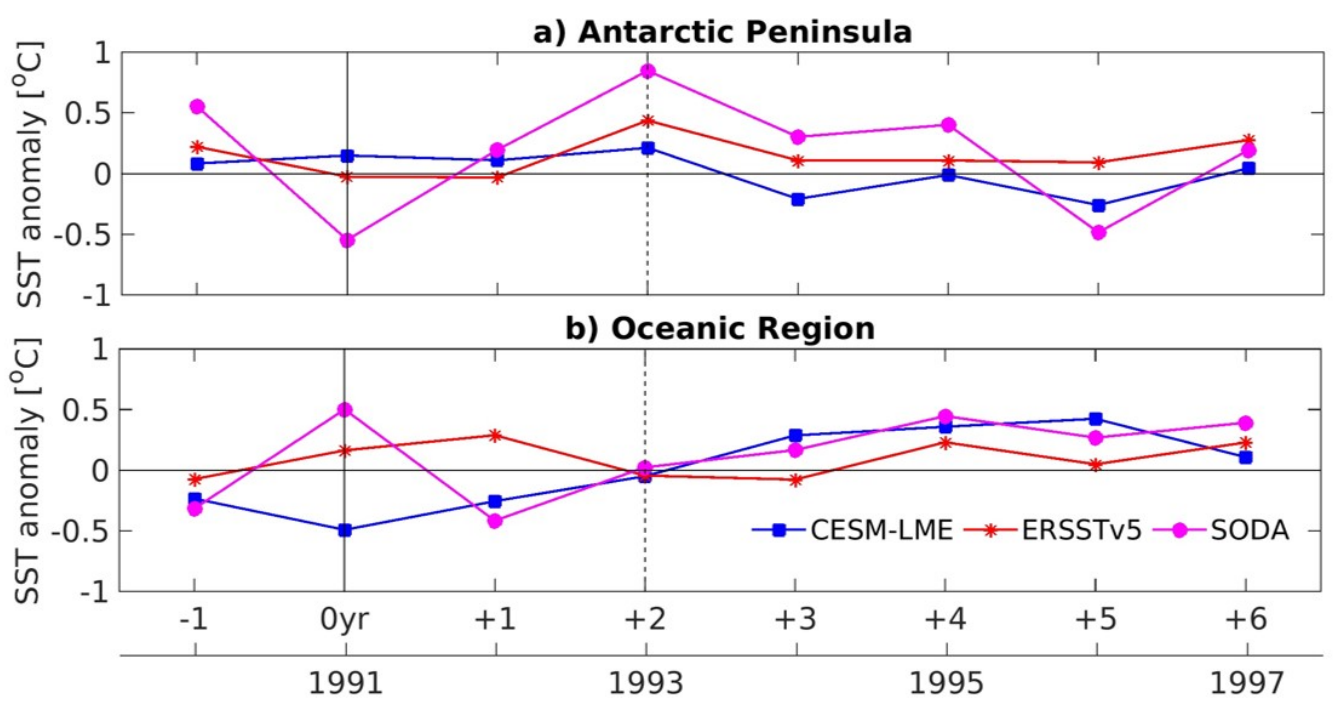

Figure 3.35: $\mathbf{S S T}\left[{ }^{\circ} \mathbf{C}\right]$ anomaly time series | (a) Antarctic Peninsula region and (b) oceanic region, the same regions as Figure 3.29. The different data sets are represented in colors as described in the legend. The continuous vertical line mark the eruption year (Yr 0, 1991) and the dotted vertical line the second year after the eruption (Yr +2, 1993).

Even though it is difficult to separate the volcanic signal from other forcings in the PD (Church et al., 2005), the warming signal in the Weddell Sea is detected in all data sets at $\mathrm{Yr}+2$. The fact that the volcanic triggered warming happens only at $\mathrm{Yr}+2$ in the observations may be explained by the background conditions. Zanchettin et al. (2013) discuss that the existence of multiple response pathways is possible depending on the background condition, therefore the already existing warming may have delayed the oceanic response in the Weddell Sea. Another important point worth emphasizing is that Mt. Pinatubo eruption is much shorter lived compared to LM eruptions because, as mentioned in Gleckler et al. (2006), it occurred relative to a ongoing anthropogenically forced ocean warming.

Finally, to verify if the wind stress displays the same changes as in the LM results, the zonal and meridional wind stress are analyzed (Figures 3.36 and 3.37). The similarity of these changes with the composite ones are important, since TAUX and TAUY have been considered the trigger to the positive anomaly anomaly generated after the LM eruptions. Results from Mt. Pinatubo SODA and CESM-LME reveal similar results (Figure 3.36a,b respectively). The prevailing westerlies have increased in magnitude and also shifted southward as observed in the LM (Karpechko et al., 2010; Zanchettin et al., 
2014; Stenchikov, 2016).
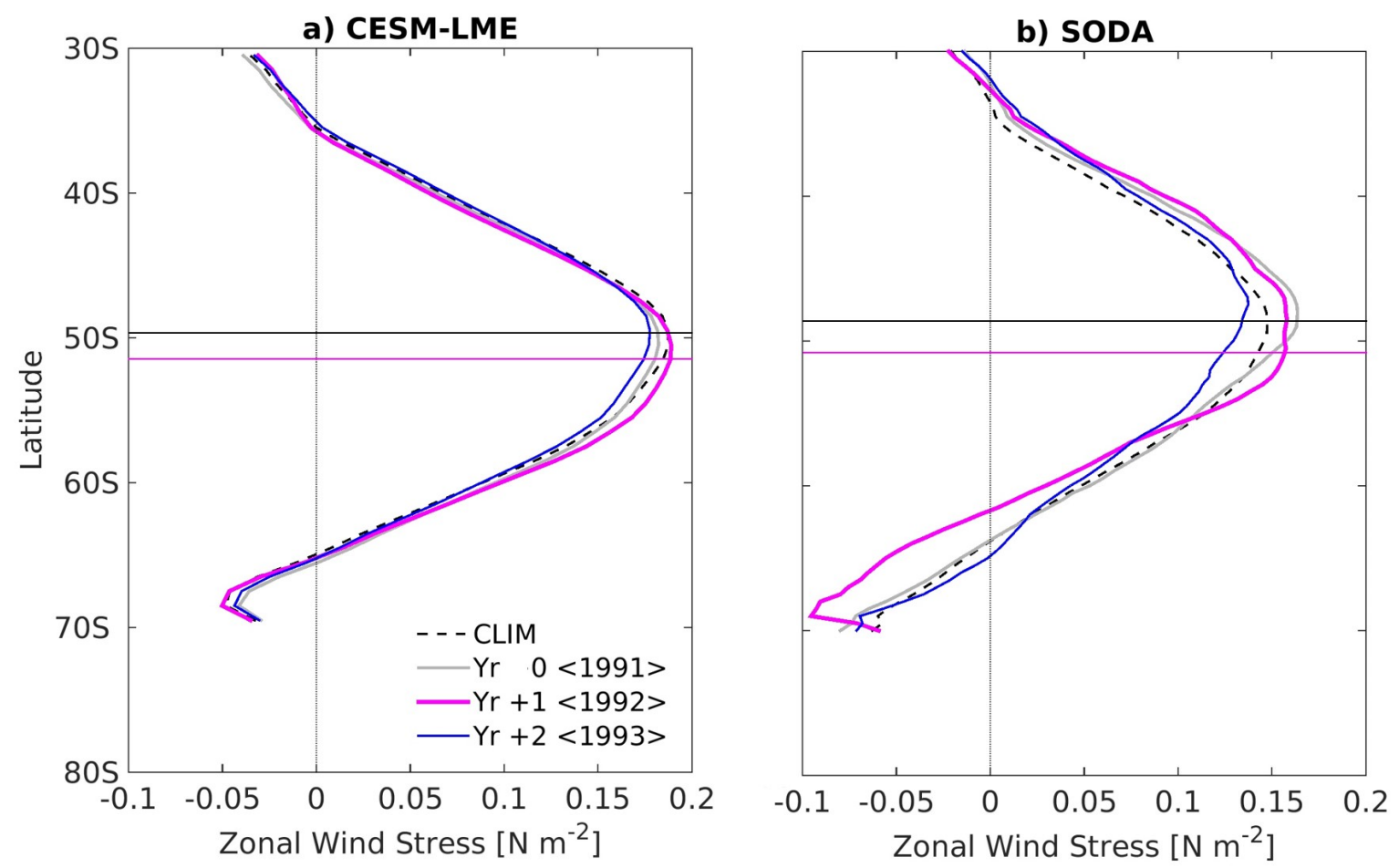

Figure 3.36: Zonal wind stress $\left[\mathrm{N} \mathrm{m}^{-2}\right]$ zonal average for the South Atlantic Ocean | (a) CESM-LME and (b) SODA. The dotted line is the climatological DJF mean for the period of 1980-2005. The vertical lines represent the associated maximum zonal wind stress position for the climatology (black line) and $\mathrm{Yr}+1$ (magenta line).

Overall, the SODA zonal wind stress is smaller in magnitude than CESM-LME $(0.15 \mathrm{~N}$ $\mathrm{m}^{-2}$ and $0.175 \mathrm{~N} \mathrm{~m}^{-2}$ maximum respectively). Figure 3.36 shows the zonal average of TAUX for CESM-LME and SODA, the black dotted line is the austral summer climatology for the period 1980-2005. The first year after the eruption $(\mathrm{Yr}+1,1992)$ shows the prevailing westerlies southward drift for both data sets, in CESM-LME of $\sim 1^{\circ}$ and $\mathrm{SODA} \sim 2^{\circ}$ represented by the horizontal lines in Figure 3.36. Although in SODA during the eruption year (1991) TAUX has shown larger maximum, there is no southward drift. In both cases the zonal wind stress has become smaller than the climatology in 1993 (Yr +2) austral summer.

The largest TAUY response to Mt. Pinatubo eruption has been during the first austral summer after the eruption (1992), as seen in Figure 3.37. 
a) CESM-LME TAUY Climatology

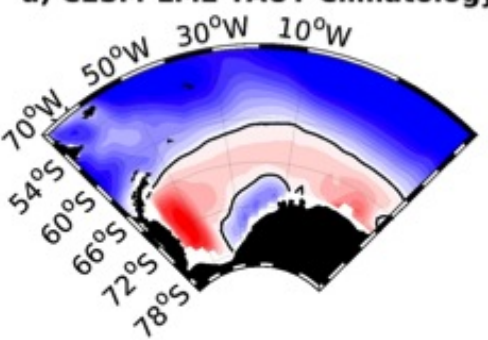

d) SODA TAUY Climatology

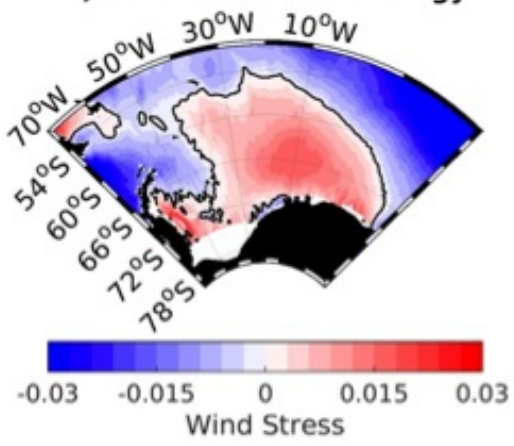

b) $\mathrm{Yr}+1$ Anomaly

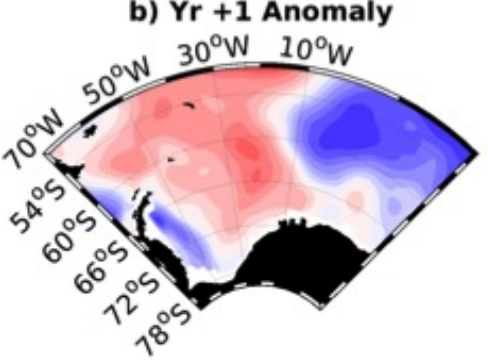

e) $\mathrm{Yr}+1$ Anomaly

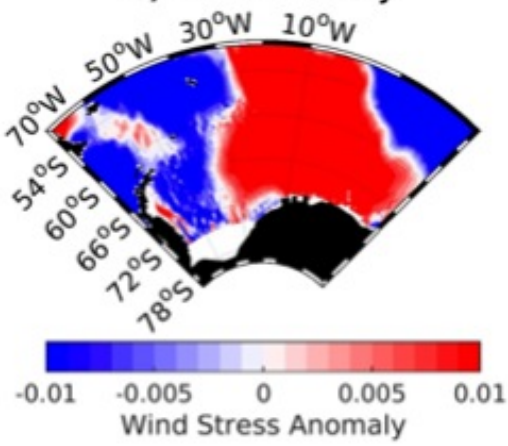

c) $<$ Climatology $>+<\mathrm{Yr}+1$ Anomaly $>$

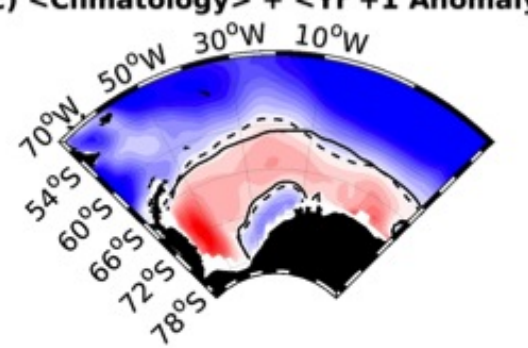

f) $<$ Climatology $>+<\mathrm{Yr}+1$ Anomaly $>$

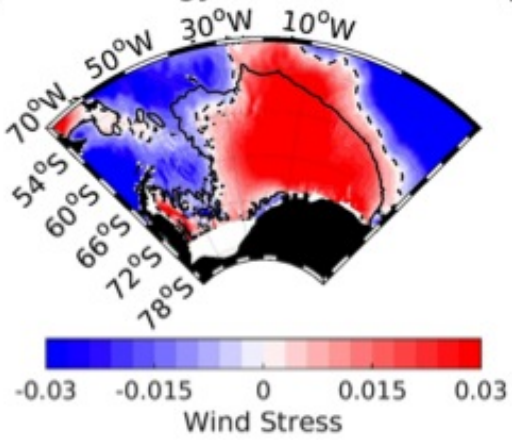

Figure 3.37: Meridional wind estress response at $\mathbf{y r}+\mathbf{1} \mid$ The right-hand column is 1980-2005 TAUY [ $\mathrm{N} \mathrm{m}^{-2}$ ] climatological mean, in the central column the $\mathrm{Yr}+1$ (1992) anomaly and the left-hand column the sum of both for $[(\mathbf{a}),(\mathbf{b}),(\mathbf{c})]$ CESM-LME and $[(\mathrm{d}),(\mathrm{e}),(\mathrm{f})]$ SODA. The continuous line represent the zero contour of the climatological mean and the dotted line the zero contour resultant from the year after Mt. Pinatubo eruption (1992).

However, in the northern Antarctic Peninsula region the anomalies are not enough to change the circulation, as observed in the LM. That is probably because the climatological TAUY zero contour in the modern period is already placed in the Weddell Sea. This supports the idea that the westerlies southward drift may be enough to trigger the surface warm anomaly in the Weddell Sea post-eruption scenario.

Extracting the volcanic signal from observations, such as SODA and ERSSTv5, is difficult given the relatively short-lived forcing (Meronen et al., 2012) and the anthropogenically forced background (Gleckler et al., 2006; Zanchettin et al., 2013). Mt. Pinatubo SST at $\mathrm{Yr}+2$ after eruption scenario response near the Antarctic Peninsula may be warming, rather than the expected cooling that would act as offset of the anthropogenic warming (Delworth et al., 2005; Gleckler et al., 2006). Moreover, surface warming driven at least partially by the southward shift of the westerlies at $\mathrm{Yr}+1$ may have potential impacts for recent sea-ice production and melt. 


\section{CONCLUSIONS}

The response of the South Atlantic Ocean, including the Weddell Sea, to volcanic eruptions was evaluated using simulation results from the Last Millennium Ensemble experiment of the Community Earth System Model (CESM-LME). Despite the uncertainties related to complex earth system models (Zanchettin et al., 2017), the use of 15 ensembles and 7 eruptions (a total of 105 events) allowed a solid description of air-sea major impacts and to separate the forced climate response from internal variability (Fasullo et al., 2017). In this sense, this study emphasize the importance of ensemble experiments to reproduce the internal dynamics of the coupled climate system for interpretation of simulated regional past climates (Zanchettin et al., 2012).

Volcanism is the cause of great non-anthropogenic perturbations on the Earth climate through energy imbalance changes. Air-sea properties showed evident and significant (at $90 \%$ level) response to the volcanic forcing in the first austral summer after the eruption $(\mathrm{Yr}+1)$, the surface presented an overall cooling, on average $0.6-0.8^{\circ} \mathrm{C}$, located at specific latitudes (i.e., 30S and 65S), which is robust given the small ensemble spread in the time series. Results also showed SSS general increase of 0.06 between 40-50S, that was above the internal variability. In the zonal wind stress composite a positive anomaly in $60 \mathrm{~S}$ $\left(0.02 \mathrm{~N} \mathrm{~m}^{-2}\right)$ was identified, accompanied by negative anomaly of the same magnitude at $45 \mathrm{~S}$. While the meridional wind stress field depicted a negative anomaly of $0.006 \mathrm{~N}$ $\mathrm{m}^{-2}$ located near the Antarctic Peninsula, and a great positive anomaly in $45 \mathrm{~S}$ of $0.01 \mathrm{~N}$ $\mathrm{m}^{-2}$. Surface properties had different recovery periods, TAUX and TAUY were close to the background condition of $\mathrm{Yr}-1$, generally at $\mathrm{Yr}+3$. However, SST and SSS was still significant at least up to $\mathrm{Yr}+5$. Moreover, different relaxation periods were observed dependent on the latitude, both at the surface and at depth, suggesting that higher latitudes may recover faster for SST and SSS anomalies. 
In this context, composite analysis also pointed to different regional signals, such as the positive temperature anomaly $\left(0.8^{\circ} \mathrm{C}\right)$ accompanied by positive salinity anomaly $(\sim 0.16)$ developed near the Antarctic Peninsula in the Weddell Sea.

The present analysis suggested that the anomalous warm ocean surface responds more strongly to changes in the ocean dynamics, rather than to the radiative forcing (i.e., expected cooling), as consequence of the volcanic forcing. During the first austral summer after the eruption $(\mathrm{Yr}+1)$, a strengthening of $0.03 \mathrm{~N} \mathrm{~m}^{-2}$ of the prevailing westerlies was observed, which was accompanied by a southward shift of $\sim 2^{\circ}$. At the same time, the wind circulation over the Weddell Sea became confined, which led to total inversion of the meridional component of the wind stress near the northern Antarctic Peninsula. The meridional wind changed from a northward to a southward circulation near the Antarctic Peninsula northernmost extension. As a response to the wind changes, the ACC southern extent increased in about 10\%, enhancing mixing in the northern Antarctic Peninsula in the Weddell Sea. In addition, around $\sim 600 \mathrm{~m}$ depth, the Weddell Gyre outflow weakened in $\sim 16 \%$, at the same time that the inflow region warmed $\left(0.08^{\circ} \mathrm{C}\right)$. Thus, some of the water that was supposed to be exported out of the Weddell Gyre is trapped in the subsurface region near the Antarctic Peninsula in the Weddell Sea.

Thus, changes in the meridional wind stress in the northern Antarctic Peninsula, accumulated warmer subsurface water in the Weddell Sea outflow region and the enhanced mixing near the Antarctic Peninsula, favors the formation of the detected positive SST anomaly. It was suggested that the subsurface water, such as the WDW that is warmer and saltier than the surface water, is brought up to the surface by the enhanced mixing. Because of the anomalous wind this water get trapped in the Weddell Sea surface outflow region. Thus, a warmer and saltier anomaly is formed after the eruption. In addition, sea-ice may increase its extension after an eruption (Zanchettin et al., 2014), which would contribute to increase the local salinity due to enhanced brine rejection.

The present study also evaluated the volcanic induced changes with depth. It was observed that the positive temperature anomaly of $0.3^{\circ} \mathrm{C}$ near the Antarctic Peninsula extends down to $\sim 100 \mathrm{~m}$ at $\mathrm{Yr}+1$, then forced to sink at $\mathrm{Yr}+3$ to +4 , because of 
the increased salinity, that results in denser waters. The sinking of this water would only happen after the wind forcing has faded at $\mathrm{Yr}+2$, suggesting that the change in the prevailing westerlies is the trigger for the anomalous warming near the Antarctic Peninsula after the eruption. At the same time, further north $(\sim 45 \mathrm{~S})$, the cold anomaly $\left(0.4^{\circ} \mathrm{C}\right)$ spreads down to 500-1000m from $\mathrm{Yr}+2$ and still meaningful at $\mathrm{Yr}+6$. Despite the interface of some volcanic events, it was suggested that the recovery from the volcanic eruption at depth could take at least a decade.

The 1991 eruption of Mt. Pinatubo was one of the strongest volcanic eruptions of the $20^{\text {th }}$ century and this well observed eruption served as an important case study to understand and verify mechanisms that were identified as consequence of LM eruptions. Even though the volcanic signal is difficult to separate from the other forcings in the $\mathrm{PD}$, the anomalous surface warming in the Antarctic Peninsula after the eruption was observed at $\mathrm{Yr}+2$ (1993). It was in agreement for all data sets, with SODA presenting greater SST response of $\sim 1-2^{\circ} \mathrm{C}$ than CESM-LME and ERSSTv5. The latter two showed warming of $0.8^{\circ} \mathrm{C}$. The delayed response compared to the LM eruptions was probably relate to the PD background conditions, which accounts for an already exiting warming.

This result is also supported by the zonal wind stress increase at $\mathrm{Yr}+1$ (1992). In addition and more important, the prevailing westerlies have shifted south. The meridional wind stress did not show reversion of direction in the northern Antarctic Peninsula, because the climatological (1980-2005) meridional wind stress zero contour was already displaced south. Fact that supports the idea that the westerlies southward drift triggers the SST positive anomaly formation in the northern Antarctic Peninsula in the Weddell Sea. Therefore, the present analysis suggested that the Mt. Pinatubo and LM eruptions involve similar mechanisms, although there is a delayed SST response.

In this sense, the post-eruption aftermath in a regional context such as for the northern Antarctic Peninsula in the Weddell Sea may not act as an offset of the anthropogenic warming as suggested in Delworth et al. (2005) and Gleckler et al. (2006). Moreover, surface warming after an eruption may have potential impacts for recent sea-ice production and melt, given the high sea-ice sensitivity to the stability of the seawater column, wind 
and ocean currents (Zhong et al., 2011).

Another interesting aspect that has been recently studied by Fasullo et al. (2017) is the potential climate implications of future eruptions. The authors showed that in a global warming scenario, the surface climate response to the eruption is amplified. Authors emphasized that even an amplified cooling remains much less than the associated warming of the anthropogenic forcing. Therefore, an eruption response such as the warming near Antarctic Peninsula in the Weddell Sea shown in the present analysis, would be a potential amplifying factor for the ongoing global warming. How the warming observed in the LM and Mt. Pinatubo would respond to increased background warming should be under further investigation. Finally, the use of isotopes in complex climate models (Colose et al., 2016) to better understand the consequences of the volcanic forcing could be key approach to verify the robustness of the already suggested mechanism. Therefore, continuing to study the dynamical response mechanisms of great volcanic eruptions (e.g., Fasullo et al., 2017), validating the climate models with observations, proxy data (e.g., Stevenson et al., 2016), reanalysis data sets, and other new resources as isotopes, remains an useful exercise for improving the understanding of climate variability in longer time scales. 


\section{References}

Abram, N. J., R. Mulvaney, F. Vimeux, S. J. Phipps, J. Turner, and M. H. England (2014). Evolution of the Southern Annular Mode during the past millennium. Nature Climate Change 4(7), 1-6.

Andrews, D. G. (2010). An Introduction to Atmospheric Physics.

Balmaseda, M. a., K. E. Trenberth, and E. Källén (2013, may). Distinctive climate signals in reanalysis of global ocean heat content. Geophysical Research Letters 40(9), $1754-1759$.

Barnes, E. A., S. Solomon, and L. M. Polvani (2016). Robust wind and precipitation responses to the Mount Pinatubo eruption, as simulated in the CMIP5 models. Journal of Climate 29(13), 4763-4778.

Bender, F. A. M., A. M. L. Ekman, and H. Rodhe (2010). Response to the eruption of Mount Pinatubo in relation to climate sensitivity in the CMIP3 models. Climate Dynamics 35(5), 875-886.

Berger, A. L. (1978). Long-Term Variations of Daily Insolation and Quaternary Climatic Changes.

Bothe, O., M. Evans, L. F. Donado, E. G. Bustamante, J. Gergis, J. F. GonzalezRouco, H. Goosse, G. Hegerl, A. Hind, J. Jungclaus, D. Kaufman, F. Lehner, N. McKay, A. Moberg, C. C. Raible, A. Schurer, F. Shi, J. E. Smerdon, L. Von Gunten, S. Wagner, E. Warren, M. Widmann, P. Yiou, and E. Zorita (2015). Continental-scale temperature 
variability in PMIP3 simulations and PAGES 2k regional temperature reconstructions over the past millennium. Climate of the Past 11(12), 1673-1699.

Boyer, T. P., J. I. Antonov, O. K. Baranova, C. Coleman, H. E. Garcia, A. Grodsky, D. R. Johnson, R. A. Locarnini, A. V. Mishonov, T. D. O. Brien, C. R. Paver, J. R. Reagan, D. Seidov, I. V. Smolyar, M. M. Zweng, and K. D. Sullivan (2013). World Ocean Database 2013 (NOAA Atlas ed.). NOAA Atlas NESDIS.

Brad Adams, J., M. E. Mann, and C. M. Ammann (2003). Proxy evidence for an El Nino-like response to volcanic forcing. Nature 426(6964), 274-278.

Carter, L., I. McCave, and M. J. Williams (2008). Circulation and Water Masses of the Southern Ocean: A Review. In F. Florindo and M. Siegert (Eds.), Developments in Earth 8 Environmental Sciences, Volume 8, pp. 85-114. Elsevier B.V.

Carton, J. A., G. A. Chepurin, and L. Chen (2018). An updated reanalysis of ocean climate using the Simple Ocean Data Assimilation version 3 (SODA3). Manuscrip in preparation -(-),-

Carton, J. A. and B. S. Giese (2008). A Reanalysis of Ocean Climate Using Simple Ocean Data Assimilation (SODA). Monthly Weather Review 136(8), 2999-3017.

Cavalcanti, I. F. d. A., N. J. Ferreira, M. G. A. J. da Silva, and M. A. F. d. S. Dias (2009). Tempo e Clima no Brasil (Primeira ed.). Oficina de Textos.

Cavalieri, D. J. and C. L. Parkinson (2008). Antarctic sea ice variability and trends, 1979-2006. Journal of Geophysical Research 113(C7), C07004.

Cazenave, A. (2005). Sea level and volcanoes. Nature 438(2), 1-4.

Cheng, L., K. E. Trenberth, J. Fasullo, T. Boyer, J. Abraham, and J. Zhu (2017). Improved estimates of ocean heat content from 1960 to 2015. Science Advances 3, $1-11$. 
Church, J. a., N. J. White, and J. M. Arblaster (2005). Significant decadal-scale impact of volcanic eruptions on sea level and ocean heat content. Nature 438(7064), $74-7$.

Cole-Dai, J. (2010). Volcanoes and climate. Wiley Interdisciplinary Reviews: Climate Change 1(6), 824-839.

Cole-Dai, J., E. Mosley-Thompson, and D. Qin (1999). Evidence of the 1991 Pinatubo volcanic eruption in South Polar snow. Chinese Science Bulletin 44 (8), 756-760.

Cole-Dai, J., E. Mosley-Thompson, and L. G. Thompson (1997). Quantifying the Pinatubo volcanic signal in south polar snow. Geophysical Research Letters $24(21)$, $1679-2682$.

Colose, C. M., A. N. LeGrande, and M. Vuille (2016). Hemispherically asymmetric volcanic forcing of tropical hydroclimate during the last millennium. Earth System Dynamics 7(3), 681-696.

Crowley, T. J., G. Zielinski, B. Vinther, R. Udisti, K. Kreutz, J. Cole-Dai, and E. Castellano (2008). Volcanism and the little ice age. PAGES news 16(2), 22-23.

Deacon, G. E. (1979). The Weddell gyre. Deep Sea Research Part A, Oceanographic Research Papers 26(9), 981-995.

Dee, D. and S. Uppala (2008). Variational bias correction in ERA-Interim.

Delworth, T. L., V. Ramaswamy, and G. L. Stenchikov (2005). The impact of aerosols on simulated ocean temperature and heat content in the 20th century. Geophysical Research Letters 32(24), 1-4.

Ding, Y., J. A. Carton, G. A. Chepurin, G. Stenchikov, A. Robock, L. T. Sentman, and J. P. Krasting (2014). Ocean response to volcanic eruptions in Coupled Model Intercomparison Project 5 simulations. Journal of Geophysical Research 119, 56225637. 
Evan, A. T., D. J. Vimont, A. K. Heidinger, J. P. Kossin, and R. Bennartz (2009). The role of aerosols in the evolution of Tropical North Atlantic Ocean temperature. Science 324(May), 778-781.

Fasullo, J. T. and R. S. Nerem (2016). Interannual Variability in Global Mean Sea Level Estimated from the CESM Large and Last Millennium Ensembles. Water 8(491), $1-13$.

Fasullo, J. T., R. Tomas, S. Stevenson, B. Otto-Bliesner, E. Brady, and E. Wahl (2017). The amplifying influence of increased ocean stratification on a future year without a summer. Nature Communications 8(1), 1-10.

Gao, C., A. Robock, and C. Ammann (2008). Volcanic forcing of climate over the past 1500 years: An improved ice core-based index for climate models. Journal of Geophysical Research Atmospheres 113(23), 1-15.

Gerlach, T. (2011). Volcanic versus anthropogenic carbon dioxide. Eos 92(24), 201-202.

Gibbons, J. D. and S. Chakraborti (2003). Nonparametric Statistical Inference (Fourth ed.). New York, USA: Marcel Dekker, Inc.

Gleckler, P. J., K. AchutaRao, J. M. Gregory, B. D. Santer, K. E. Taylor, and T. M. L. Wigley (2006). Krakatoa lives: The effect of volcanic eruptions on ocean heat content and thermal expansion. Geophysical Research Letters 33(17), 1-5.

Goosse, H., H. Renssen, A. Timmermann, and R. S. Bradley (2005). Internal and forced climate variability during the last millennium: A model-data comparison using ensemble simulations. Quaternary Science Reviews 24(12-13), 1345-1360.

Graf, H.-F., Q. Li, and M. A. Giorgetta (2007). Volcanic effects on climate: revisiting the mechanisms. Atmospheric Chemistry and Physics Discussions 7(2), 3941-3962.

Gregory, J. M. (2010). Long-term effect of volcanic forcing on ocean heat content. Geophysical Research Letters 37(22), 1-5. 
Gregory, J. M., J. A. Lowe, and S. F. B. Tett (2006). Simulated global-mean sea level changes over the last half-millennium. Journal of Climate 19(18), 4576-4591.

Hansen, J., A. Lacis, R. Ruedy, and S. Makiko. (1992). Potential climate impact of mount Pinatubo eruption. Geophysical Research Letters 19(2), 215-218.

Hellmer, H. H., M. Rhein, G. Heinemann, J. Abalichin, W. Abouchami, O. Baars, U. Cubasch, K. Dethloff, L. Ebner, E. Fahrbach, M. Frank, G. Gollan, R. J. Greatbatch, J. Grieger, V. M. Gryanik, M. Gryschka, J. Hauck, M. Hoppema, O. Huhn, T. Kanzow, B. P. Koch, G. König-langlo, U. Langematz, G. C. Leckebusch, C. Lüpkes, S. Paul, A. Rinke, B. Rost, M. R. van der Loeff, M. Schröder, G. Seckmeyer, T. Stichel, V. Strass, R. Timmermann, S. Trimborn, U. Ulbrich, C. Venchiarutti, U. Wacker, W. Sascha, and D. Wolf-Gladrow (2016). Meteorology and oceanography of the Atlantic sector of the Southern Ocean - a review of German achievements from the last decade. Ocean Dynamics 66(1), 1379-1413.

Heywood, K. J., A. C. Naveira Garabato, D. P. Stevens, and R. D. Muench (2004). On the fate of the Antarctic Slope Front and the origin of the Weddell Front. Journal of Geophysical Research C: Oceans 109(6), 1-13.

Huang, B., P. W. Thorne, V. F. Banzon, T. Boyer, G. Chepurin, J. H. Lawrimore, M. J. Menne, T. M. Smith, R. S. Vose, and H.-M. Zhang (2017). Extended Reconstructed Sea Surface Temperature version 5 (ERSSTv5): Upgrades, Validations, and Intercomparisons. Journal of Climate 5, JCLI-D-16-0836.1.

Hurrell, J. W., M. M. Holland, P. R. Gent, S. Ghan, J. E. Kay, P. J. Kushner, J. F. Lamarque, W. G. Large, D. Lawrence, K. Lindsay, W. H. Lipscomb, M. C. Long, N. Mahowald, D. R. Marsh, R. B. Neale, P. Rasch, S. Vavrus, M. Vertenstein, D. Bader, W. D. Collins, J. J. Hack, J. Kiehl, and S. Marshall (2013). The community earth system model: A framework for collaborative research. Bulletin of the American Meteorological Society 94(9), 1339-1360. 
Hurtt, G. C., L. P. Chini, S. Frolking, R. A. Betts, J. Feddema, G. Fischer, J. P. Fisk, K. Hibbard, R. A. Houghton, A. Janetos, C. D. Jones, G. Kindermann, T. Kinoshita, K. Klein Goldewijk, K. Riahi, E. Shevliakova, S. Smith, E. Stehfest, A. Thomson, P. Thornton, D. P. van Vuuren, and Y. P. Wang (2011). Harmonization of landuse scenarios for the period 1500-2100: 600 years of global gridded annual land-use transitions, wood harvest, and resulting secondary lands. Climatic Change 109(1), $117-161$.

IPCC (2013). Summary for Policymakers. In Stocker, V. B. T.F., D. Qin, G.-K. Plattner, M. Tignor, S.K. Allen, J. Boschung, A. Nauels, Y. Xia, and P. M. (ed (Eds.), In: Climate Change 2013: The Physical Science Basis. Contribution of Working Group I to the Fifth Assessment Report of the Intergovernmental Panel on Climate Change, Volume 1542, pp. 33-36. Cambridge, United Kingdom and New York, NY, USA: Cambridge University Press.

Johnson, G. C. (2008). Quantifying Antarctic Bottom Water and North Atlantic Deep Water volumes. Journal of Geophysical Research: Oceans 113(5), 1-13.

Joseph, R. and N. Zeng (2011). Seasonally modulated tropical drought induced by volcanic aerosol. Journal of Climate 24(8), 2045-2060.

Jullion, L., A. C. Naveira Garabato, S. Bacon, M. P. Meredith, P. J. Brown, S. Torresvaldes, K. G. Speer, P. R. Holland, J. Dong, D. Bakker, M. Hoppema, B. Loose, H. J. Venables, W. J. Jenkins, and F. Eberhard (2014). The contribution of the Weddell Gyre to the lower limb of the Global Overturninh Circulation. Journal of Geophysical Research 119(6), 3357-3377.

Jullion, L., A. C. Naveira Garabato, S. Bacon, M. P. Meredith, P. J. Brown, S. TorresValdés, K. G. Speer, P. R. Holland, J. Dong, D. Bakker, M. Hoppema, B. Loose, H. J. Venables, W. J. Jenkins, M. J. Messias, and E. Fahrbach (2014). The contribution of the Weddell Gyre to the lower limb of the Global Overturning Circulation. Journal of Geophysical Research: Oceans 119(6), 3357-3377. 
Karpechko, A. Y., N. P. Gillett, M. Dall'Amico, and L. J. Gray (2010). Southern Hemisphere atmospheric circulation response to the El Chich??n and Pinatubo eruptions in coupled climate models. Quarterly Journal of the Royal Meteorological Society 136 (652), 1813-1822.

Kay, J. E., C. Deser, A. Phillips, A. Mai, C. Hannay, G. Strand, J. M. Arblaster, S. C. Bates, G. Danabasoglu, J. Edwards, M. Holland, P. Kushner, J. F. Lamarque, D. Lawrence, K. Lindsay, A. Middleton, E. Munoz, R. Neale, K. Oleson, L. Polvani, and M. Vertenstein (2015). The community earth system model (CESM) large ensemble project : A community resource for studying climate change in the presence of internal climate variability. Bulletin of the American Meteorological Society 96(8), 1333-1349.

Kerr, R. (2010). Produção E Exportação De Águas Profundas No Entorno Do Continente Antártico. Ph. D. thesis, Federal University of Rio Grande.

Kerr, R., T. S. Dotto, M. M. Mata, H. H. Hellmer, R. Kerr, T. S. Dotto, M. M. Mata, and H. Hartmut (2017). Three decades of deep water mass investigation in the Weddell Sea ( $1984-2014$ ): temporal variability and changes. Deep-Sea Research Part II in press, 1-43.

Kerr, R., M. M. Mata, and C. A. E. Garcia (2009). On the temporal variability of the Weddell Sea Deep Water Masses On the temporal variability of the Weddell Sea Deep Water masses. Antarctic Science 21(4)(August), 383-400.

Kim, S.-J. and B.-M. Kim (2012). Response to the Pinatubo and 1259 Volcanic Eruptions. Ocean and Polar Research 34(September), 305-323.

Landrum, L., B. L. Otto-Bliesner, E. R. Wahl, A. Conley, P. J. Lawrence, N. Rosenbloom, and H. Teng (2013). Last millennium climate and its variability in CCSM4. Journal of Climate 26(4), 1085-1111.

Langmann, B. (2014). On the Role of Climate Forcing by Volcanic Sulphate and Volcanic Ash. Advances in Meteorology 2014(340123), 1-17. 
Lehner, F., A. P. Schurer, G. C. Hegerl, C. Deser, and T. L. Fr??licher (2016). The importance of ENSO phase during volcanic eruptions for detection and attribution. Geophysical Research Letters 43(6), 2851-2858.

Levitus, S., J. Antonov, and T. Boyer (2005). Warming of the world ocean, 1955-2003. Geophysical Research Letters 32(2), L02604.

Levitus, S., J. I. Antonov, T. P. Boyer, O. K. Baranova, H. E. Garcia, R. a. Locarnini, a. V. Mishonov, J. R. Reagan, D. Seidov, E. S. Yarosh, and M. M. Zweng (2012, may). World ocean heat content and thermosteric sea level change (0-2000 m), 1955-2010. Geophysical Research Letters 39(10), 1-5.

Li, J., S.-P. Xie, E. R. Cook, M. S. Morales, D. A. Christie, N. C. Johnson, F. Chen, R. D'Arrigo, A. M. Fowler, X. Gou, and K. Fang (2013). El Niño modulations over the past seven centuries. Nature Climate Change 3(9), 822-826.

Maher, N., S. McGregor, M. H. England, and A. S. Gupta (2015). Effects of volcanism on tropical variability. Geophysical Research Letters 42(14), 6024-6033.

Maher, N., A. SenGupta, and M. H. England (2014). Drivers of decadal hiatus periods in the 20th and 21st centuries. Geophysical Research Letters 41(16), 5978-5986.

Mann, M. E., Z. Zhang, S. Rutherford, R. S. Bradley, M. K. Hughes, D. Shindell, C. Ammann, G. Faluvegi, and F. Ni (2009). Global signatures and dynamical origins of the Little Ice Age and Medieval Climate Anomaly. Science (New York, N.Y.) 326(5957), 1256-60.

Marshall, G. J. (2003). Trends in the Southern Annular Mode from observations and reanalyses. Journal of Climate 16(24), 4134-4143.

McGraw, M. C., E. A. Barnes, and C. Deser (2016). Reconciling the observed and modeled Southern Hemisphere circulation response to volcanic eruptions. Geophysical Research Letters 43(13), 7259-7266. 
McGregor, H. V., M. N. Evans, H. Goosse, G. Leduc, B. Martrat, J. A. Addison, P. G. Mortyn, D. W. Oppo, M.-S. Seidenkrantz, M.-A. Sicre, S. J. Phipps, K. Selvaraj, K. Thirumalai, H. L. Filipsson, and V. Ersek (2015). Robust global ocean cooling trend for the pre-industrial Common Era. Nature Geoscience 8(9), 671-677.

Meehl, G. A., H. Teng, N. Maher, and M. H. England (2015). Effects of the Mount Pinatubo eruption on decadal climate prediction skill of Pacific sea surface temperatures. Geophysical Research Letters 42(10), 1-7.

Meredith, M. P. (2013). Replenishing the abyss. Nature Geoscience 6(3), 166-167.

Meredith, M. P., A. C. Naveira Garabato, A. L. Gordon, and G. C. Johnson (2008). Evolution of the deep and bottom waters of the Scotia Sea, Southern Ocean during 1995-2005. Journal of Climate 21 (13), 3327-3343.

Meronen, H., S. V. Henriksson, P. Räisänen, and A. Laaksonen (2012). Climate effects of northern hemisphere volcanic eruptions in an Earth System Model. Atmospheric Research 114-115, 107-118.

Mignot, J., M. Khodri, C. Frankignoul, and J. Servonnat (2011). Volcanic impact on the Atlantic Ocean over the last millennium. Climate of the Past 7(4), 1439-1455.

Miller, G. H., Á. Geirsdóttir, Y. Zhong, D. J. Larsen, B. L. Otto-Bliesner, M. M. Holland, D. A. Bailey, K. A. Refsnider, S. J. Lehman, J. R. Southon, C. Anderson, H. Björnsson, and T. Thordarson (2012). Abrupt onset of the Little Ice Age triggered by volcanism and sustained by sea-ice/ocean feedbacks. Geophysical Research Letters $39(2), 1-5$.

Newhall, C. G. and S. Self (1982). The volcanic explosivity index (VEI) an estimate of explosive magnitude for historical volcanism. Journal of Geophysical Research 87(C2), 1231. 
Nicholls, K. W., S. Østerhus, K. Makinson, T. Gammelsroed, and E. Fahrbach (2009). Ice-Ocean Processes over the continental shelf of the Southern Weddell Sea, Antarctica: A Review. Reviews of Geophysics 47(2007), 1-23.

Núñez-Riboni, I. and E. Fahrbach (2009). Seasonal variability of the Antarctic Coastal Current and its driving mechanisms in the Weddell Sea. Deep-Sea Research I 56, 1927-1941.

Otterå, O. H. (2008). Simulating the effects of the 1991 Mount Pinatubo volcanic eruption using the ARPEGE atmosphere general circulation model. Advances in Atmospheric Sciences 25(2), 213-226.

Otterå, O. H., M. Bentsen, H. Drange, and L. Suo (2010). External forcing as a metronome for Atlantic multidecadal variability. Nature Geoscience 3(10), 688-694.

Otto-Bliesner, B. L., E. C. Brady, J. Fasullo, A. Jahn, L. Landrum, S. Stevenson, N. Rosenbloom, A. Mai, and G. Strand (2016). Climate variability and change since 850 ce an ensemble approach with the community earth system model. Bulletin of the American Meteorological Society 97(5), 787-801.

Pausata, F. S., C. Karamperidou, R. Caballero, and D. S. Battisti (2016). ENSO response to high-latitude volcanic eruptions in the Northern Hemisphere: The role of the initial conditions. Geophysical Research Letters 43(16), 8694-8702.

Pausata, F. S. R., L. Chafik, R. Caballero, and D. S. Battisti (2015). Impacts of high-latitude volcanic eruptions on ENSO and AMOC. Proceedings of the National Academy of Sciences 112(45), 201509153.

Pongratz, J., C. Reick, T. Raddatz, and M. Claussen (2008). A reconstruction of global agricultural areas and land cover for the last millennium. Global Biogeochemical Cycles 22(3), 1-16. 
Pontes, G. M., A. S. Gupta, and A. S. Taschetto (2016). Projected changes to South Atlantic boundary currents and confluence region in the CMIP5 models: the role of wind and deep ocean changes. Environmental Research Letters 11(9), 1-9.

Predybaylo, E., G. L. Stenchikov, A. T. Wittenberg, and F. Zeng (2017). Impacts of a Pinatubo-size volcanic eruption on ENSO. Journal of Geophysical Research: Atmospheres 122(1), 925-947.

Randall, D. A., R. A. Wood, S. Bony, R. Colman, T. Fichefet, J. Fyve, V. Kattsov, A. Pitman, J. Shukla, J. Srinivasan, R. J. Stouffer, A. Sumi, and K. E. Taylor (2007). Climate Models and Their Evaluation. In S. Solomon, D. Qin, M. Manning, Z. Chen, M. Marquis, K. B. Averyt, M. Tignor, and H. L. Miller (Eds.), Climate Change 200\%: The Physical Science Basis. Contribution of Working Group I to the Fourth Assessment Report of the Intergovernmental Panel on Climate Change, pp. 591-662. United Kingdom and New york, NY, USA: Cambridge University Press.

Robertson, R., M. Visbeck, A. L. Gordon, and E. Fahrbach (2002). Long-term temperature trends in the deep waters of the Weddell Sea. Deep-Sea Research Part II: Topical Studies in Oceanography 49(21), 4791-4806.

Robock, A. (2000). Volcanic Eruptions and Climate. Reviews of Geophysics 32(2), $191-219$.

Robock, A. (2002). The Climatic Aftermath. Science 296(May), 64-65.

Robock, A., T. Adams, M. Moore, L. Oman, and G. Stenchikov (2007). Southern Hemisphere atmospheric circulation effects of the 1991 Mount Pinatubo eruption. Geophysical Research Letters 34(23), 1-6.

Robock, A. and J. Mao (1992). Winter Warming from large volcanic eruptions. Geophysical Research Letters 12(24), 2405-2408. 
Roscoe, H. K. and J. D. Haigh (2007). Influences of ozone depletion, the solar cycle and the QBO on the Southern Annular Mode. Quarterly Journal of the Royal ... 133 (October), 937-948.

Ryan, S., M. Schröder, O. Huhn, and R. Timmermann (2016). On the warm inflow at the eastern boundary of the Weddell Gyre. Deep-Sea Research Part I: Oceanographic Research Papers 10\%, 70-81.

Santer, B. D., S. Solomon, C. Bonfils, M. D. Zelinka, J. F. Painter, F. Beltran, J. C. Fyfe, G. Johannesson, C. Mears, D. A. Ridley, J. P. Vernier, and F. J. Wentz (2015). Observed multivariable signals of late 20th and early 21st century volcanic activity. Geophysical Research Letters 42(2), 500-509.

Schmidt, G. A., J. H. Jungclaus, C. M. Ammann, E. Bard, P. Braconnot, T. J. Crowley, G. Delaygue, F. Joos, N. A. Krivova, R. Muscheler, B. L. Otto-Bliesner, J. Pongratz, D. T. Shindell, S. K. Solanki, F. Steinhilber, and L. E. A. Vieira (2011). Climate forcing reconstructions for use in PMIP simulations of the Last Millennium (v1.0). Geoscientific Model Development 4(1), 33-45.

Schneider, D. P., C. M. Ammann, B. L. Otto-Bliesner, and D. S. Kaufman (2009). Climate response to large, high-latitude and low-latitude volcanic eruptions in the Community Climate System Model. Journal of Geophysical Research 114(D15101), $1-21$.

Sicre, M. A., I. R. Hall, J. Mignot, M. Khodri, U. Ezat, M. X. Truong, J. Eiríksson, and K. L. Knudsen (2011). Sea surface temperature variability in the subpolar Atlantic over the last two millennia. Paleoceanography 26(4), 1-10.

Sigl, M., J. R. McConnell, M. Toohey, M. Curran, S. B. Das, R. Edwards, E. Isaksson, K. Kawamura, S. Kipfstuhl, K. Krüger, L. Layman, O. J. Maselli, Y. Motizuki, H. Motoyama, D. R. Pasteris, and M. Severi (2014). Insights from Antarctica on volcanic forcing during the Common Era. Nature Climate Change 4(July), 6-10. 
Sigl, M., M. Winstrup, J. R. McConnell, K. C. Welten, G. Plunkett, F. Ludlow, U. Büntgen, M. Caffee, N. Chellman, D. Dahl-Jensen, H. Fischer, S. Kipfstuhl, C. Kostick, O. J. Maselli, F. Mekhaldi, R. Mulvaney, R. Muscheler, D. R. Pasteris, J. R. Pilcher, M. Salzer, S. Schüpbach, J. P. Steffensen, B. M. Vinther, and T. E. Woodruff (2015). Timing and climate forcing of volcanic eruptions for the past 2,500 years. Nature 523(7562), 543-9.

Smith, D. M., B. B. B. Booth, N. J. Dunstone, R. Eade, L. Hermanson, G. S. Jones, A. A. Scaife, K. L. Sheen, and V. Thompson (2016). Role of volcanic and anthropogenic aerosols in the recent global surface warming slowdown. Nature Climate Change 6(10), 936-940.

Stenchikov, G. (2016). The Role of Volcanic Activity in Climate and Global Change. In T. M. Letcher (Ed.), Climate change, Obeserved impacts on planet Earth (Second ed.)., Chapter 26, pp. 1-588. ELSEVIER.

Stenchikov, G., T. L. Delworth, V. Ramaswamy, R. J. Stouffer, A. Wittenberg, and F. Zeng (2009). Volcanic signals in oceans. Journal of Geophysical Research Atmospheres 114(16), 1-13.

Stenchikov, G. L., I. Kirchner, A. Robock, H.-F. Graf, J. C. Antuña, R. G. Grainger, A. Lambert, and L. Thomason (1998). Radiative forcing from the 1991 Mount Pinatubo volcanic eruption. Journal of Geophysical Research 103, 13837-13857.

Stevenson, S., J. T. Fasullo, B. L. Otto-Bliesner, R. A. Tomas, and C. Gao (2017). Role of eruption season in reconciling model and proxy responses to tropical volcanism. Proceedings of the National Academy of Sciences 114(8), 201612505.

Stevenson, S., B. Otto-Bliesner, J. Fasullo, and E. Brady (2016). "El Niño Like" hydroclimate responses to last millennium volcanic eruptions. Journal of Climate 29(8), $2907-2921$. 
Talley, L. (2013). Closure of the global overturning circulation through the Indian, Pacific and Southern Oceans: Schematics and transports. Oceanography 26(1), 80-97.

Talley, L., G. Pickard, W. J. Emery, and J. Swift (2011). Descriptive Physical Oceanography: An introduction (6th ed.). New York, USA: Academic Press.

Thompson, D. W. J., S. Solomon, P. J. Kushner, M. H. England, K. M. Grise, and D. J. Karoly (2011). Signatures of the Antarctic ozone hole in Southern Hemisphere surface climate change. Nature Geoscience 4(11), 741-749.

Timmreck, C. (2012). Modeling the climatic effects of large explosive volcanic eruptions. Wiley Interdisciplinary Reviews: Climate Change 3(6), 545-564.

Tomczak, M. and J. S. Godfrey (2001). Regional Oceanography: An Introduction.

Trenberth, K. E. and A. Dai (2007). Effects of Mount Pinatubo volcanic eruption on the hydrological cycle as an analog of geoengineering. Geophysical Research Letters 34 (April), 1-5.

Trenberth, K. E., J. T. Fasullo, and M. A. Balmaseda (2014). Earth's Energy Imbalance. Journal of Climate 27(9), 3129-3144.

Vieira, L. E., S. K. Solanki, A. V. Krivov, and I. G. Usoskin (2011). Evolution of the solar irradiance during the Holocene. Astronomy \& Astrophysics 531, A6.

Zanchettin, D., O. Bothe, H. F. Graf, S. J. Lorenz, J. Luterbacher, C. Timmreck, and J. H. Jungclaus (2013). Background conditions influence the decadal climate response to strong volcanic eruptions. Journal of Geophysical Research Atmospheres 118(10), 4090-4106.

Zanchettin, D., O. Bothe, C. Timmreck, J. Bader, A. Beitsch, H. F. Graf, D. Notz, and J. H. Jungclaus (2014). Inter-hemispheric asymmetry in the sea-ice response to volcanic forcing simulated by MPI-ESM (COSMOS-Mill). Earth System Dynamics 5(1), 223242. 
Zanchettin, D., F. S. Pausata, M. Khodri, C. Timmreck, H. Graf, J. H. Jungclaus, A. Robock, A. Rubino, and V. Thompson (2017). Toward predicting volcanically-forced decadal climate variability. CLIVAR Exchanges 72(1), 25-31.

Zanchettin, D., C. Timmreck, H. F. Graf, A. Rubino, S. Lorenz, K. Lohmann, K. Krüger, and J. H. Jungclaus (2012). Bi-decadal variability excited in the coupled ocean-atmosphere system by strong tropical volcanic eruptions. Climate Dynamics 39(1-2), 419-444.

Zhong, Y., G. H. Miller, B. L. Otto-Bliesner, M. M. Holland, D. A. Bailey, D. P. Schneider, and A. Geirsdottir (2011). Centennial-scale climate change from decadallypaced explosive volcanism: A coupled sea ice-ocean mechanism. Climate Dynamics 37(11-12), 2373-2387. 